University of Louisville

ThinkIR: The University of Louisville's Institutional Repository

\title{
Mental health and substance use disorders and treatment receipt among pregnant women in the United States, 2008-2014 : trend analysis, likelihood of treatment receipt, and ethnic disparities in mental health treatment.
}

Taghreed Nayel Salameh

University of Louisville

Follow this and additional works at: https://ir.library.louisville.edu/etd

Part of the Maternal, Child Health and Neonatal Nursing Commons

\section{Recommended Citation}

Salameh, Taghreed Nayel, "Mental health and substance use disorders and treatment receipt among pregnant women in the United States, 2008-2014 : trend analysis, likelihood of treatment receipt, and ethnic disparities in mental health treatment." (2017). Electronic Theses and Dissertations. Paper 2775. https://doi.org/10.18297/etd/2775

This Doctoral Dissertation is brought to you for free and open access by ThinkIR: The University of Louisville's Institutional Repository. It has been accepted for inclusion in Electronic Theses and Dissertations by an authorized administrator of ThinkIR: The University of Louisville's Institutional Repository. This title appears here courtesy of the author, who has retained all other copyrights. For more information, please contact thinkir@louisville.edu. 
MENTAL HEALTH AND SUBSTANCE USE DISORDERS AND TREATMENT

RECEIPT AMONG PREGNANT WOMEN IN THE UNITED STATES, 2008-2014:

TREND ANALYSIS, LIKELIHOOD OF TREATMENT RECEIPT, AND ETHNIC

DISPARITIES IN MENTAL HEALTH TREATMENT

By

Taghreed Nayel Salameh

B.S.N., Hashemite University, 2003

M.S.N., Jordan University of Science and Technology, 2006

\begin{abstract}
A Dissertation
Submitted to the Faculty of the School of Nursing of the University of Louisville In Partial Fulfillment of the Requirements For the Degree of
\end{abstract}

Doctor of Philosophy in Nursing

School of Nursing University of Louisville Louisville, Kentucky 
Copyright 2017 by Taghreed Nayel Salameh

All rights reserved 

MENTAL HEALTH AND SUBSTANCE USE DISORDERS AND TREATMENT

RECEIPT AMONG PREGNANT WOMEN IN THE UNITED STATES, 2008-2014:

TREND ANALYSIS, LIKELIHOOD OF TREATMENT RECEIPT, AND ETHNIC

DISPARITIES IN MENTAL HEALTH TREATMENT

By

Taghreed Nayel Salameh

B.S.N., Hashemite University, 2003

M.S.N., Jordan University of Science and Technology, 2006

A Dissertation Approved on

July 21, 2017

By the following Dissertation Committee

Dissertation Director

Lynne A. Hall, DrPH, RN

Timothy N. Crawford, PhD, MPH

Ruth R. Staten, PhD, APRN-CS-NP

Martin T. Hall, PhD, MSSW 


\section{DEDICATION}

I dedicate this dissertation...

To my parents, Nayel Salameh and Laila Al-Qaisi, for their endless love, encouragement, and confidence in me. You have always given me the strength to 'keep trying, keep reaching, and keep dreaming!'

To my husband, Murad Khamayseh, for his unconditional support, constant love, and patience during three years of study; I share this accomplishment with you!

To my past and future dreams... Thank you God for everything you have given me!!! 


\section{ACKNOWLEDGMENTS}

I will forever be thankful to my dissertation committee chair, Dr. Lynne Hall. Thank you for your deep and sincere support and respect during these past three years. Thank you for your meticulous input to this research work. Thank you for devoting your time and guidance throughout my dissertation journey. You are my best model not only for a scientist, mentor, teacher, but also for a human being.

I am very grateful to Dr. Timothy Crawford for his scientific advice, statistical knowledge, and many insightful suggestions. Dr. Crawford was patient and instrumental in responding to all my questions while exploring and analyzing a large data set. It gives me immense pleasure to thank Dr. Ruth Staten for her encouragement and invaluable input on this dissertation. I would like to express my deepest appreciation to Dr. Martin Hall. It has been an honor to be one of his students, and his acceptance to serve in my committee, despite the short notice, made this summer graduation come true. Thank you my stellar committee. Thank you for making this dissertation stronger and more valuable!

I extend my gratitude and thankfulness to the great faculty at the School of Nursing for their academic advising, passion, and exceptional teaching. Thank you Dr. Sandra Smith, Dr. Celeste Shawler, Dr. Barbra Polivka, Dr. Becky Christian, and Dr. Carla Hermann. Special thanks go to Dean Mercia Hern for her support and encouragement during my study period. My deep thanks are also extended to my fellow 
PhD students, Graduate Research Assistants, Vickie Tencer, and Karin Gates. Thanks all for your kindness, support, and providing a second family to me. Special thanks also go to Elizabeth Smigieliski for her help in developing the search strategy of the systematic review in this dissertation. I also thank friends and families I have met in Louisville (I cannot list all the names here but you know who you are!) for their support and caring in all meanings; I am eternally grateful to you.

To my wonderful family, thank you for your continuous support, encouragement, and love. Thank you for inspiring me to follow my dreams, and I always knew that you want the best for me. To my husband, I do not find the words to express my gratitude. Thank you for being you! You are such a treasure in my life, and together we will reach for the stars!!! 


\begin{abstract}
MENTAL HEALTH AND SUBSTANCE USE DISORDERS AND TREATMENT

RECEIPT AMONG PREGNANT WOMEN IN THE UNITED STATES, 2008-2014:

TREND ANALYSIS, LIKELIHOOD OF TREATMENT RECEIPT, AND ETHNIC DISPARITIES IN MENTAL HEALTH TREATMENT
\end{abstract}

Taghreed Salameh

July 21,2017

Pregnant women and their children are at risk for devastating health consequences when pregnancy is associated with poor mental health and substance use problems. Yet, most of what is known about these significant issues in pregnant women came from clinical samples which limits the generalizability of the findings to the national population. Therefore, the purposes of this dissertation were to examine trends from 2008 to 2014 in mental health and substance use disorders and treatment receipt, and explore factors associated with treatment receipt in pregnant women aged 18-44 years in the United States. This dissertations contains three manuscripts: (1) a systematic review of trend and population-based studies on mental health and substance use disorders and treatment receipt in pregnant women in the United States; (2) a trend study on mental health and substance use disorders and treatment receipt among pregnant and nonpregnant women in the United States from 2008 to 2014; and (3) a population-based 
study of factors associated with mental health and substance use treatment receipt in pregnant women.

The review of trend studies showed that illicit drug use disorder increased in pregnant women over the past decade, particularly opioid and marijuana use disorders. Despite the increase in treatment admissions for these disorders from 1992 to 2012, the overall treatment admission rate for pregnant women remained relatively stable at $4 \%$. Although antidepressant use increased from 1995 to 2010 in pregnant women, there is a lack of trend studies addressing the changes in mental health disorders over the same time period. A review of population-based studies revealed that White ethnicity, older reproductive age, college education, and health insurance coverage are associated with mental health and substance use treatment receipt.

In the second manuscript, trends in mental health and substance use disorders and treatment receipt were compared across one-to-two pairs of matched groups of pregnant $(n=5,520)$ and non-pregnant women $(n=11,040)$ who participated in the 2008-2014 National Survey on Drug Use and Health (NSDUH). There was no difference in these trends by pregnancy status from 2008 to 2014 . Yet, past-year anxiety disorder, pastmonth psychological distress, and illicit drug use disorder increased in the total sample of pregnant and nonpregnant women from 2008 to 2014, whereas trends in mental health treatment receipt and unmet need for substance use treatment did not change over the same time period.

In the final manuscript, secondary analysis of the 2008-2014 NSDUH was conducted with data from 5,520 pregnant women (1,106 with mental health problems and 521 with substance use disorders) who were 18-44 years old. The best predictors of 
receipt of mental health treatment included: past-year anxiety disorder, major depressive episode, serious psychological distress, college education, health insurance coverage, and White ethnicity. Predictors of substance use treatment receipt were: illicit drug abuse and dependence, alcohol dependence, comorbid anxiety/depression, White ethnicity, and urban residency. Compared to Whites, nonWhite pregnant women with major depressive episode, serious psychological distress, substance use disorders, and/or comorbid mental health and substance use disorders had lower odds of receiving mental health treatment. The findings of this dissertation indicate that there is a gap between the need and the receipt of mental health and substance use treatment in pregnant women. Improved recognition and access to treatment for mental health and substance use disorders in this vulnerable population is critical. Preventive and interventional strategies are required to address the mental health needs of ethnic minority pregnant women with mental health and/or substance use disorders. 


\section{TABLE OF CONTENTS}

PAGE

ACKNOWLEDGMENTS ...............................................................................................

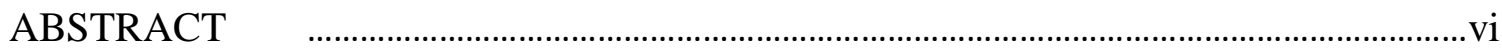

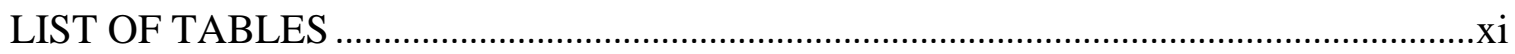

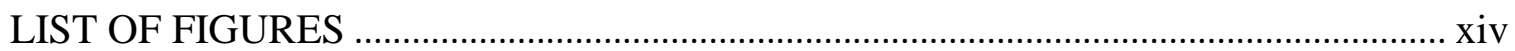

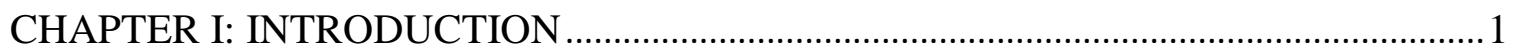

CHAPTER II: Mental Health and Substance Use Disorders and Treatment Receipt among Pregnant Women in the United States: A Systematic Review of Trend and Population-Based Studies …………………………………....

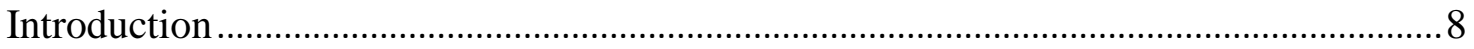

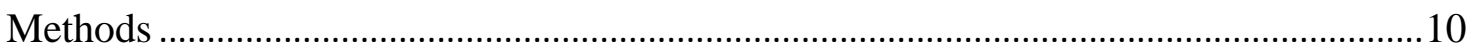

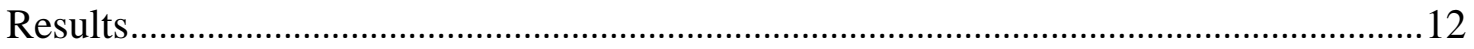

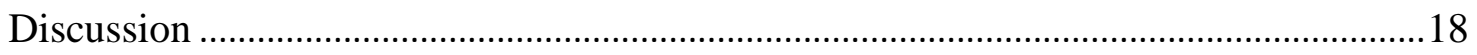

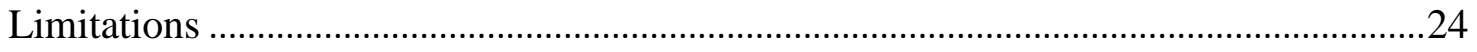

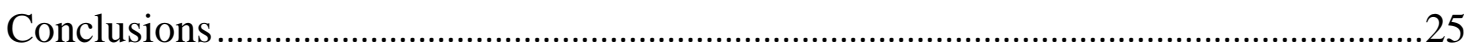

CHAPTER III: Trends in Mental Health and Substance Use Disorders and

Treatment Receipt among Pregnant and Nonpregnant Women in the

United States, 2008-2014 ……………………………………………......43

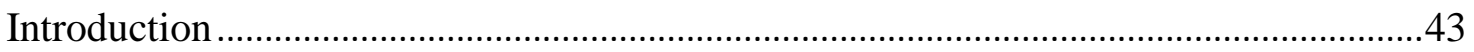

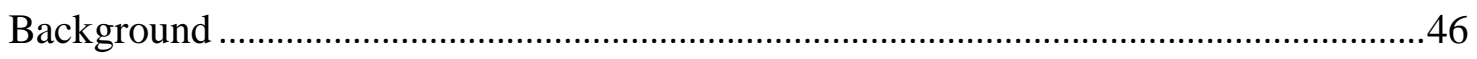

ix 
Methods

Results

Discussion

Limitations .75

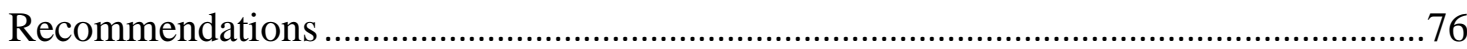

CHAPTER IV: Predictors of Mental Health and Substance Use Treatment Receipt and Ethnic Disparities in Mental Health Treatment in a National Sample of Pregnant Women with Mental Health and/or Substance Use Disorders.

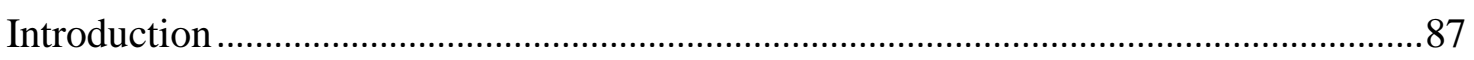

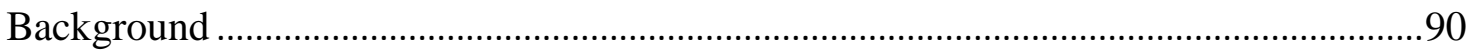

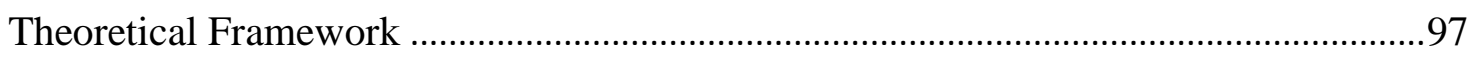

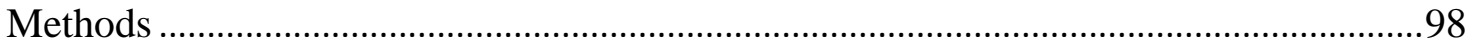

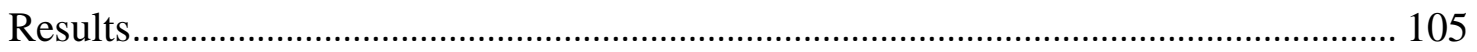

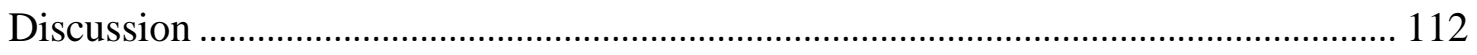

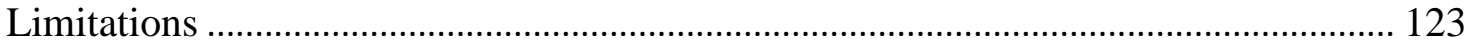

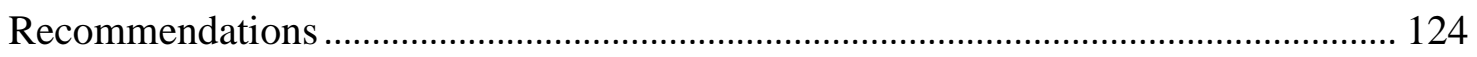

CHAPTER V: Discussion and Conclusions ............................................................... 142

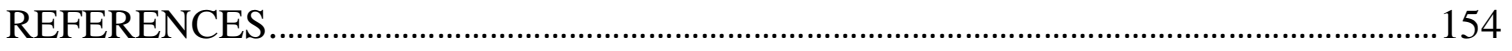

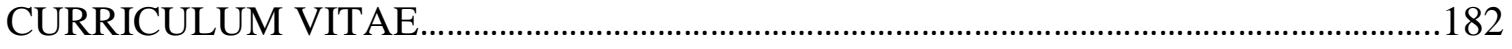


TABLE

\section{LIST OF TABLES}

1. Search Terms Addressing Mental Health and Substance Use Disorder in Pregnant Women in the United Stated in Three Databases...........................26

2. Trend Studies on Mental Health and Substance Use Disorders and Treatment Receipt in Pregnant Women of Childbearing Age in the United States, 2008-2017...27

3. Population-based Studies on Mental Health and Substance Use Treatment Receipt in Pregnant Women of Childbearing Age

4. Sociodemographic Characteristics of Matched Samples of Pregnant and Non-pregnant Women Aged 18-44, NSDUH 2008-2014 .78

5. Logistic Regression Modeling the Probability of Mental Health and Substance Use Disorders and Treatment Receipt from 2008-2014 among a Matched Sample of Pregnant and Nonpregnant Women, NSDUH .............................. 82

6. Logistic Regression Modeling the Probability of the Receipt of Mental Health Treatment by Pregnant and Nonpregnant Women with Mental Illness from 2008 to 2014, Controlling for Severity of Illness, NSDUH.

7. Perceived Barriers to Mental Health Treatment and Substance Use Treatment in Pregnant and Nonpregnant Women Perceived Need for Treatment from 2008-2010 to 2011-2014 .86

8. Socio-demographic Characteristics of Pregnant Women Aged 18-44, 
NSDUH 2008-2014.

9. Characteristics Associated with Receipt of Mental Health Treatment among Pregnant Women with Mental Health Problems Aged 18-44 Years, NSDUH 2008-2014

10. Characteristics Associated with Receipt of Substance Use Treatment among Pregnant Women with Substance Use Disorders Aged 18-44 Years, NSDUH 2008-2014

11. Logistic Regression Using Backward Elimination to Identify the Best Predictive Model of the Probability of Mental Health Treatment Receipt among Pregnant Women Aged 18-44 years with Mental Health Problems, Controlling for Time, NSDUH 2008-2014.....

12. Logistic Regression Using Backward Elimination to Identify the Best Predictive Model of the Probability of Substance Use Treatment Receipt among Pregnant Women Aged 18-44 years with Substance Use Disorders, NSDUH 2008-2014, Controlling Time.

13. Percentages of Mental Health Treatment Modalities in Non-Hispanic White and Nonwhite Pregnant Women with Mental Health and Substance Use Disorders and Aged 18-44 Years, NSDUH 2008-2014.

14. Logistic Regression Model of the Probability of the Receipt of Mental Health Treatment in Pregnant Women Aged 18-44 Years by Type of Mental Health and/or Substance Use Disorders and Ethnicity, NSDUH 2008-2014.... 135

15. Differences in Perceived Barriers to Mental Health Treatment among Pregnant Women with Mental Health and/or Substance Use 
Disorders and Perceived Need for Treatment, NSDUH (2008-2014)...............136 


\section{LIST OF FIGURES}

$\begin{array}{lll}\text { FIGURE PAGE } & \text { PAR }\end{array}$

1. PRISMA flow chart for studies selection process............................42

2. Trends in mental health problems rates from 2008 to 2014 among a matched sample of pregnant and nonpregnant women aged 18-44, National Survey on Drug Use and Health .................................................... 79

3. Trends in substance use disorders rates from 2008 to 2014 among a matched sample of pregnant and nonpregnant women, National Survey on Drug Use and Health

4. Trends in rates of treatment receipt for mental health and substance use disorders from 2008-2014 among a matched sample of pregnant and nonpregnant women, National Survey on Drug Use and Health.... .81

5. Weighted percentages and rank ordering of perceived barriers to mental health and substance use treatment from 2008-2010 to 2011-2014 among women of childbearing age perceived need for treatment, National Survey

on Drug Use and Health.

6. Weighted percentages and rank ordering of perceived barriers to mental health treatment from 2008-2010 to 2011-2014 among pregnant and nonpregnant women perceived need for treatment, National Survey on Drug Use and Health.

7. The Behavioral Model of Health Services Use 
8. Theoretical framework adapted the Behavioral Model of Health Services Use......138

9. Perceived barriers to mental health treatment in White and NonWhite pregnant women with mental health problems who perceived need for treatment, National Survey on Drug Use and Health, 2008-2014...........................139

10. Perceived barriers to mental health treatment in White and NonWhite pregnant women with substance use disorders who perceived a need for treatment, National Survey on Drug Use and Health.................................. 140

11. Perceived barriers to mental health treatment in pregnant women with comorbid mental health and substance use disorders who perceived a need for treatment, National Survey on Drug Use and Health, 2008-2014.......................141 


\section{CHAPTER I}

\section{INTRODUCTION}

Mental health and substance use disorders are significant public health issues that have deleterious effects on the mother and her child. However, there is hope to improve maternal mental health and promote better futures for mothers and their children. This message of hope for women is created and advanced by researchers, policy makers, healthcare providers, and women themselves (United States Department of Health and Human Services [USDHHS], 2009). In response to this message of hope, the purposes of this dissertation were to examine trends in mental health and substance use disorders and treatment receipt, and explore factors associated with treatment receipt in pregnant women aged 18-44 years in the United States.

This dissertation consists of an introduction, three manuscripts, and a discussion chapter in which the findings of the three chapters are integrated. First, a systematic review of trend and population-based studies was conducted to describe mental health and substance use disorders and treatment receipt among pregnant women in the United States. Second, trends from 2008 to 2014 in mental health and substance use disorders and treatment receipt among pregnant and nonpregnant women in the United States were examined. Third, the Behavioral Model of Health Services Use (Andersen, 1995) was used to examine factors associated with the receipt of treatment for mental health and substance use disorders among pregnant women in the United States. 
Serious mental health conditions disproportionately affect women (Hasin, Goodwin, Stinson, \& Grant, 2005; Kessler, Berglund, et al., 2003) and are common among women of childbearing age (Farr, Bitsko, Hayes, \& Dietz, 2010; Ko, Farr, Dietz, \& Robbins, 2012). In the United States, up to $12.4 \%$ of pregnant women suffer from depression (Ko et al., 2012; Le Strat, Dubertret, \& Le Foll, 2011; Melville, Gavin, Guo, Fan, \& Katon, 2010; Vesga-Lopez et al., 2008), and anxiety often occurs with depression (Bowen et al., 2014; Le Strat et al., 2011). These serious mental health conditions are associated with substance use problems (Connelly, Hazen, Baker-Ericzen, Landsverk, \& Horwitz, 2013; Le Strat et al., 2011) and increase the risk for developing chronic disorders such as diabetes (Farr, Hayes, Bitsko, Bansil, \& Dietz, 2011).

Prenatal mental illness takes a toll on maternal-child health. Maternal complications associated with poor mental health during pregnancy include preterm delivery (Accortt, Cheadle, \& Dunkel Schetter, 2015; Grigoriadis et al., 2013), low birth weight (Accortt et al., 2015), and postpartum depression (Goodman, Chenausky, \& Freeman, 2014). The mother-child relationship also is negatively affected (Grigoriadis et al., 2013; Rossen et al., 2016), and children of depressed mothers are at risk for behavioral and cognitive disorders (Csaszar, Melichercikova, \& Dubovicky, 2014; Kingston, Tough, \& Whitfield, 2012). Substance use disorders comorbid with mental health problems (Connelly et al., 2013), and children of substance using mothers are also at risk for mental disorders and harmful substance use, even after controlling for other childhood experiences (Jaaskelainen, Holmila, Notkola, \& Raitasalo, 2016).

The Substance Abuse and Mental Health Services Administration (SAMHSA, 2014b) reported that 5.4\% of pregnant women used illicit drugs in the past month and a 
higher percentage of them (9.4\%) used alcohol in 2012 and 2013. Alcohol use during pregnancy can cause fetal alcohol syndrome (Lehikoinen, Orden, Heinonen, \& Voutilainen, 2016). Prenatal marijuana use is also associated with intrauterine growth restriction (IUGR) (Metz \& Stickrath, 2015) and may adversely affect children's neurodevelopment (Jaques et al., 2014). In addition, cocaine-using women are at risk for placental abruption, preterm birth, IUGR, and impaired neurodevelopment in exposed infants (Lambert \& Bauer, 2012).

Prenatal exposure to psychotherapeutic drugs, particularly opioids, is associated with preterm birth and Neonatal Abstinence Syndrome (NAS) (Narkowicz, Plotka, Polkowska, Biziuk, \& Namiesnik, 2013). NAS is characterized by extreme irritability, tremors, seizures, vomiting, diarrhea, and inconsolability from drug withdrawal (Hudak $\&$ Tan, 2012). Infants with NAS stayed in the hospital for an average of 16.9 days with a mean hospitalization cost of \$66,700 in 2012 (Patrick, Davis, Lehmann, \& Cooper, 2015). Hence, prenatal substance use is an ongoing public health problem (Narkowicz et al., 2013) representing burden to society because of costs associated with health care for substance-exposed infants (Patrick et al., 2015) and child protective services interventions (Ondersma, Simpson, Brestan, \& Ward, 2000).

Despite ongoing medical recommendations (American College of Obstetricians and Gynecologists [ACOG], 2015b) and state screening initiatives (Agency for Healthcare Research and Quality, 2016), maternal depression is rarely diagnosed (Ko et al., 2012) or treated (Glasheen, Colpe, Hoffman, \& Warren, 2015; Ko et al., 2012; VesgaLopez et al., 2008); anxiety also is more often ignored than screened or studied (Fairbrother, Janssen, Antony, Tucker, \& Young, 2016; Fairbrother, Young, Janssen, 
Antony, \& Tucker, 2015). Moreover, pregnant women with substance use disorders are rarely screened and referred to treatment by health care providers (McCabe \& Arndt, 2012; Terplan, Smith, Kozloski, \& Pollack, 2010). Unfortunately, numerous obstacles (e.g., stigma and cost) impede pregnant women from receiving treatment for mental health (Ko et al., 2012) and substance use problems (Jackson \& Shannon, 2012a). In addition, there are scant drug treatment programs targeting these women (Guttmacher Institute, 2017). This is of critical concern in the presence of health care disparities experienced by ethnic and racial minorities of pregnant women with mental health problems (Chang, Tabet, Elder, Kiel, \& Flick, 2016).

Given the vulnerability of pregnant women and the complexity of mental health and substance use disorders, understanding the seriousness of these disorders and the pattern of treatment receipt among pregnant women over time is warranted. Such information is critical for proper allocation of prevention and treatment resources nationwide. Yet, there is a paucity of review studies that shed the light on recent trends in mental health and substance use disorders and treatment receipt among pregnant women in the United States. The majority of review studies focused on the screening of depression during pregnancy or postpartum (Lancaster et al., 2010; O'Connor, Rossom, Henninger, Groom, \& Burda, 2016; Thombs et al., 2014; van der Zee-van den Berg, Boere-Boonekamp, Haasnoot-Smallegange, \& Reijneveld, 2017), while a few addressed barriers and facilitators to depression care during pregnancy (Byatt, Levin, Ziedonis, Simas, \& Allison, 2015; Byatt, Simas, Lundquist, Johnson, \& Ziedonis, 2012).

Chapter Two presents a systematic review of the literature on mental health and substance use disorders and treatment receipt among pregnant women in the United 
States. The purpose of this review was to synthesize findings of trend and populationbased studies on mental health and substance use disorders and treatment receipt among pregnant women in the United States. Trend and population-based studies were selected for this systematic review to inform policy makers, healthcare providers, researchers, and others about the seriousness of maternal mental health and substance use disorders and what factors influencing access to treatment among pregnant women. The hope is to inspire future research and spur a change in maternal mental health through developing preventive and intervention strategies.

The passage of the Mental Health Parity and Addiction Equity Act (MHPAEA) (2008) and the Patient Protection and Affordable Care Act (PPACA) (2010) indicates major implications to enhance women's access to health care such as health coverage expansion and integrating mental health and substance use treatment services with primary medical care. However, there is limited literature addressing recent trends in mental health and substance use disorders and receipt of treatment in the United States (Mojtabai \& Jorm, 2015), particularly among pregnant women. It is crucial to examine the difference in these patterns between pregnant and nonpregnant women. Such information will help in designing unique preventive strategies and program interventions according to the specific needs of pregnant women.

Chapter Three presents a trend study of mental health and substance use disorders and treatment receipt among pregnant and nonpregnant women in the United States. Secondary analysis of the 2008-2014 National Survey on Drug Use and Health (NSDUH) was conducted to compare trends in mental health and substance use disorders and treatment receipt by pregnancy status. One-to-two pairs of pregnant $(n=5,520)$ and non- 
pregnant women $(n=11,040)$ were matched using propensity score matching. Pregnancy status was regressed onto age, ethnicity, marital status, education level, employment status, income, health insurance, and county urbanicity. A series of logistic regression models was conducted to examine potential interactions between pregnancy status and time in predicting: past-year major depressive episode (MDE); anxiety disorder; pastmonth serious psychological distress; past-year any mental illness; past-year alcohol use disorder; illicit drug use disorder; mental health treatment receipt; and unmet need in the receipt of substance use treatment. This study also compared trends in mental health treatment receipt by pregnancy status among women with past-year any mental illness. Furthermore, barriers to mental health and substance use treatment were compared among women of childbearing age across two time periods, 2008-2010 and 2011-2014.

Although prenatal mental health has been given little attention compared to postpartum depression, most of what is known is about factors associated with poor mental health during pregnancy (Fairbrother et al., 2016; Fairbrother et al., 2015; Le Strat et al., 2011; Vesga-Lopez et al., 2008) rather than factors related to mental health treatment receipt. Likewise, there is sparse evidence about factors associated with the receipt of substance use treatment among pregnant women. In Chapter Four, the Behavioral Model of Health Services Use (Andersen, 1995) was used to examine factors associated with mental health and substance use treatment among pregnant women with mental health and substance use disorders in the United States. This model was chosen because it integrates individual and contextual determinants of health services use: (a) predisposing characteristics (e.g., ethnicity); (b) enabling factors (e.g., health insurance 
coverage); and (c) need factors (e.g., MDE, substance use disorders, and perceived need for treatment).

Secondary analysis of the 2008-2014 NSDUH was conducted. A sample of 1,106 pregnant women with mental health problems (i.e., past-year MDE, anxiety disorder, or serious psychological distress) and 521 pregnant women with substance use disorders (i.e., alcohol use disorder or illicit drug use disorder) were included in this study. A series of logistic regression models was used to identify predictors of mental health/substance use treatment receipt as well as ethnic disparities in the receipt of mental health treatment among pregnant women with mental health and/or substance use disorders. In addition, barriers to mental health treatment were compared and contrasted across types of mental health and/or substance use disorders and ethnicity.

Finally, Chapter Five is an integration of the findings of Chapters Two, Three, and Four. Research, practice, and policy implications generated from the three manuscripts were summarized and discussed. 
CHAPTER II

MENTAL HEALTH AND SUBSTANCE USE DISORDERS AND TREATMENT RECEIPT AMONG PREGNANT WOMEN IN THE UNITED STATES: A SYSTEMATIC REVIEW OF TREND AND POPULATION-BASED STUDIES

\section{Introduction}

Mental health problems affect $8.2 \%$ to $13.0 \%$ of pregnant women (Cook et al., 2010; Le Strat, Dubertret, \& Le Foll, 2011, 2011; Vesga-Lopez et al., 2008) and have devastating health consequences on the mother and her child (Csaszar, Melichercikova, \& Dubovicky, 2014; Goodman, Chenausky, \& Freeman, 2014; Grigoriadis et al., 2013; Rossen et al., 2016). Prenatal substance use is common among pregnant women with mental health issues (Connelly, Hazen, Baker-Ericzen, Landsverk, \& Horwitz, 2013) and represents a perennial public health concern (Narkowicz, Plotka, Polkowska, Biziuk, \& Namiesnik, 2013). In 2012 and 2013, 5.4\% of pregnant women reported past-month use of illicit drugs and 9.4\% of them drank alcohol (Substance Abuse and Mental Health Services Administration [SAMHSA], 2014b).

Alcohol consumed during pregnancy is associated with fetal alcohol syndrome (Lehikoinen, Orden, Heinonen, \& Voutilainen, 2016) and low birth weight (Irner, Teasdale, Nielsen, Vedal, \& Olofsson, 2012). Prenatal illicit drug use is associated with medical and obstetric complications (Lambert \& Bauer, 2012; Metz \& Stickrath, 2015), impaired neurodevelopment in prenatally exposed infants (Jaques et al., 2014), and costs related to their prolonged hospitalization (Patrick, Davis, Lehmann, \& Cooper, 2015), 
and child protective services (Ondersma, Simpson, Brestan, \& Ward, 2000). Yet, mental health and substance use disorders continue to be unrecognized and undertreated in pregnant women (Connelly et al., 2013; Glasheen, Colpe, Hoffman, \& Warren, 2015; Ko, Farr, Dietz, \& Robbins, 2012; Vesga-Lopez et al., 2008), irrespective of ongoing screening initiatives (Agency for Healthcare Research and Quality, 2016), legislation (Mental Health Parity and Addiction Equity Act [MHPAEA], 2008; Patient Protection and Affordable Care Act [PPACA], 2010), and available effective treatment modalities (Baker et al., 2010; Marais et al., 2011; May et al., 2013; Meyer, Johnston, Crocker, \& Heil, 2015).

Although pregnancy represents an ideal time to screen and intervene with substance and mental health issues (Connelly et al., 2013), pregnant women face numerous obstacles to access mental health and substance use treatment (United States Department of Health and Human Services [USDHHS], 2009; Center for Substance Abuse Treatment [CSAT], 2009). Proper distribution of prevention and treatment resources requires an understanding of the significance of mental health and substance use disorders during pregnancy nationwide. Hence, a review of trend studies on mental health and substance use problems and treatment receipt among pregnant women in the United States is warranted to understand the changes in these disorders over time.

Prior and recent review studies focused on clinical studies addressing screening of depression in pregnant or postpartum women (Lancaster et al., 2010; O'Connor, Rossom, Henninger, Groom, \& Burda, 2016; Thombs et al., 2014; van der Zee-van den Berg, Boere-Boonekamp, Haasnoot-Smallegange, \& Reijneveld, 2017). Two recent systematic reviews focused on studies addressing barriers and facilitators to depression care during 
pregnancy (Byatt, Levin, Ziedonis, Simas, \& Allison, 2015; Byatt, Simas, Lundquist, Johnson, \& Ziedonis, 2012). To our knowledge, no prior review studies examined factors related to mental health and substance use treatment receipt among pregnant women from trend and population-based studies in the United States. Understanding these factors from population-based samples rather than clinical samples is important to inform health policy so that strategies can be implemented to improve access to mental health and substance use treatment. Therefore, the purpose of this systematic review was to synthesize findings from trend and population-based studies to describe mental health and substance use disorders and treatment receipt in pregnant women of childbearing age in the United States.

\section{Method}

This review was performed using the Preferred Reporting Items Systematic Review and Meta-analysis (PRISMA) guidelines (Moher, Liberati, Tetzlaff, \& Altman, 2009). To decrease the risk of bias (Riesenberg \& Justice, 2014), three databases were searched: CINAHL, PubMed, and PsychINFO. The search strategy was developed and vetted by a master's prepared medical librarian. The search terms used in this review included subject headings and MeSH terms according to the requirements of each database (see Table 1).

Only peer-reviewed research articles published between 2007 and 2017 were included. Eligible studies were limited to population-based and trend studies on mental health or substance use disorders or treatment receipt for these disorders in pregnant women published in the last 10 years. The search was limited to English language publications, human subjects, and adults aged 18 years and older. This review was 
limited to trend studies addressing mental health or substance use disorders or treatment receipt over time among pregnant women in the United States. If multiple trend studies used overlapping data sources or time points, the most recent study that reported national estimates was included. Studies that examined trends over less than five years and those that did not specifically address substance abuse or dependence during pregnancy were excluded from the review.

This review also focused on population-based studies of treatment receipt for mental health and substance use disorders. Population-based studies were included if they reported national/statewide data on mental health or substance use disorders or treatment receipt irrespective of the study design. Hence, population-based studies of randomly selected participants as well as population-based prospective/retrospective cohort studies were included in this review. Large national surveys comparing pregnant and nonpregnant women in regards treatment receipt for mental health and substance use disorders were also included.

\section{Data Extraction and Analysis}

All primary studies were retrieved through the selected databases and screened for the eligibility based on the inclusion criteria. The references in each database were screened for duplication. Then the references list was compared between databases to eliminate duplicate articles. Next, the titles and abstracts were reviewed to identify articles that met the inclusion criteria. If this was not clear, the full text was reviewed. 


\section{Results}

\section{Study Selection}

The initial search resulted in 1,620 articles that were further screened for duplication. Eliminating the duplicating articles within and between databases resulted in 1,209 articles. After removing articles with obviously irrelevant titles, a total of 450 articles were reviewed at the abstract level. Of these, 402 articles were eliminated due to lack of relevance to the present review. In addition, full text review resulted in eliminating another 22 articles. After screening based on the inclusion criteria, 26 research articles were included in the final review. Two additional articles identified from a review of reference lists of the selected articles were included (see Figure 1).

\section{Trends in Mental Health and Substance Use Disorders and Treatment Receipt}

Table 2 shows the characteristics of nine trend studies addressing changes in mental health and substance use disorders and treatment receipt in pregnant women over time. Among these studies, three studies addressed trends in antidepressant use during pregnancy (Andrade et al., 2008; Bobo et al., 2014; Meunier, Bennett, \& Coco, 2013), and only one study focused on examining trends in psychotropic medications (Hanley \& Mintzes, 2014). Overall, these studies showed an increase in antidepressant use during pregnancy from 1995 to 2010 (Andrade et al., 2008; Bobo et al., 2014; Meunier et al., 2013). However, one study showed an inconsistent trend in antidepressant use as it increased from 1995 to 2004 then declined in 2007 (Bobo et al., 2014). Hanley and Mintzes (2014) found that the rate of psychotropic medication use was relatively stable between 2006 and 2011, while antidepressant use decreased slightly between 2010 and 2011. No trend studies were found that addressed patterns of mental health treatment 
receipt other than prescription medications over time as well as there is a lack of trend studies that examined changes of mental health problems in pregnant women over time.

Among trend studies addressing substance use disorders and treatment among pregnant women, one study examined trends in maternal abuse of various substances (Pan \& Yi, 2013) and another one focused on opioid dependence or abuse during pregnancy (Maeda, Bateman, Clancy, Creanga, \& Leffert, 2014). Three studies addressed trends in treatment admission for different types of substances using the Treatment Episode Data Set (TEDS) (Martin, Longinaker, Mark, Chisolm, \& Terplan, 2015; Martin, Longinaker, \& Terplan, 2015; McCabe \& Arndt, 2012).

Based on the 1999-2008 Nationwide Inpatient Sample dataset, Pan and Yi (2013) reported an increase in opioid, cannabis and hallucinogens, and methamphetamine abuse during pregnancy over time. However, cocaine abuse declined significantly while alcohol abuse decreased slightly. From 1998 to 2011, the prevalence of opioid use disorders increased from $0.17 \%$ to $0.39 \%$ among pregnant women (Maeda et al., 2014).

Studies of trends in substance use treatment showed an increase in admission rates for drug abuse whereas a decrease in alcohol-related abuse admissions occurred from 1998 to 2008 (McCabe \& Arndt, 2012). From 1992 to 2012, the rate of treatment admissions for marijuana as a primary substance of use increased; however, treatment admission for cocaine and alcohol use decreased over the same time period (Martin, Longinaker, Mark, et al., 2015). One study focused specifically on opioid use treatment and showed an increase in admission rate from 1\% in 1992 to $19 \%$ in 2012 (Martin, Longinaker, \& Terplan, 2015). 


\section{Mental Health and Substance Use Treatment Receipt}

Table 3 shows the characteristics of 19 population-based studies addressing mental health and substance use treatment receipt among pregnant women in the United States. Among these studies, 11 studies addressed mental health treatment receipt, three studies addressed substance use treatment receipt, one study focused on mental health treatment receipt in substance use treatment setting, and four studies discussed barriers to mental health treatment.

The rate of mental health treatment receipt ranged from $6.3 \%$ to $49.6 \%$ among pregnant women (Byatt, Xiao, Dinh, \& Waring, 2016; Chang, Tabet, Elder, Kiel, \& Flick, 2016; Cook et al., 2010; Glasheen et al., 2015; Ko et al., 2012; Le Strat et al., 2011; Roberson et al., 2016). Four studies focused specifically on estimating the rate of antidepressant use and indicated that $2.2 \%$ to $27 \%$ of pregnant women used antidepressant during prenatal period (Bennett, Marcus, Palmer, \& Coyne, 2010; Geier, Hills, Gonzales, Tum, \& Finley, 2015; Wu \& Davis-Ajami, 2014; Yamamoto, McCormick, \& Burris, 2015). Two studies addressed pharmacotherapy for mental health problems in pregnant women; $1.4 \%$ of women used anxiolytic or antidepressant medications (Roberson et al., 2016), whereas 39.6\% of women used prescription medications for any emotion, nerve, or mental health problems (Ko et al., 2012). Ko et al. (2012) also reported that $7.2 \%$ of pregnant women required inpatient treatment for any mental health problem.

Data based on two national survey studies showed that pregnant women are less likely to receive mental health treatment compared to nonpregnant women even after adjusting for confounding variables (Glasheen et al., 2015; Vesga-Lopez et al., 2008). 
However, two other national surveys did not show any difference between pregnant and nonpregnant women in the receipt of mental health treatment (Ko et al., 2012; Le Strat et al., 2011). Yet, a cohort study based on California State Medicaid program 2006-2009 showed that pregnant women had a lower odds of depression diagnosis or treatment (Geier et al., 2015). Three studies reported the adjusted association between pregnancy status and mental health receipt without highlighting the contribution of other sociodemographic characteristics (Ko et al., 2012; Le Strat et al., 2011; Vesga-Lopez et al., 2008). Yet, Glasheen et al. (2015) found that mental health treatment receipt among women of childbearing age was related to White ethnicity, older reproductive age, college education, having a history of depression or anxiety. Likewise, Geier et al. (2015) reported that White ethnicity, age of 25 years or older, and urban residence were associated with depression treatment.

Of studies conducted solely among pregnant women, factors associated with mental health treatment receipt included White ethnicity (Bennett et al., 2010; Byatt et al., 2016; Chang et al., 2016), older reproductive age, college education, marital status, tobacco use, physical or psychological abuse (Chang et al., 2016), having assistance/insurance coverage (Bennett et al., 2010; Chang et al., 2016), having a current (Byatt et al., 2016) or past mental health problem (Roberson et al., 2016), and urban residency (Cook et al., 2010). Among these studies, there was only one study conducted among a nationally representative sample of pregnant women (Byatt et al., 2016).

Three studies explicitly addressed ethnic care disparities among pregnant women. A study based on the Florida Healthy Start prenatal screening program indicated that the rate of life-time mental health treatment receipt was highest among White pregnant 
women, while the rate was lowest among Mexicans and other Hispanics (Chang et al., 2016). Another study based on the 2006-2010 National Ambulatory Medical Care Survey and the National Hospital Ambulatory Medical Care Survey revealed that nonWhite pregnant women had lower odds of antidepressant use even after controlling for maternal age, insurance type, region of the country, and survey type (Yamamoto et al., 2015). Interestingly, Coleman-Cowger (2012) examined disparities in mental health treatment based on the 2008 Global Appraisal of Individual Needs Data among past-year pregnant women who entered substance use treatment. This study showed that higher proportions of Hispanics and African Americans had not received mental health treatment compared to Mixed or White women.

Four studies addressed barriers to mental health treatment among pregnant women. One compared barriers to mental health treatment between pregnant and nonpregnant women using the 2005-2009 National Survey on Drug Use and Health (NSDUH) (Ko et al., 2012). The most common barriers were cost, opposition to treatment, stigma, time/transportation limitation, and not knowing where to go. These perceived barriers did not differ by pregnancy status. Two studies examined factors associated with provider-patient conversation regarding depression based on state (Liu \& Tronick, 2012) and national-level data (Farr, Ko, Burley, \& Gupta, 2016). These factors included age of less than 35 years (versus > 35 years), Medicaid coverage, White ethnicity (Farr et al., 2016; Liu \& Tronick, 2012), and being unmarried (Farr et al., 2016). In addition, non-US born pregnant women and those who visited a private doctor had lower odds of having a conversation about depressed mood with health care providers (Liu \& Tronick, 2012). From the healthcare providers' perception, the 2008-2009 
Virginia Department of Health Data showed that common barriers to treatment/referrals of pregnant women with depression included the lack of time, available treatment services, reimbursement, and provider knowledge/skills (Price, Corder-Mabe, \& Austin, 2012).

Three studies addressed substance use treatment receipt. A study based on the 2002-2006 NSDUH indicated that less than $20 \%$ of women of childbearing age with substance use disorders received substance use treatment; however, pregnant women did not have a lower odds of receipt of substance use treatment compared to nonpregnant women (Terplan, McNamara, \& Chisolm, 2012). Yet, women of childbearing age who were employed, aged 21-25 (versus less than 20 years), had high school education or equivalent, and those who did not have governmental assistance had a lower odds of substance use treatment receipt compared to their counterpart group. A population-based study in Massachusetts 2003-2007 showed that pregnant women who received substance use treatment were more likely to be age of 30 or older, have some college education, be married, and have private insurance and fewer health or psychiatric conditions, and less likely to be Black or Hispanic compared to those who did not receive treatment (Kotelchuck et al., 2017).

A study based on the 2013 TEDS compared characteristics of pregnant women who received treatment for opioid use disorder by United States census regions (Hand, Short, \& Abatemarco, 2017). Compared to the South, pregnant women who received substance use treatment in other regions were more likely to be admitted to medication assisted treatment, and use heroin and injection drugs. Pregnant women with opioid use 
disorder in the South were less likely to have health insurance coverage, have more than a high school education level, and be married.

\section{Discussion}

\section{Trend Studies on Mental Health and Substance Use Disorder and Treatment Receipt}

The findings of this review demonstrated an increase from 1995 to 2010 in antidepressant use during pregnancy (Andrade et al., 2008; Bobo et al., 2014; Meunier et al., 2013). Although antidepressants were the most common psychotropic medications used among pregnant women, the rate of psychotropic medication use from 2006 to 2011 was stable and antidepressant use slightly decreased between 2010 and 2011 (Hanley \& Mintzes, 2014). Although this suggests a shift in antidepressant use, a careful interpretation of the pattern of antidepressant use across studies is required. For instance, Hanley and Mintzes (2014) used a large private insurance claims database, the Truven Health Market Scan Database, to examine trends in psychotropic medications and this limits the generalizability of trend findings to women covered by Medicaid. The only trend study that used a nationally representative sample of women in prenatal care showed an increase in antidepressant use from 2002 to 2010 (Meunier et al., 2013). Yet, trend studies of antidepressant use did not report medication use disparities among pregnant women over time. In addition, this review did not find any trend studies that specifically examined changes in mental health problems among pregnant women over time.

Changes in the type of substance use disorders among pregnant women over the past decade were revealed in this review. Findings from the 1999-2008 Nationwide 
Inpatient Sample dataset showed an increase in opioid, cannabis and hallucinogens, and methamphetamine related disorders over time, and a decrease in cocaine and alcohol use disorders among pregnant women (Pan \& Yi, 2013). The highest increase in substance use issues was for cannabis and opioids. Congruently, marijuana was the most common illicit drug used in the United States among adults aged 12 or older (SAMHSA, 2014b). The rate of prenatal opioid use disorder also corresponds with the epidemic increase in opioid abuse among the general population (Centers for Disease Control and Prevention [CDC], 2013).

The decrease in cocaine use disorder among pregnant women can be related to the increase in public awareness regarding the cocaine effects (United States Department of Justice, National Drug Intelligence center, 2011). However, the slight decrease in the national estimate of alcohol use disorder in pregnant women should be reviewed with the consideration that pregnant women may continue to consume low to moderate levels of alcohol that cannot be classified as alcohol use disorder (Pan \& Yi, 2013). Yet, the overall decrease in alcohol use disorder can be due to the tremendous efforts in publically informing pregnant women about the risks of alcohol consumption on the mother and her infant (McCabe \& Arndt, 2012).

Notably, there were very few trend studies on national estimates of maternal substance use disorders, and no studies addressed recent trends of these disorders. Yet, ongoing trend studies show an epidemic increase in Neonatal Abstinence Syndrome (NAS) in the United States (Patrick, Davis, Lehman, \& Cooper, 2012; Patrick et al., 2015; Tolia et al., 2015), reflecting an increase in maternal substance use issues, especially opioids. Tolia et al. (2015) reported an increase in Neonatal Intensives Care 
Unit (NICU) admissions for infants with NAS in the United States from seven cases per 1,000 admissions in 2004 to 27 cases per 1,000 admissions in 2013. Opioid pain relievers were the most commonly used medications among pregnant women from 2012 through 2013.

Interestingly, this review revealed that trends in substance use treatment admissions are congruent with the trends in substance use disorders. McCabe and Arndt (2012) reported an increase in drug abuse admissions and a decrease in alcohol abuse admissions from 1998 to 2008. Other studies based on the 1992-2012 TEDS also showed an increase in treatment admissions for marijuana, methamphetamine, and opioids, and in contrast, a decrease in treatment admissions for cocaine and alcohol (Martin, Longinaker, Mark, et al., 2015; Martin, Longinaker, \& Terplan, 2015). Although these patterns are promising, a majority of pregnant women with substance use disorders do not receive treatment (Terplan et al., 2012), and their rate of admission for substance use treatment remained relatively stable at 4\% from 1992 to 2012 (Martin, Longinaker, Mark, et al., 2015). Pregnant women continue to face obstacles to access treatment such as the lack of availability of treatment programs and stigma (CSAT, 2009). Hence, understanding the characteristics of women who received treatment over time can also help to identify disparities and tailor intervention strategies to enhance treatment utilization.

This review indicated that admissions for substance use treatment among pregnant women who were younger (Martin, Longinaker, Mark, et al., 2015; McCabe \& Arndt, 2012), White, had comorbid psychiatric illness (Martin, Longinaker, Mark, et al., 2015; Martin, Longinaker, \& Terplan, 2015), and live in the South (Martin, Longinaker, \& Terplan, 2015) increased over time. Unfortunately, the majority of admission referrals of 
these women have been continued to be through criminal justice systems from 1992 to 2012 (Martin, Longinaker, Mark, et al., 2015; Martin, Longinaker, \& Terplan, 2015; McCabe \& Arndt, 2012), suggesting that most health care providers did not screen women for substance use issues during prenatal care (McCabe \& Arndt, 2012). This review included only trend studies of substance use treatment admission based on the TEDS which draws data from publically funded facilities in the United States (SAMHSA, Center for Behavioral Health Statistics and Quality [CBHSQ], 2017); this may bias the trend findings, as private funded facilities are excluded. In addition, TEDS does not distinguish new admissions from readmissions which may also affect the estimation of the rate of treatment receipt for each individual.

\section{Population-based Studies on Mental Health and Substance Use Treatment Receipt}

This review of findings from national surveys revealed mixed results regarding the association between pregnancy status and the receipt of mental health treatment. This may be due to the heterogeneity of the samples and measures of mental health problems. For instance, studies based on National Epidemiologic Survey on Alcohol and Related Conditions (NESARC) measured psychiatric disorders using structured clinical interviews. Based on this dataset, Vesga-lopez et al. (2008) studied women with any psychiatric disorder while Le Start et al. (2011) only included women with major depression. On the other hand, the NSDUH measured mental health problems using selfreport questions operationalizing the Diagnostic and Statistical Manual of Mental Disorders: DSM-IV (American Psychiatric Association [APA], 1994) and included the Kessler Distress Scale (Kessler, Barker, et al., 2003). Glasheen et al. (2015) studied women of childbearing age with past-month psychological distress using data from the 
NSDUH, while Ko et al. (2012) included women with past-year major depressive episode.

Overall, a majority of pregnant women who need mental health and substance use treatment do not receive it which has critical implications. First, there is a need to focus on socio-economically disadvantaged women and to increase health insurance coverage to improve treatment receipt. Further intervention strategies are also required to help rural, younger, and low educated women access mental health treatment. However, very few population-based studies identified factors associated with treatment receipt among a nationally representative sample of pregnant women.

Second, ethnic health care disparities in the receipt of mental health treatment still exist among pregnant women and even extend to those with substance use disorders. This finding is congruent with the presence of healthcare disparities among the general population (Snowden, 2012). Disparities in antidepressant use are also of particular concern, especially since the rate of antidepressant use is lower than rate of counseling among pregnant women (Ko et al., 2012). Both the American Psychiatric Association (APA) and American College of Obstetricians and Gynecologists (ACOG) recommend antidepressant use during pregnancy if the benefits to the mother with possible risks to the fetus and newborn are balanced (Yonkers et al., 2009). Yet, there is a lack of nationally representative studies on disparities in mental health treatment receipt among pregnant women.

Third, barriers to mental health treatment receipt are complex and involve patientlevel obstacles (i.e., opposition to treatment and stigma), logistic barriers (i.e., cost and lack of time/transportation), and provider-level barriers (i.e., patient-provider 
communication, providers' competency in treatment/referrals, and inadequate available services). These findings are congruent with a systematic review of 49 studies on barriers and facilitators to perinatal depression treatment (Byatt et al., 2015).

Fourth, although one study based on the NSDUH did not find a difference between pregnant and nonpregnant women in substance use treatment receipt, trend findings based on the TEDS showed that the rate of treatment admissions among pregnant females was stable from 1992 to 2012 at only 4\% (Martin, Longinaker, Mark, et al., 2015). Notably, there is a paucity of studies that specifically differentiate the characteristics of pregnant substance use treatment recipients and nonrecipients. Yet, this review suggested that health insurance coverage is necessary to increase treatment receipt. Further intervention strategies are also warranted to increase access to substance use treatment among ethnic minority pregnant women and other vulnerable segments including those with a low education level.

Fifth, there was no population-based study that specifically addressed barriers to substance use treatment among pregnant women. However, using data from the 2013 TEDS, Hand et al. (2017) reported that pregnant women in the South who have opioid use disorder are less likely to receive medication assisted treatment compared to pregnant women in other regions. In addition, the proportion of pregnant women who received medication assisted treatment declined nationally from 44\% in 1992 to $37 \%$ in 2012 (Martin, Longinaker, \& Terplan, 2015). This may be due to a lack of health insurance coverage and available treatment services (Hand et al., 2017). 


\section{Limitations}

There are some limitations to this systematic review. Unpublished studies (e.g., dissertations) and articles of studies solely conducted among pregnant women under age 18 years were not included in this review. This review included population-based studies and trend studies on mental health and substance use disorders among pregnant women and was not a meta-analysis; therefore, the effect sizes of the various studies were not calculated and compared. There is a lack of trend studies on mental health problems among pregnant women, and there is a paucity of nationally representative studies on recent trends in substance use disorders among pregnant women in the United States. Hence, a clear conclusion regarding the trend in these disorders cannot be drawn. Relatively few studies examined trends in antidepressant use among pregnant women, and no studies were found in which trends in the receipt of any treatment modalities (i.e., prescription medications, outpatient counseling, or inpatient treatment) were examined. All studies included in this review reported trends in substance use treatment receipt based on the TEDS which limits the true estimation of treatment receipt among pregnant women as privately funded treatments were not included. The paucity of studies conducted among nationally representative samples of pregnant women limits any conclusions regarding barriers to and factors influencing the receipt of mental health and substance use treatment in the United States. Finally, studies in this review were restricted to population-based and trend studies in the United States and may not be representative of mental health and substance use disorders and treatment receipt among pregnant women globally. 


\section{Conclusions}

This review indicates that the rates of antidepressant use have increased from 1995 to 2010 among pregnant women in the United States. However, there was no study that examined trend in the receipt of any mental health treatment over time among pregnant women. Overall, illicit drug use has increased while alcohol use disorder decreased over the past decade among pregnant women. Marijuana and prescription opioid use disorders are ongoing public health concerns in pregnant women. Despite the increase in treatment admissions for these disorders from 1992 to 2012, the overall admission rate for pregnant women remained relatively stable at $4 \%$.

There is a critical need for innovative preventive interventions for mental health and substance use disorders, especially for vulnerable pregnant women including ethnic minorities and those with a low education level. There is a need for policies and treatment programs to increase access to health insurance and utilization of mental health and substance use treatment services among pregnant women. Further research is needed to address ethnic care disparities, barriers to, and factors associated with treatment receipt among a nationally representative sample of pregnant women. Future systematic reviews need to include studies from different countries to compare trend data and findings regarding factors associated with treatment receipt for mental health and substance use disorders across various health systems. 
Table 1

Search Terms Addressing Mental Health and Substance Use Disorders in Pregnant Women in the United Stated in Three Databases

\begin{tabular}{ll}
\hline Database & Search Terms \\
\hline CINAHL & (MH "Depression") OR (MH "Anxiety") OR (MH "Symptom \\
& Distress") OR (MH "Substance Use Disorders") OR (MH \\
& "Substance Abuse") OR (MH "Alcohol-Related Disorders") \\
& OR (MH "Inhalant Abuse") OR (MH "Substance Abuse, \\
& Intravenous") OR (MH "Substance Abuse, Perinatal") OR (MH \\
& "Substance Dependence") AND (MH "Pregnancy") AND (MH \\
& "United States+") \\
& ((((((((((("Depression"[Mesh] OR "Depressive \\
& Disorder"[Mesh])) OR ("Anxiety"[Mesh] OR "Anxiety \\
& Disorders"[Mesh])) OR "Alcoholism"[Mesh]) OR "Binge \\
& Drinking"[Mesh]) OR "Amphetamine-Related \\
& Disorders"[Mesh]) OR "Cocaine-Related Disorders"[Mesh]) \\
& OR "Marijuana Abuse"[Mesh]) OR "Opioid-Related \\
& Disorders"[Mesh])) AND (("Pregnant Women"[Mesh]) OR \\
& "Pregnancy"[Mesh]))) AND "United States"[Mesh] \\
& ((DE "Pregnancy") AND ((DE "Major Depression" OR DE \\
& "Depression (Emotion)") OR (DE "Anxiety" OR DE "Anxiety \\
& Disorders") OR (DE "Distress") OR (DE "Drug Dependency") \\
& OR (DE "Alcoholism") OR (DE "Drug Abuse") OR (DE \\
& "Alcohol Abuse") OR (DE "Substance Use Disorder"))) AND \\
& (United States OR US OR U.S OR USA) \\
PsychInfo &
\end{tabular}


Table 2

Trend Studies on Mental Health and Substance Use Disorders and Treatment Receipt in Pregnant Women of Childbearing Age in the United States, 2008-2017

\begin{tabular}{|c|c|c|c|c|}
\hline $\begin{array}{l}\text { Authors, } \\
\text { Year }\end{array}$ & Purpose & Data source, Sample & Findings & Comments \\
\hline $\begin{array}{l}\text { Andrade et } \\
\text { al., } 2008\end{array}$ & $\begin{array}{l}\text { Examine the } \\
\text { prevalence of } \\
\text { antidepressant drugs } \\
\text { use among pregnant } \\
\text { women in the United } \\
\text { States }\end{array}$ & $\begin{array}{l}\text { - Health Maintenance } \\
\text { Organization Research } \\
\text { Network Center for } \\
\text { Education and } \\
\text { Research on } \\
\text { Therapeutics, 2001- } \\
2005 \\
\text { - } n=118,935 \text { deliveries } \\
(2001-2005) \\
\text { - } n=148,107 \text { deliveries } \\
(1996-2000)\end{array}$ & $\begin{array}{l}\text { Rates of antidepressant drug } \\
\text { use increased from } 2.0 \% \text { in } \\
1996 \text { to } 7.6 \% \text { in } 2004 \text { and } \\
2005\end{array}$ & $\begin{array}{l}\text { - Seven health plans were } \\
\text { included across the United } \\
\text { States } \\
\text { - No description of women's } \\
\text { characteristics }\end{array}$ \\
\hline $\begin{array}{l}\text { Bobo et al., } \\
2014\end{array}$ & $\begin{array}{l}\text { Examine if the } \\
\text { antidepressant } \\
\text { prescription declined } \\
\text { in pregnant women } \\
\text { after the } \\
\text { announcement of the } \\
\text { U.S. and Canadian } \\
\text { advisory warning } \\
\text { about the risks of } \\
\text { antidepressant in } 2004\end{array}$ & $\begin{array}{l}\text { - Tennessee Medicaid, } \\
\text { 1995-2007 } \\
\text { - } N=228,876 \text { singleton } \\
\text { pregnancies among } \\
\text { women }\end{array}$ & $\begin{array}{l}\text { Rates per } 1,000 \text { increased } \\
\text { steadily from } 1995(66.0) \text { to } \\
2001 \text { (182.8), sharply } \\
\text { increased from } 2002(290.8) \\
\text { to } 2004(397.6) \text {, then } \\
\text { declined post-warning } \\
\text { release to } 195.4 \text { in } 2007\end{array}$ & $\begin{array}{l}\text { Antidepressant users tended } \\
\text { to be mostly: Caucasian, } \\
\text { married, rural residents, } \\
\text { smokers, and with substance } \\
\text { abuse diagnoses and medical } \\
\text { comorbidity }\end{array}$ \\
\hline
\end{tabular}




\begin{tabular}{|c|c|c|c|c|}
\hline $\begin{array}{l}\text { Authors, } \\
\text { Year }\end{array}$ & Purpose & Data source, Sample & Findings & Comments \\
\hline $\begin{array}{l}\text { Hanley \& } \\
\text { Mintzes, } \\
2014\end{array}$ & $\begin{array}{l}\text { Examine the rate of } \\
\text { psychotropic } \\
\text { medication use during } \\
\text { pregnancy from } 2006 \\
\text { to } 2011\end{array}$ & $\begin{array}{l}\text { - Truven Health Market } \\
\text { Scan database, 2006- } \\
2011 \\
\text { - } N=343,299 \text { women } \\
\text { who had a live birth }\end{array}$ & $\begin{array}{l}\text { - The rate of psychotropic } \\
\text { medicines use was } \\
\text { relatively stable between } \\
2006 \text { and } 2011(10.3 \%) \text {. } \\
\text { - A slight decrease in } \\
\text { antidepressant use between } \\
2010(6.7 \%) \text { and } \\
2011(6.4 \%) \\
\text { - The use of stimulants } \\
\text { increased from } 0.4 \% \text { in } \\
2007 \text { to } 0.9 \% \text { in } 2011 \text {. }\end{array}$ & $\begin{array}{l}\text { - The most common types: } \\
\text { antidepressants }(6.5 \%), \\
\text { anxiolytics }(4.2 \%), \\
\text { antipsychotics }(1.1 \%) \text { and } \\
\text { stimulants }(0.6 \%) \text {. } \\
\text { - Rates of use of } \\
\text { psychotropic medicines } \\
\text { were higher before } \\
\text { pregnancy than in first and } \\
\text { second pregnancy } \\
\text { trimesters }\end{array}$ \\
\hline
\end{tabular}

Maeda, Examine trends in Batema, opioid abuse or Clancy, dependence during Creanga, \& pregnancy in the Leffert, United Stated from 2014
- Nationwide Inpatient Sample of the Healthcare Cost and Utilization Project, 1998-2011

- $N=56,900,512$ delivery admissions
The prevalence of opioid use disorder during pregnancy increased from 1.7 per 1,000 delivery admissions in 1998 to 3.9 per 1,000 in 2011
The most significant increase in opioid use disorder (from 1.8 per 1,000 delivery admissions in 1998 to 4.5 per 1,000 deliveries in 2011) occurred within the age group of 20 to 34 years 


\begin{tabular}{|c|c|c|c|c|}
\hline $\begin{array}{l}\text { Authors, } \\
\text { Year }\end{array}$ & Purpose & Data source, Sample & Findings & Comments \\
\hline $\begin{array}{l}\text { Martin, } \\
\text { Longinaker, } \\
\text { Mark, } \\
\text { Chisolm, \& } \\
\text { Terplan, } \\
2015\end{array}$ & $\begin{array}{l}\text { Examine recent } \\
\text { trends in substance } \\
\text { use treatment } \\
\text { admissions of } \\
\text { pregnant women for } \\
\text { marijuana use } \\
\text { in the United States }\end{array}$ & $\begin{array}{l}\text { - Treatment Episodes } \\
\text { Data Set, 1992-2012 } \\
\text { - } N=420,665 \text { substance } \\
\text { abuse treatment } \\
\text { admissions of } \\
\text { pregnant women }\end{array}$ & $\begin{array}{l}\text { The rate of admissions } \\
\text { for marijuana increased } \\
\text { from } 6 \% \text { to } 20 \% \text { The rate of } \\
\text { admission for other primary } \\
\text { substance of use: Decreased } \\
\text { for cocaine ( } 40 \% \text { to } 6 \%) \\
\text { and alcohol }(28 \% \text { to } 12 \%) \text {; } \\
\text { Increased for methamphet- } \\
\text { amines ( } 4 \% \text { to } 13 \%) \text {, heroin } \\
(4 \% \text { to } 9 \%) \text {, and opioids } \\
(<1 \% \text { to } 11 \%)\end{array}$ & $\begin{array}{l}\text { - The rate of treatment } \\
\text { admissions of pregnant } \\
\text { women stayed stable at } 4 \% \\
\text { - Rates of admissions of } \\
\text { whites and those with } \\
\text { comorbid psychiatric } \\
\text { illness increased overtime } \\
\text { - Rates of admissions of } \\
\text { non--high school graduates, } \\
\text { homeless and married } \\
\text { women decreased over time }\end{array}$ \\
\hline
\end{tabular}

$\begin{array}{ll}\text { Martin, } & \text { Examine recent trends } \\ \text { Longinaker, } & \text { in substance abuse } \\ \text { \& Terplan, } & \text { treatment admissions } \\ 2015 & \begin{array}{l}\text { of pregnant women } \\ \text { for prescription } \\ \\ \text { opioids }\end{array}\end{array}$

Martin, Longinaker, \& Terplan opioids

\section{- Treatment Episodes} Data Set, 1992-2012

- $N=420,665$ substance abuse treatment admissions of pregnant women
- The rate reporting any prescription opioid abuse increased from 2\% in 1992 to $28 \%$ in 2012

- The rate opioids use as the primary substance of abuse increased from $1 \%$ to $19 \%$
- The rate of admissions increased overtime among: whites, those aged 21-29 years, with comorbid psychiatric illness, and live in the South

- Criminal justice referrals increased from $11 \%$ to $17 \%$ 


\begin{tabular}{|c|c|c|c|c|}
\hline $\begin{array}{l}\text { Authors, } \\
\text { Year }\end{array}$ & Purpose & Data source, Sample & Findings & Comments \\
\hline $\begin{array}{l}\text { McCabe \& } \\
\text { Arndt, } 2012\end{array}$ & $\begin{array}{l}\text { To examine trends in } \\
\text { substance abuse and } \\
\text { demographic from } \\
1998 \text { to } 2008 \text { among } \\
\text { pregnant women } \\
\text { admitted into } \\
\text { substance abuse } \\
\text { treatment }\end{array}$ & 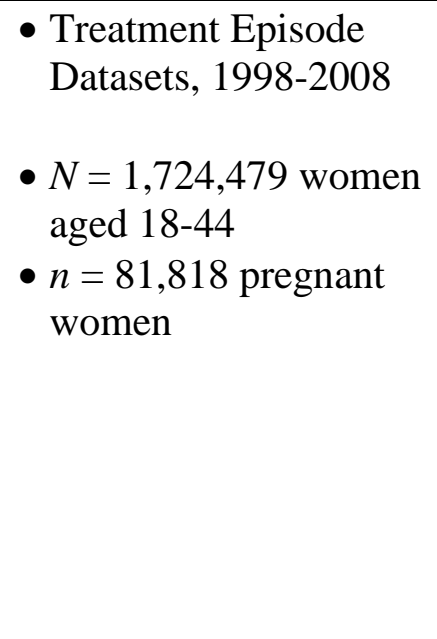 & $\begin{array}{l}\text { - Decrease in alcohol-related } \\
\text { abuse rates: from } 49.3 \% \text { to } \\
37.6 \% \text { of pregnant women } \\
\text { - Increase in drug abuse in } \\
\text { pregnant women from } \\
47.8 \% \text { to } 60.9 \% \\
\text { - Trends were more } \\
\text { pronounced in pregnant } \\
\text { women compared to } \\
\text { nonpregnant women }\end{array}$ & $\begin{array}{l}\text { - Characteristics of pregnant } \\
\text { women entering treatment } \\
\text { compared to nonpregnant } \\
\text { women: younger, } \\
\text { unmarried, homeless, less } \\
\text { than high school education, } \\
\text { on public assistance or with } \\
\text { no source of income } \\
\text { - Rates of ages } 21-24 \\
\text { increased from } 22.8 \% \text { to } \\
31.3 \% \text {; Referrals from the } \\
\text { criminal justice system } \\
\text { increased over time }\end{array}$ \\
\hline $\begin{array}{l}\text { Meunier, } \\
\text { Bennett, \& } \\
\text { Coco, } 2013\end{array}$ & $\begin{array}{l}\text { Determine national } \\
\text { rates of antidepressant } \\
\text { prescription during } \\
\text { pregnancy and } \\
\text { examine the trends in } \\
\text { the use of prenatal } \\
\text { antidepressants }\end{array}$ & $\begin{array}{l}\text { - National Ambulatory } \\
\text { Medical Care Survey } \\
\text { and National Hospital } \\
\text { Ambulatory Medical } \\
\text { Care Survey, 2002- } \\
2010 \\
\text { - } N=27,328 \text { prenatal } \\
\text { visits }\end{array}$ & $\begin{array}{l}\text { The rate of visits by pregnant } \\
\text { women who received a } \\
\text { prescription for an } \\
\text { antidepressant increased } \\
\text { from } .7 \% \text { in } 2002-2006 \text { to } \\
2.1 \% \text { in } 2007-2010\end{array}$ & $\begin{array}{l}\text { Characteristics of the women } \\
\text { (majority): aged } 21 \text { or older } \\
\text { and were Whites }\end{array}$ \\
\hline
\end{tabular}




\begin{tabular}{|c|c|c|c|c|}
\hline $\begin{array}{l}\text { Authors, } \\
\text { Year }\end{array}$ & Purpose & Data source, Sample & Findings & Comments \\
\hline $\begin{array}{l}\text { Pan \& Yi, } \\
2013\end{array}$ & $\begin{array}{l}\text { Examine trends in } \\
\text { hospitalization of } \\
\text { infants prenatally } \\
\text { exposed to alcohol or } \\
\text { drugs }\end{array}$ & $\begin{array}{l}\text { - Nationwide Inpatient } \\
\text { Sample dataset, 1999- } \\
2008 \\
\text { - } n=3,842,837 \\
\text { hospitalized live birth } \\
\text { in } 1999 \\
\text { - } n=4,253,656 \\
\text { hospitalized live birth } \\
\text { in } 2008\end{array}$ & $\begin{array}{l}\text { - Rates of maternal } \\
\text { substance use-related } \\
\text { problems per } 10,000 \\
\text { liveborn deliveries from } \\
1999 \text { to } 2008 \text { : } \\
\text { - Cocaine decreased from } \\
38.9 \text { to } 23.8 \\
\text { - Alcohol decreased from } \\
10.6 \text { to } 9.4 \\
\text { - Opioids increased from } \\
13.7 \text { to } 22.0 \\
\text { - Cannabis and } \\
\text { hallucinogens: increased } \\
\text { from } 30.2 \text { to } 52.1 \\
\text { - Methamphetamines } \\
\text { increased from } 6.9 \text { to } 11.2\end{array}$ & \\
\hline
\end{tabular}


Table 3

Population-based Studies on Mental Health and Substance Use Treatment Receipt in Pregnant Women of Childbearing Age

\begin{tabular}{|c|c|c|c|}
\hline $\begin{array}{l}\text { Authors, } \\
\text { Year }\end{array}$ & Purpose & $\begin{array}{l}\text { Survey Design, } \\
\text { Sample }\end{array}$ & $\begin{array}{l}\text { Screening/Treatment } \\
\text { Measurement }\end{array}$ \\
\hline $\begin{array}{l}\text { Bennett, } \\
\text { Marcus, } \\
\text { Palmer, \& } \\
\text { Coyne, } \\
2010\end{array}$ & $\begin{array}{l}\text { Examine if } \\
\text { pregnancy is related } \\
\text { to the } \\
\text { discontinuation of } \\
\text { depression care in } \\
\text { low-income women }\end{array}$ & $\begin{array}{l}\text { - Descriptive } \\
\text { comparative cohort } \\
\text { study, Medicaid } \\
\text { claims data from } \\
\text { all } 50 \text { states } 1999 \text { - } \\
2000 \\
\text { - } N=6,474 \text { women } \\
\text { aged 15-45 years } \\
(n=3,237 \\
\text { pregnant women; } \\
n=3,237 \text { matched } \\
\text { control cohort of } \\
\text { nonpregnant } \\
\text { women) }\end{array}$ & $\begin{array}{l}\text { - Depression: } \\
\text { International } \\
\text { Classification of } \\
\text { Diseases, Ninth Revision } \\
\text { (ICD-9) codes } \\
\text { - Depression treatment: } \\
\text { antidepressant } \\
\text { medications or a } \\
\text { depression care visit }\end{array}$ \\
\hline
\end{tabular}

Rates/Factors Associated with Treatment Receipt

Rates of depression care:

- Antidepressants: $27 \%$ pregnant women, $62 \%$ nonpregnant women

- Care visits: $31 \%$ pregnant women, $49 \%$ nonpregnant women

Factors related to treatment receipt:

- White women had fewer depression care visits during the pregnancy period compared to nonWhites

- Nonwhite pregnant women had fewer antidepressant use in postpartum period compared to Whites

- Pregnant women not receiving assistance had fewer depression care

Byatt, Xiao, Examine the Dinh, \& Waring, 2016 relationship between mental health care use and depressive symptoms among pregnant women
- National Health and Nutrition

Examination Survey, 2005-2012

- $N=463$ pregnant women aged 20-44 years
- Depressive symptoms: Patient Health Questionnaire

- Mental health care use: self-report of seeing or talking to a mental health professional about mental health
Rate of mental health care use:

- $12 \%$ of women with depressive symptoms; $4 \%$ of non-depressed

- Women with depressive symptoms had higher adjusted odds ratio of care use compared to those without depressive symptoms

- Only multiracial and other ethnicity had lower adjusted odds of care use compared to whites 


\begin{tabular}{|c|c|c|c|c|}
\hline $\begin{array}{l}\text { Authors, } \\
\text { Year }\end{array}$ & Purpose & $\begin{array}{l}\text { Survey Design, } \\
\text { Sample }\end{array}$ & $\begin{array}{l}\text { Screening/Treatment } \\
\text { Measurement }\end{array}$ & $\begin{array}{l}\text { Rates/Factors Associated with Treatment } \\
\text { Receipt }\end{array}$ \\
\hline $\begin{array}{l}\text { Chang, } \\
\text { Tabet, } \\
\text { Elder, Kiel, } \\
\text { \& Flick, } \\
2016\end{array}$ & $\begin{array}{l}\text { Examine lifetime } \\
\text { mental health } \\
\text { services use in } \\
\text { relation to ethnicity } \\
\text { among pregnant } \\
\text { women }\end{array}$ & $\begin{array}{l}\text { - Cross-sectional } \\
\text { population-based } \\
\text { study: Florida } \\
\text { Healthy Start } \\
\text { prenatal screening } \\
\text { program, 2008- } \\
2012 \\
\text { - } N=81,910 \\
\text { pregnant women } \\
\text { with depressive } \\
\text { disorder }\end{array}$ & $\begin{array}{l}\text { Depressive symptoms: } \\
\text { one question addressed } \\
\text { feeling down, depressed, } \\
\text { or hopeless in the last } \\
\text { month } \\
\text { - Mental health treatment: } \\
\text { self-report of lifetime } \\
\text { use of mental health } \\
\text { services or counseling }\end{array}$ & $\begin{array}{l}\text { - Rates of mental health services use: } 26 \\
\% \text { all sample, } 42.5 \% \text { Whites, } 11.5 \% \\
\text { Mexican and other Hispanics } \\
\text { Predictors of mental health care: } \\
\text { - Tobacco use, physical or psychological } \\
\text { abuse, and illness across ethnic groups } \\
\text { - Demographics (age of } 30 \text { years or } \\
\text { older, college education, unmarried } \\
\text { status among non-Hispanic } \\
\text { Asian/Pacific Islander, insurance } \\
\text { coverage ) }\end{array}$ \\
\hline
\end{tabular}

Coleman- Determine if

Cowger, disparity

2012 in mental health

treatment exist in

pregnant women

entered substance

use treatment across

ethnicity and age

groups
- Global Appraisal of Individual

Needs Data, 2008

- $N=502$ past-year pregnant women aged 12-43 years
- Mental health: Internal Mental Distress Scale, Behavioral Complexity Scale, or endorsing suicidal thoughts

- Treatment receipt: selfreport of treatment receipt for mental or psychological problem
- Rate of mental health treatment need vs. receipt: $78.3 \%$ vs. $38.3 \%$

- Treatment disparities: Hispanic and African American had higher proportions of no treatment receipt than the Mixed or Whites

- No difference in treatment receipt by age groups among those who needed treatment 


\begin{tabular}{ll}
\hline $\begin{array}{l}\text { Authors, } \\
\text { Year }\end{array}$ & Purpose \\
\hline Cook et al., & $\begin{array}{l}\text { Estimate the rate of } \\
\text { 12-month and } \\
\text { lifetime psychiatric } \\
\text { disorders in low- } \\
\text { income pregnant } \\
\text { women and the rat } \\
\text { of treatment receip }\end{array}$ \\
& \\
& \\
Farr, Ko, & $\begin{array}{l}\text { Examine the } \\
\text { prevalence and } \\
\text { purley, \& } \\
\text { pupta, 2016 } \\
\text { of discussing } \\
\text { depression with a } \\
\text { prenatal care } \\
\text { provider }\end{array}$
\end{tabular}

Geier, Hills, Determine rates and Gonzales, Tum, \& Finley, 2015

\section{predictors of} depression detection and treatment of new mothers in comparison of nonpregnant women

Survey Design, $\quad$ Screening/Treatment $\quad$ Rates/Factors Associated with Treatment

Sample Measurement Receipt

- Cross-sectional

- Diagnostic and
Prevalence of treatment in pregnant Statistical Manual of women:

- $N=744$ low income pregnant, Special Supplement Nutrition Program for Women, Infants and Children,

Missouri 20002001

- A secondary analysis of 2011 data from the Pregnancy Risk assessment Monitoring System

- $N=32,827$

- Retrospective longitudinal cohort study, California State Medicaid (Medi-Cal) program 2006$2009 \mathrm{~N}=76,493$
Mental Disorders: DSMIV

- Broad definition of treatment: speaking with a doctor or other professionals about psychiatric symptoms.

- Prenatal education: selfreport of whether a health care provider talked with the women about her depressive feeling during pregnancy or after birth.

- Depression: ICD-9 code for any depressive illness

- Treatment: receipt of antidepressant prescription and/or psychotherapy services
- $28.9 \%$ for any anxiety disorder

- $37.7 \%$ for major depressive episode

- $22.2 \%$ for any substance use disorder

- $26.2 \%$ for any psychiatric disorder excluding nicotine

- Rural women with a psychiatric disorder were less likely to receive treatment than urban women $(20.7 \%$ vs. $29.5 \%$ )

- Rate of prenatal education: $71.9 \%$ Predictors of discussing depressive symptoms (higher adjusted odds):

- Demographics (age < 35 years vs. $\geq 35$ years, unmarried status, Medicaid recipients, Hispanic Whites vs. Asians/Pacific Islanders)

- Rate of antidepressant use: $2.7 \%$ pregnant, $10.8 \%$ nonpregnant Predictors of depression diagnosis/ treatment (higher adjusted odds)

- Pregnant women had lower odds

- Demographics (Age of 25 years or older, White/African/Asian vs. Hispanics, urban vs. rural women) 


\begin{tabular}{|c|c|c|c|c|}
\hline $\begin{array}{l}\text { Authors, } \\
\text { Year }\end{array}$ & Purpose & $\begin{array}{l}\text { Survey Design, } \\
\text { Sample }\end{array}$ & $\begin{array}{l}\text { Screening/Treatment } \\
\text { Measurement }\end{array}$ & $\begin{array}{l}\text { Rates/Factors Associated with Treatment } \\
\text { Receipt }\end{array}$ \\
\hline $\begin{array}{l}\text { Glasheen, } \\
\text { Colpe, } \\
\text { Hoffman, \& } \\
\text { Warren, } \\
2015\end{array}$ & $\begin{array}{l}\text { Examine the rates } \\
\text { and correlates of } \\
\text { mental health } \\
\text { treatment receipt } \\
\text { among pregnant and } \\
\text { postpartum women } \\
\text { with serious } \\
\text { psychological } \\
\text { distress }\end{array}$ & $\begin{array}{l}\text { - NSDUH 2008- } \\
\text { 2012: cross- } \\
\text { sectional survey } \\
\text { - } N \sim 4,600 \\
\text { pregnant, } 8,000 \\
\text { postpartum, and } \\
\text { 80,400 not } \\
\text { pregnant or } \\
\text { postpartum of } \\
\text { childbearing age } \\
\text { (18-44 years). }\end{array}$ & $\begin{array}{l}\text { - Serious psychological } \\
\text { distress: Kessler Distress } \\
6 \text { Scale (past-month) } \\
\text { - Mental health treatment: } \\
\text { self-report of the receipt } \\
\text { of treatment for } \\
\text { emotions, nerves, and } \\
\text { mental health problems }\end{array}$ & $\begin{array}{l}\text { Prevalence of past-year mental health } \\
\text { treatment receipt: } \\
\text { - } 38.5 \% \text { pregnant women; } 49.5 \% \\
\text { postpartum women; } 51.5 \% \\
\text { nonpregnant women } \\
\text { Predictors of mental health treatment } \\
\text { (sample included childbearing-aged } \\
\text { women): } \\
\text { - Pregnancy status (pregnant women had } \\
\text { lower odds of treatment receipt) } \\
\text { - Demographics (white ethnicity, older } \\
\text { age, college graduates, health } \\
\text { insurance, history of depression/ } \\
\text { anxiety) (higher odds) }\end{array}$ \\
\hline $\begin{array}{l}\text { Hand, } \\
\text { Short, \& } \\
\text { Abatemarco } \\
2017\end{array}$ & $\begin{array}{l}\text { Compare data related } \\
\text { to substances used, } \\
\text { characteristics of } \\
\text { treatment, and } \\
\text { demographics } \\
\text { of pregnant women } \\
\text { entering treatment } \\
\text { for opioid use } \\
\text { disorder between } \\
\text { geographical regions }\end{array}$ & $\begin{array}{l}\text { - Treatment } \\
\text { Episodes Database- } \\
\text { Admissions, } 2013 \\
\text { - } N=8,656 \text { pregnant } \\
\text { women with opioid } \\
\text { use disorder }\end{array}$ & $\begin{array}{l}\text { - Substance use: self- } \\
\text { report by the individual } \\
\text { - Treatment modalities for } \\
\text { the current admission: } \\
\text { methadone-assisted } \\
\text { treatment and } \\
\text { detoxification. }\end{array}$ & $\begin{array}{l}\text { - Pregnant women received treatment in } \\
\text { the South were less likely to: have } \\
\text { health insurance, be married, and have } \\
\text { an education level of more than high } \\
\text { school } \\
\text { - Compared to the South, pregnant } \\
\text { women entering treatment in other } \\
\text { regions were more likely to: be } \\
\text { admitted to medication assisted } \\
\text { treatment, use heroin, and inject drugs }\end{array}$ \\
\hline
\end{tabular}




\begin{tabular}{|c|c|c|c|}
\hline $\begin{array}{l}\text { Authors, } \\
\text { Year }\end{array}$ & Purpose & $\begin{array}{l}\text { Survey Design, } \\
\text { Sample }\end{array}$ & $\begin{array}{l}\text { Screening/Treatment } \\
\text { Measurement }\end{array}$ \\
\hline $\begin{array}{l}\text { Ko, Farr, } \\
\text { Dietz, \& } \\
\text { Robbins, } \\
2012\end{array}$ & $\begin{array}{l}\text { Estimate the } \\
\text { prevalence and } \\
\text { predictors of } \\
\text { undiagnosed } \\
\text { depression, treatment } \\
\text { prevalence and } \\
\text { barriers among } \\
\text { reproductive-aged } \\
\text { women }\end{array}$ & $\begin{array}{l}\text { - NSDUH 2005- } \\
\text { 2009: cross- } \\
\text { sectional survey } \\
\text { - } N=9,032 \\
\text { reproductive-aged } \\
\text { (18-44) women } \\
\text { with major } \\
\text { depressive episode } \\
\text { - } n=375 \text { pregnant } \\
\text { women } \\
\text { - } n=8,657 \\
\text { nonpregnant } \\
\text { women) }\end{array}$ & $\begin{array}{l}\text { - Major depressive } \\
\text { episode: nine questions } \\
\text { based on the DSM-IV } \\
\text { criteria } \\
\text { - Mental health treatment: } \\
\text { self-report of the receipt } \\
\text { of treatment for } \\
\text { emotions, nerves, and } \\
\text { mental health problems. }\end{array}$ \\
\hline
\end{tabular}

Rates/Factors Associated with Treatment Receipt

- Past-year mental health treatment receipt rates in women with major depressive episode:

$49.6 \%$ pregnant women; $53.7 \%$ nonpregnant women

- Rates by treatment modality in pregnant vs. nonpregnant women: $39.6 \%$ vs. $47.4 \%$ for prescription medication;

$36.3 \%$ vs. $35.5 \%$ for counseling; $7.2 \%$ vs. $4.7 \%$ for inpatient treatment (No difference by pregnancy status in the receipt of any treatment, after adjusting for socio-demographic characteristics)

- Barriers to treatment in women: cost, opposition to treatment, stigma concerns, time or transportation limitations, and not knowing where to go for treatment 


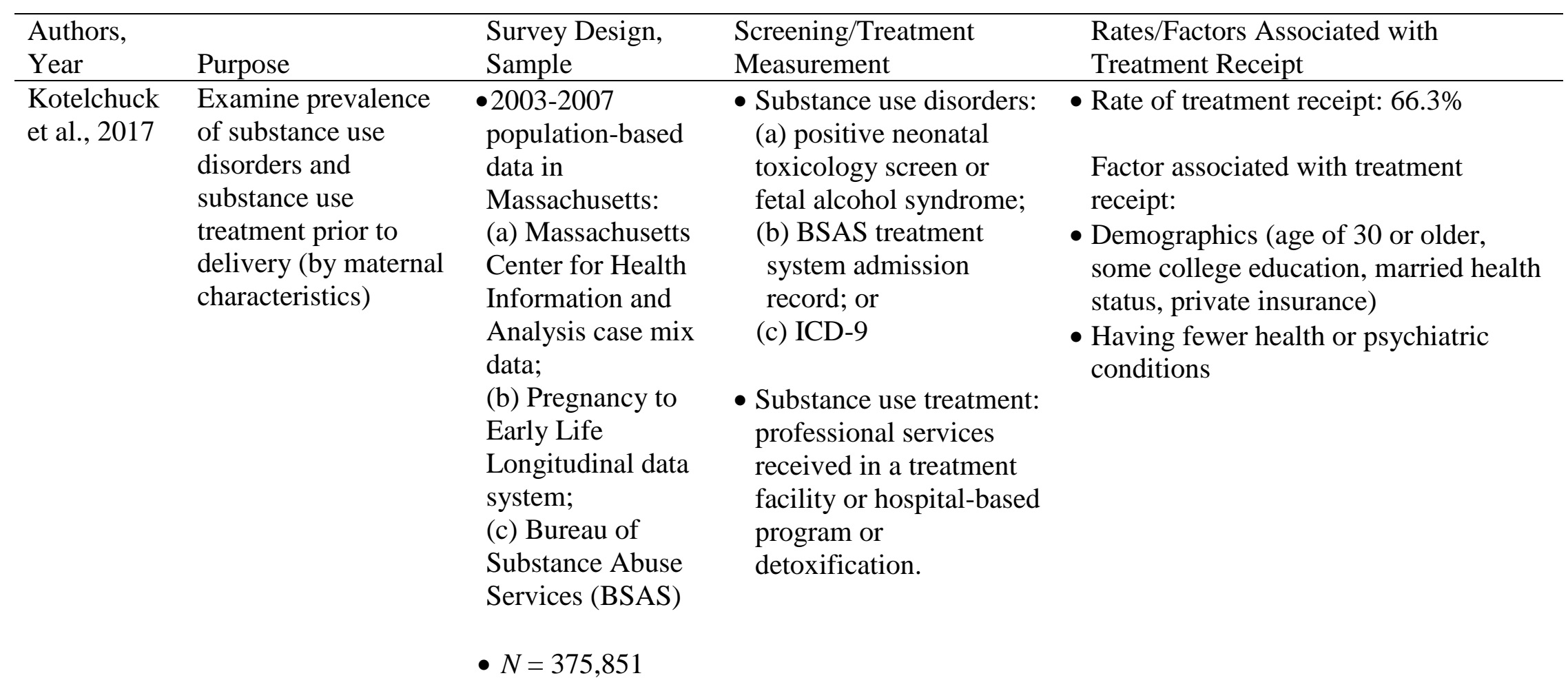




\begin{tabular}{|c|c|c|c|c|}
\hline $\begin{array}{l}\text { Authors, } \\
\text { Year }\end{array}$ & Purpose & $\begin{array}{l}\text { Survey Design, } \\
\text { Sample }\end{array}$ & $\begin{array}{l}\text { Screening/Treatment } \\
\text { Measurement }\end{array}$ & $\begin{array}{l}\text { Rates/Factors Associated with } \\
\text { Treatment Receipt }\end{array}$ \\
\hline $\begin{array}{l}\text { Le Strat, } \\
\text { Dubertre, \& } \\
\text { Le Foll, } \\
2011\end{array}$ & $\begin{array}{l}\text { Examine the } \\
\text { prevalence } \\
\text { and correlates of } \\
\text { Major Depressive } \\
\text { Episode in pregnant } \\
\text { and postpartum } \\
\text { women }\end{array}$ & $\begin{array}{l}\text { - 2001-2002 } \\
\text { National } \\
\text { Epidemiological } \\
\text { Survey on Alcohol } \\
\text { and Related } \\
\text { Conditions: cross- } \\
\text { sectional survey } \\
\text { - } N=1,524 \text { pregnant } \\
\text { women (current or } \\
\text { past-12 months } \\
\text { pregnant women) }\end{array}$ & $\begin{array}{l}\text { - } D S M-I V \\
\text { - Receiving treatment for } \\
\text { anxiety or mood in } \\
\text { health professional } \\
\text { clinic, hospital, } \\
\text { emergency room, or } \\
\text { prescribed medication } \\
\text { - Receiving treatment for } \\
\text { substance use in } \\
\text { hospital, outpatient } \\
\text { clinic, detoxification, } \\
\text { methadone maintenance } \\
\text { program, or 12-steps } \\
\text { meeting }\end{array}$ & $\begin{array}{l}\text { Rates of treatment receipt in pregnant } \\
\text { vs. nonpregnant women with major } \\
\text { depression: } \\
\text { - } 36.98 \% \text { vs. } 44.83 \% \text { for any disorder } \\
\text { - } 23.76 \% \text { vs. } 33.77 \% \text { for depression } \\
\text { - } 26.55 \% \text { vs. } 31.68 \% \text { for anxiety } \\
\text { - } 12.85 \% \text { vs. } 9.80 \% \text { for alcohol/drug use } \\
\text { Differences in treatment receipt: } \\
\text { - Pregnant women with depression had } \\
\text { higher adjusted odds of treatment } \\
\text { receipt compared to pregnant women } \\
\text { without depression } \\
\text { - Pregnant women with depression had } \\
\text { lower odds of the receipt of treatment } \\
\text { compared to nonpregnant women (but } \\
\text { not significant after adjusting for } \\
\text { socio-demographics) }\end{array}$ \\
\hline $\begin{array}{l}\text { Liu \& } \\
\text { Tronick, } \\
2012\end{array}$ & $\begin{array}{l}\text { Examine social } \\
\text { determinants of } \\
\text { provider-patient } \\
\text { conversations } \\
\text { regarding depressed } \\
\text { mood during the } \\
\text { perinatal period }\end{array}$ & $\begin{array}{l}\text { - New York City } \\
\text { Pregnancy Risk } \\
\text { Assessment } \\
\text { Monitoring System } \\
\text { data, 2004-2007 } \\
\text { - } N=3,597\end{array}$ & $\begin{array}{l}\text { Conversation about mood: } \\
\text { self-report if a health } \\
\text { care provider talked with } \\
\text { respondents about blues } \\
\text { or depression during } \\
\text { pregnancy or after. }\end{array}$ & $\begin{array}{l}\text { - About } 50 \% \text { of women had conversation } \\
\text { - Predictors of having conversation } \\
\text { (lower odds): age of } 35 \text { years or above, } \\
\text { non-US born women, and private } \\
\text { doctor, and no prenatal assistance, } \\
\text { Asian/Pacific Islander vs. Whites (less } \\
\text { likely). }\end{array}$ \\
\hline
\end{tabular}




\begin{tabular}{|c|c|c|c|c|}
\hline $\begin{array}{l}\text { Authors, } \\
\text { Year }\end{array}$ & Purpose & $\begin{array}{l}\text { Survey Design, } \\
\text { Sample }\end{array}$ & $\begin{array}{l}\text { Screening/Treatment } \\
\text { Measurement }\end{array}$ & $\begin{array}{l}\text { Rates/Factors Associated with Treatment } \\
\text { Receipt }\end{array}$ \\
\hline $\begin{array}{l}\text { Price, } \\
\text { Corder- } \\
\text { Mabe, \& } \\
\text { Austin, } \\
2012\end{array}$ & $\begin{array}{l}\text { Examine perceptions } \\
\text { of healthcare } \\
\text { providers' about } \\
\text { depression screening } \\
\text { and confidence in } \\
\text { screening, treatment, } \\
\text { and referring of } \\
\text { women }\end{array}$ & $\begin{array}{l}\text { - Virginia } \\
\text { Department of } \\
\text { Health Data, 2008- } \\
2009 \\
\text { - } N=1,498 \\
\text { healthcare } \\
\text { providers }\end{array}$ & $\begin{array}{l}\text { - 36-item survey } \\
\text { instrument: demo- } \\
\text { graphics, self-reported } \\
\text { attitudes and beliefs } \\
\text { regarding perinatal } \\
\text { depression, barriers and } \\
\text { facilitators to treatment, } \\
\text { and satisfaction with } \\
\text { training }\end{array}$ & $\begin{array}{l}\text { Rate of treatment/referral } \\
\text { - } 51.6 \% \text { routine treatment/referral } \\
\text { - } 33.5 \% \text { occasional treatment/referral } \\
\text { - } 12.7 \% \text { rare or no treatment/referral } \\
\text { - Common barriers: Inadequate time } \\
\text { (41.4\%), inadequate available treatment } \\
\text { services }(24.4 \%), \text { inadequate } \\
\text { reimbursement }(17.8 \%) \text {, and } \\
\text { inadequate provider's skills }(15.8 \%) \text {. }\end{array}$ \\
\hline $\begin{array}{l}\text { Roberson et } \\
\text { al., } 2016\end{array}$ & $\begin{array}{l}\text { Examine the } \\
\text { prevalence of } \\
\text { depression, anxiety, } \\
\text { pharmacotherapy, } \\
\text { and health-seeking } \\
\text { behaviors during } \\
\text { perinatal period in } \\
\text { multiethnic women } \\
\text { in Hawaii }\end{array}$ & $\begin{array}{l}\text { - Hawaii Pregnancy } \\
\text { Risk Assessment } \\
\text { Monitoring System } \\
\text { Data, 2009-2011 } \\
\text { - } N=4,735 \text { women }\end{array}$ & $\begin{array}{l}\text { - Anxiety/depression } \\
\text { symptoms: Self-report of } \\
\text { having depression or } \\
\text { anxiety, feeling of } \\
\text { sadness } \\
\text { - Treatment: self-report of } \\
\text { receiving treatment for } \\
\text { anxiety or depression or } \\
\text { taking prescription drugs }\end{array}$ & $\begin{array}{l}\text { Rate of mental health care: } \\
\text { - } 7.3 \% \text { for visiting a healthcare worker } \\
\text { - } 1.4 \% \text { for antianxiety or antidepression } \\
\text { prescription } \\
\text { Factors associated with prescription } \\
\text { drugs use: } \\
\text { - Pre-pregnancy depression or anxiety }\end{array}$ \\
\hline
\end{tabular}




\begin{tabular}{lll}
\hline Authors, & & Survey Design, \\
Year & Purpose & Sample \\
\hline Terplan, & Examine substance & $\bullet$ 2002-2006 \\
McNama- & use, treatment need, & National Survey on \\
ra, \& & and treatment receipt & Drug Use and \\
Chisolm, & in pregnant and & Health: cross- \\
2012 & nonpregnant women. & sectional survey
\end{tabular}

- $N=140,000$

women of

childbearing age

(12-44 years)
- 2001-2002

National

Epidemiologic

Survey on Alcohol

and Related

Conditions: cross-

sectional survey

- $N=14,895$ women of childbearing age (18-50 years)
Screening/Treatment Measurement

- Operationalization of

substance abuse or dependence based on $D S M-I V$ criteria

- Substance use treatment receipt: self-report of receiving substance use treatment

- DSM-IV criteria

- Mental health treatment receipt questions are disorder-specific addressing if respondents required hospitalizatio, visiting emergency room, or asked help from a therapist or doctor, or needed prescribed medication.
Rates/Factors Associated with Treatment Receipt

- Rate of treatment receipt $<20 \%$

Factors associated with substance use treatment receipt in women of childbearing age (after adjusting for other variables in regression model)

- Pregnant had lower odds of treatment receipt (but not significant)

- Demographics (employed women, age of 21-25 compared to < 20, high school or equivalent) (lower odds)

Rates of past-year treatment seeking in pregnant, postpartum, and nonpregnant women:

- $10.5 \%, 11.1 \%, 16.5 \%$ for any psychiatric disorder

- $14.3 \%, 15.0 \%, 25.5 \%$ for mood disorder

- $6.1 \%, 7.5 \%, 11.6 \%$ for anxiety disorder

- $9.9 \%, 8.3 \%, 6.0 \%$ for alcohol use disorder

- $30.3 \%, 17.0 \%, 34.6 \%$ for illicit drug use

- Pregnant women had lower odds of treatment receipt for mood disorders but not for anxiety after adjusting socio-demographic characteristics 


\begin{tabular}{|c|c|c|c|c|}
\hline $\begin{array}{l}\text { Authors, } \\
\text { Year }\end{array}$ & Purpose & $\begin{array}{l}\text { Survey Design, } \\
\text { Sample }\end{array}$ & $\begin{array}{l}\text { Screening/Treatment } \\
\text { Measurement }\end{array}$ & $\begin{array}{l}\text { Rates/Factors Associated with } \\
\text { Treatment Receipt }\end{array}$ \\
\hline $\begin{array}{l}\text { Wu \& } \\
\text { Davis- } \\
\text { Ajami, } 2014\end{array}$ & $\begin{array}{l}\text { Determine antenatal } \\
\text { antidepressant } \\
\text { treatment persistence } \\
\text { and factors } \\
\text { associated with that } \\
\text { in low-income, } \\
\text { insured pregnant } \\
\text { women }\end{array}$ & $\begin{array}{l}\text { - Retrospective } \\
\text { cohort study using } \\
\text { South Carolina } \\
\text { Medicaid claims } \\
\text { data } 2004-2009 \\
\text { - } N=804 \text { pregnant } \\
\text { women aged } 18 \\
\text { years or older }\end{array}$ & $\begin{array}{l}\text { - Major depression: } \\
\text { ICD-9 } \\
\text { - Antidepressant } \\
\text { medications use: } \\
\text { pharmacy claims }\end{array}$ & $\begin{array}{l}\text { Rate of antenatal depressants use } \\
\text { behaviors: } \\
\text { - } 20 \% \text { used more than one antidepressant } \\
\text { - } 45 \% \text { treatment nonpersistence } \\
\text { - Predictors of treatment nonpersistence: } \\
\text { Nonwhite ethnicity, previous antenatal } \\
\text { depressant use before pregnancy } \\
\text { (higher odds) }\end{array}$ \\
\hline $\begin{array}{l}\text { Yamamoto, } \\
\text { McCormic- } \\
\mathrm{k}, \& \text { Burris, } \\
2015\end{array}$ & $\begin{array}{l}\text { Determine the rate of } \\
\text { antidepressants use } \\
\text { in pregnant women } \\
\text { during outpatient } \\
\text { care visits and if } \\
\text { these rates varied by } \\
\text { ethnicity }\end{array}$ & $\begin{array}{l}\text { - 2006-2010 } \\
\text { National } \\
\text { Ambulatory } \\
\text { Medical Care } \\
\text { Survey and the } \\
\text { National Hospital } \\
\text { Ambulatory } \\
\text { Medical Care } \\
\text { Survey } \\
\text { - } N=\text { average of } \\
37.8 \text { million visits } \\
\text { per year for } \\
\text { pregnant women }\end{array}$ & $\begin{array}{l}\text { - Depression: ICD-9 } \\
\text { - Antidepressants use and } \\
\text { cognitive behavioral } \\
\text { therapy }\end{array}$ & $\begin{array}{l}\text { Rate of mental health care: } \\
-2.2 \% \text { of all visits, antidepressants use } \\
\text { - } 2 \% \text { of all visits, cognitive behavioral } \\
\text { therapy } \\
\text { - Compared to visits for White women, } \\
\text { Non-White women had lower odds of } \\
\text { antidepressant use while depressed } \\
\text { controlling maternal age, insurance } \\
\text { type, region of the country, and survey } \\
\text { type }\end{array}$ \\
\hline
\end{tabular}




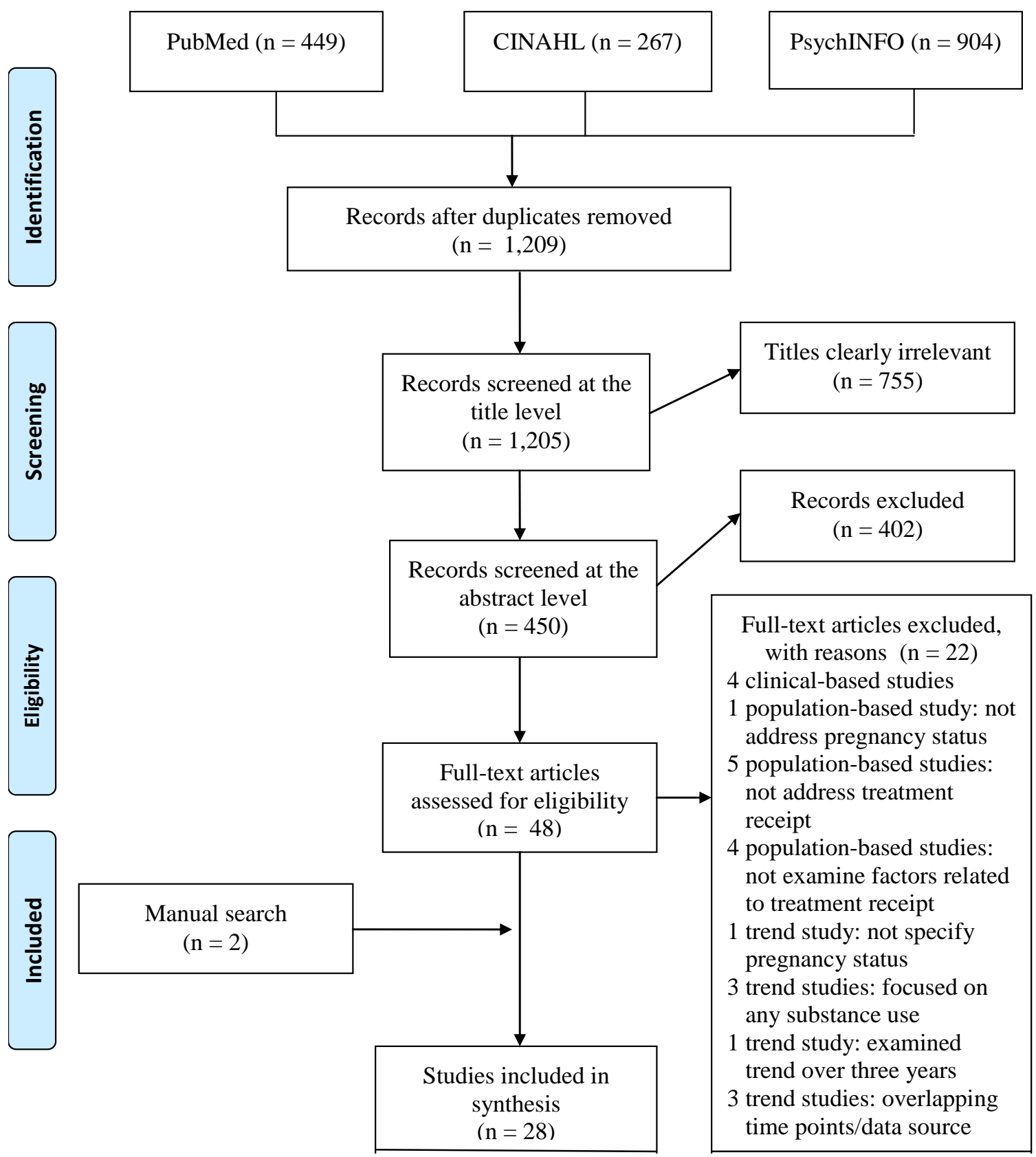

Figure 1. PRISMA flow chart for studies selection process. Adapted from "Preferred Reporting Items for Systematic Reviews and Meta-Analyses: The PRISMA Statement" by D. Moher, A. Liberati, J. Tetzlaff, D. G. Altman, and The PRISMA Group, 2009, PLoS Medecine, 6(6), e1000097. 


\section{CHAPTER III}

\section{TRENDS IN MENTAL HEALTH AND SUBSTANCE USE DISORDERS AND TREATMENT RECEIPT AMONG PREGNANT AND NONPREGNANT WOMEN IN THE UNITED STATES, 2008-2014}

\section{Introduction}

Treatment for mental and substance use disorders will cost the nation $\$ 280.5$ billion in 2020, an increase from the $\$ 171.7$ billion cost in 2009 (Substance Abuse and Mental Health Services Administration [SAMHSA], 2014a). Mental health and substance use problems are major public health issues affecting women of childbearing age. Depression is prevalent among women of childbearing age in the United States. Data from large national surveys indicate the prevalence of depression in childbearing-aged women is between $7.3 \%$ to $12.4 \%$ (Cook et al., 2010; Ko, Farr, Dietz, \& Robbins, 2012; Le Strat, Dubertret, \& Le Foll, 2011; Mota, Cox, Enns, Calhoun, \& Sareen, 2008; VesgaLopez et al., 2008). Women living with depression are at increased risk of having chronic medical conditions (Farr, Hayes, Bitsko, Bansil, \& Dietz, 2011) and substance use disorders (Connelly, Hazen, Baker-Ericzen, Landsverk, \& Horwitz, 2013; Le Strat et al., 2011). These interrelated disorders need to be recognized and treated using an integrated approach to ensure effective treatment (United States Department of Health and Human Services [USDHHS], 2009). The purpose of this study was to compare trends in mental health and substance use disorders and treatment receipt of pregnant and nonpregnant women from 2008 to 2014 . 
Among mothers, mental illness and substance use disorders have a profound negative effect on the mother and her child (Connelly et al., 2013; Homish, Cornelius, Richardson, \& Day, 2004; Jaaskelainen, Holmila, Notkola, \& Raitasalo, 2016). Pregnant women with poor mental health are at increased risk for preterm birth (Grigoriadis et al., 2013), postpartum depression (Goodman, Chenausky, \& Freeman, 2014; Norhayati, Hazlina, \& Asrenee, Emilin, 2015), and diminished quality of life (Goodman et al., 2014). Prenatal alcohol use is associated with deleterious effects such as fetal alcohol syndrome (Lehikoinen, Orden, Heinonen, \& Voutilainen, 2016). Illicit drug use during pregnancy is also associated with preterm birth and Neonatal Abstinence Syndrome (NAS) (Narkowicz, Plotka, Polkowska, Biziuk, \& Namiesnik, 2013).

The American College of Obstetricians and Gynecologists (ACOG, 2015a, 2015b) endorses a universal screening for mental health and substance use problems during pregnancy. However, findings based on large national surveys indicated that most women who needed mental health and substance use treatment did not receive them (Glasheen, Colpe, Hoffman, \& Warren, 2015; Ko et al., 2012; Le Strat et al., 2011; Vesga-Lopez et al., 2008). This indicates that women face unique barriers (e.g., cost and stigma) to receipt of mental health (USDHHS, 2009) and substance use treatment (Center for Substance Abuse Treatment [CSAT], 2009). Yet, recent health reforms have mandated increased availability for mental health and substance use treatment services, while emphasizing the importance of integrating both treatments with primary medical care (Mental Health Parity and Addiction Equity Act [MHPAEA], 2008; Patient Protection and Affordable Care Act [PPACA], 2010). Little is known about recent trends in mental and substance use disorders and treatment receipt, particularly mental health 
treatment in pregnant women. Indeed, previous research on trends in mental health and utilization of mental health treatment in the United States has been conducted among the general population in the 1990s (Kessler, Demler, et al., 2005). The most recent research indicated that there was an increase in the use of mental health treatment from 2001 to 2012 along with an increase in the prevalence of poor mental health for 15 days or more in the past month among the general population (Mojtabai \& Jorm, 2015). These puzzling trends question the efficacy of mental health treatment (Mojtabai \& Jorm, 2015) and raise the question of whether the same pattern of trends occurs among pregnant women.

A growing body of research is beginning to shed light on trends in substance use treatment among childbearing-aged women (Martin, Longinaker, Mark, Chisolm, \& Terplan, 2015; Martin, Longinaker, \& Terplan, 2015; McCabe \& Arndt, 2012), yet without highlighting how the unmet need for substance use treatment has also changed over time in the general population of women. This is of critical concern because less than $20 \%$ of childbearing-aged women with substance use disorders received treatment (Terplan, McNamara, \& Chisolm, 2012).

Understanding trends in mental health and substance use disorders as well as treatment receipt while comparing pregnant women and their non-pregnant counterparts may help in generalizing conclusions specific to pregnant women. In addition, addressing barriers to treatment can inform health reform and help programs facilitate treatment and tailor interventions according to the needs of pregnant women. The specific aims of this study were to:

1. Compare trends from 2008 to 2014 in mental health problems (i.e., past-year major depressive episode [MDE], anxiety disorder, and past-month psychological 
distress), past-year substance use disorders, receipt of mental health treatment, and unmet need for substance use treatment of women by pregnancy status.

2. Compare trends from 2008 to 2014 in the receipt of mental health treatment of women with mental illness by pregnancy status, controlling for severity of mental illness.

3. Compare and contrast barriers to mental health treatment and substance use treatment as perceived by pregnant and non-pregnant women from 2008-2010 to 2011-2014.

\section{Background}

Women suffer disproportionately from depression and anxiety (Kessler, Berglund, et al., 2003), and they develop substance use disorders as likely as men after the initiation of substance use (CSAT, 2009). Given the vulnerability of pregnant women (Lokuge, Frey, Foster, Soares, \& Steiner, 2011), more evidence is needed to understand how mental health and substance use disorders affect them in comparison with non-pregnant women over time. In addition, more information is needed about pattern of treatment receipt among pregnant and nonpregnant women and what barriers impede their receipt of mental health and substance use treatment over time.

\section{Trends in Mental Health and Substance Use Disorders}

Research suggests that hormonal changes in pregnant women may increase their vulnerability to develop poor mental health (Lokuge et al., 2011). Yet, there is an inconsistent pattern in the prevalence of psychiatric disorders between pregnant and nonpregnant women (Ko et al., 2012; Mota et al., 2008; Vesga-Lopez et al., 2008), reflecting heterogeneity in study populations and methods. For instance, using the 2001 
to 2002 National Epidemiologic Survey on Alcohol and Related Conditions (NESARC), Vesga-Lopez et al. (2008) found no significant differences in the 12-month prevalence of depression and anxiety between past-year pregnant $(8.4 \%, 13.0 \%$, respectively) and nonpregnant women $(8.1 \%, 14.9 \%$, respectively). Yet, Mota et al. (2008) compared pastyear prevalence of psychiatric disorders between current pregnant and nonpregnant women using the 2001-2002 NESARC. They found significant differences in the prevalence of depression (7.3\% versus $11.4 \%)$ but not for anxiety disorders (13.2\% versus $16.6 \%$ ) between pregnant and nonpregnant women. Similarly, Ko et al. (2012) used the National Survey on Drug Use and Health (NSDUH) 2005 to 2009 and found that pregnant women (7.7\%) were less likely to have MDE compared to nonpregnant women $(11.1 \%)$.

There is scarce evidence about prenatal depressive and anxiety symptoms from a national sample of pregnant women. Glasheen et al. (2015) used the NSDUH and found that the prevalence of past-month serious psychological distress in pregnant women (4.8\%) was lower than nonpregnant women (7.4\%); however, pregnant women may feel more reluctant to report mental health problems than nonpregnant women (Ko et al., 2012). Hence, in addition to the social desirability effect, inconsistent findings across studies may be related to other variables that account for the relationship between pregnancy status and psychiatric disorders but that were not measured in these studies. Further, addressing and comparing psychiatric disorders between past-year or current pregnant and nonpregnant women across studies make it difficult to draw conclusions about the differences between the two groups. 
Pregnant women generally tend to underreport substance use to avoid stigmatization and losing child custody (Wendell, 2013). National studies revealed that the prevalence of substance use disorders in pregnant women (3.7\% to $14.6 \%)$ was lower than nonpregnant women (9.5\% to 19.9\%) (Mota et al., 2008; Vesga-Lopez et al., 2008). However, these studies showed that pregnant women were less likely to have alcohol use disorders but not illicit drug use disorders compared to nonpregnant women. Yet, psychiatric disorders are prevalent in women of childbearing age regardless of pregnancy status; however, little is known about the comparison of trends in these disorders between the two groups over time.

\section{Trends in Mental Health and Substance Use Treatment Receipt}

The proportion of pregnant women exposed to atypical antipsychotics increased dramatically from 2001 to 2007 (Toh et al. 2013). However, the rate of psychotropic medicines use was fairly stable from 2006 to 2011 in pregnant women (Hanley \& Mintzes, 2014). Nevertheless, no studies were found indicating if the prevalence of mental health disorders in pregnant women declined over the same periods. Indeed, studies based on the 2001-2002 NESARC indicated that pregnant women with psychiatric disorders were less likely to receive mental health treatment (Le Strat et al., 2011; Vesga-Lopez et al., 2008). Another study based on the 2005-2009 NSDUH indicated that major depression was unrecognized more often in pregnant women $(65.9 \%)$ than nonpregnant women $(58.6 \%)$, while only half of depressed mothers

received mental health treatment (Ko et al., 2012). Notably, these studies relied on old national data and did not examine the trends in psychiatric disorders or mental health treatment among pregnant women over time. 
Concerning substance use disorders in pregnancy, McCabe and Arndt (2012) retrieved the Treatment Episode Data Set (TEDS) which indicated that alcohol abuse markedly declined from 1998 to 2008 while drug abuse increased in pregnant women; yet, this trend was more obvious in pregnant than nonpregnant women controlling for age. In addition, referrals from health care providers of substance abusing pregnant women were consistently lower compared to referrals from the criminal justice system over the same time period. A few investigators have focused on examining trends in treatment admission based on the 1992-2012 TEDS for marijuana (Martin, Longinaker, Mark, et al., 2015) and opioid use in pregnant women (Martin, Longinaker, \& Terplan, 2015), but without a comparison group of nonpregnant women. Findings of these studies showed that pregnant admissions for substance use treatment were stable over time at $4 \%$; however, admissions of pregnant women increased significantly for prescription opioids (2\% to $28 \%$ ) and marijuana use (29\% to $43 \%$ ) from 1992 to 2012 . Yet, little is known about recent trends in substance use treatment among pregnant and nonpregnant women. In addition, given the low rates of treatment for substance use, it is essential to examine if the unmet need for treatment has changed over time from a general sample of pregnant and nonpregnant women.

In the consideration of the ongoing public concerns related to mental health and addiction, the PPACA (2010) builds on the MHPAEA (2008) and mandates early identification and treatment for mental health and substance use disorders for all adults. This broad mandates covers perinatal mental health and substance use. Yet, the PPACA (2010) section 2952 focuses on research and clinical screening of postpartum depression, giving little attention to mental health during pregnancy. Yet, pregnancy provides the 
appropriate time to screen for these issues (Connelly et al., 2013). Thus, trends in mental health and treatment for mental health and substance use disorders need to be further examined in pregnant women to inform medical and legal initiatives.

\section{Barriers to Mental Health and Substance Use Treatment}

Although pregnancy can provide an optimum opportunity to offer mental health and substance use treatment (Connelly et al., 2013; Kuo et al., 2013), pregnant women have low treatment utilization rates (Glasheen et al., 2015; Vesga-Lopez et al., 2008) and may face barriers to access treatment (Ko et al., 2012; Kuo et al., 2013). In their qualitative study, Kuo et al. (2013) found that pregnant women revealed their need for treatment of both mental illness and substance use. However, judgmental family relationships, time and transportation challenged these women from seeking treatment for depression and substance use problems.

There is an ongoing evidence addressing barriers to mental health treatment among pregnant women (Goodman, 2009; Jesse, Dolbier, \& Blanchard, 2008; Kim et al., 2010; Kingston et al., 2015; Ko et al., 2012; Kopelman et al., 2008; O'Mahen \& Flynn, 2008; Rosen, Tolman, \& Warner, 2004). Common barriers reported in the literature include cost (Kim et al., 2010; Ko et al., 2012; Kopelman et al., 2008; O'Mahen \& Flynn, 2008), opposition to treatment (Jesse et al., 2008; Kingston et al., 2015; Ko et al., 2012; Rosen et al., 2004), lack of time (Kim et al., 2010; Ko et al., 2012; Rosen et al., 2004) and childcare issues (Goodman, 2009; Kopelman et al., 2008), as well as stigma concerns (Goodman, 2009; Jesse et al., 2008; Ko et al., 2012). Little is known regarding perceived barriers to mental health treatment and substance use treatment from a national sample of childbearing-aged women. A study based on the 2005-2009 NSDUH showed that 
pregnant and non-pregnant women face similar barriers to mental health treatment (Ko et al., 2012). Among these women, cost was the most common barrier, followed by opposition to treatment, and stigma.

Women face numerous obstacles in accessing substance use treatment services such as a lack of gender-specific services, the cost of treatment, stigmatization, and punitive legal actions for substance use (Otiashvili et al., 2013). According to World Health Organization (WHO, 2014), stigmatization is a significant issue that should be prevented when providing treatment to pregnant women with substance use disorders. Yet, pregnancy itself is a barrier for seeking substance use treatment (Steverson \& Rieckmann, 2009). Fear of losing child custody and prosecution may lead pregnant women to avoid treatment (Tuchman, 2010). The Guttmacher Institute (2017) reported that 24 states consider substance use in pregnancy as child abuse and three states consider it a civil commitment. In addition, 23 states mandate reporting of suspected substance abuse to the state, while seven require testing of pregnant women.

In response to inconsistent legislations across states, there are growing professional efforts to advocate for pregnant women and support treatment rather than criminalization for this vulnerable population (Advocates for Pregnant Women, 2011; American Nurses Association, 2011; National Perinatal Association, 2013). Beyond these efforts, there are limited treatment facilities to serve pregnant women with substance use disorders (Guttmacher Institute, 2017). In a qualitative study of 85 rural pregnant women in Kentucky, approximately $26 \%$ had availability issues with substance use treatment services (Jackson \& Shannon, 2012a). Moreover, 51.4\% of women considered stigma and denial as common acceptability barriers, while $49.4 \%$ of them experienced 
accessibility barriers including family responsibilities, and lack of social support and transportation.

Little is known about the pattern of obstacles that impede women of childbearing age to receive mental health and substance use treatment over time. One populationbased study showed that the proportion of women-centered services in drug treatment facilities declined slightly from 43\% in 2002 to $40 \%$ in 2009 (Terplan, Longinaker, \& Appel, 2015). Findings from the Health Reform Monitoring Survey showed that the uninsured rate among childbearing-aged women declined from $19.6 \%$ in summer 2013 to $13.3 \%$ in winter $2014-15$ along with the perceived unmet need for care due to cost; however, access to care remained stable over the same period of time (Shartzer, Garro, Pellegrini, \& Long, 2015). Notably, further studies are needed to address barriers to mental health and substance use treatment in pregnant and non-pregnant women from the general population.

\section{Methods}

\section{Design}

Secondary analysis of a large population-based dataset, the NSDUH, of childbearing-aged women in the United States from 2008 to 2014 was conducted. SAMHSA sponsored and designed the NSDUH as a national cross-sectional survey to provide population estimates of mental health and substance use in U.S household populations aged 12 or over (Center for Behavioral Health Statistics and Quality [CBHSQ], 2015). In this study, the NSDUH data were analyzed over time from 2008 as past-month psychological distress was included in the survey beginning in 2008 
(CBHSQ, 2015). In addition, past-year mental illness estimates were developed using a clinical follow-up study that started in 2008 and continued until 2012.

\section{Sample}

The NSDUH samples participants in each of the 50 states and the District of Columbia using multistage probability stratified sample (CBHSQ, 2015). Surveys are administered in person using computer-assisted personal interviewing and audio computer-assisted self-interviews (ACASI) (CBHSQ, 2015). Pregnant women aged 12 to 17 years were excluded from this study as a specific mental health module was designed in the NSDUH to provide information on mental health measures (i.e., serious psychological distress and mental illness) among adults aged 18 or older. The response rate for the survey ranged from $71.2 \%$ to $75.6 \%$ between 2008 to 2014 (USDHHS, SAMHSA, Office of Applied Studies, 2013, 2014a, 2014b, 2014c, 2014d, 2014e, 2015).

The sample for this study included data from 5,520 pregnant women and 11,040 matched nonpregnant women aged 18 to 44 years. Among these women, 1,003 pregnant and 2,634 nonpregnant women suffered from past-year mental illness.

\section{Measures}

Pregnancy status. Women self-reported their pregnancy status (yes/no) based on the following question: “Are you currently pregnant?" SAMHSA (2010) reported substantial test-retest reliability of this question (Cohen's Kappa $=.85$ ).

Major depressive episode. The NSDUH uses nine questions addressing MDE symptoms based on the Diagnostic and Statistical Manual of Mental Disorders: DSM IV criteria (CBHSQ, 2015). A participant met DSM-IV criteria for MDE (yes/no) if she reported experiencing at least five or more of nine symptoms nearly every day in the 
same 2-week period in the last 12 months, with at least one of these five symptoms being depressed mood or loss of interest in daily activities (American Psychiatric Association [APA], 1994). The MDE measure in the adult depression module of the NSDUH demonstrated moderate test-retest reliability (Cohen's Kappa = .52) $($ SAMHSA, 2010).

Anxiety disorder. Anxiety disorder was measured using one item indicating if a participant received a diagnosis of anxiety disorder from a doctor or other medical professionals in the past 12 months. This measure demonstrated acceptable test-retest reliability (Cohen's Kappa $=.73)($ SAMHSA, 2010).

Serious psychological distress. The symptoms of psychological distress in the past month were measured using the Kessler-6 (K6) Psychological Distress Scale (Kessler, Barker, et al., 2003). The K6 Scale consists of six items each followed by a 4point scale ranging from "all of the time" to "none of the time." These items indicate the frequency of feeling: nervous, hopeless, restless or fidgety, sad or depressed, that everything was an effort, and no good or worthless; thus, higher scores indicate greater psychological distress. The total score for the K6 scale ranges from 0 to 24; the cut-off score of 13 is the indicator of serious psychological distress (CBHSQ, 2015). The validity of K6 was supported by its prediction of serious mental illness (Kessler, Barker, et al., 2003). Cronbach's alpha for the K6 in this study was excellent $(\alpha=.91)$.

Mental illness. The NSDUH defines mental illness in adults aged 18 or older based on two criteria: (a) the presence of any mental disorder as determined in the Structured Clinical Interview (SCID) for DSM-IV, excluding substance use disorders; and (b) the level of functional impairment as determined by the Global Assessment of Functioning (GAF) scale (Endicott, Spitzer, Fleiss, \& Cohen, 1976). Based on these 
mental illness clinical measurements, a regression model was developed to predict the probability of mental illness among approximately 50,000 cases in a follow-up clinical study from 2008 to 2012 (CBHSQ, 2015). Specifically, this statistical model predicted mental illness measurements in the NSDUH: K6 Scale, the abbreviated version of the World Health Organization Disability Assessment Schedule (WHODAS) (Rehm et al., 1999), past-year MDE, and suicidal thoughts. Cutpoints were derived from this model to indicate any mental illness in the past year; based on the level of functional impairment, mental illness was differentiated into serious, moderate, or mild mental illness. These cutpoints then were used among the entire adult sample participated in the NSDUH (CBHSQ, 2015).

Substance use disorders. The NSDUH operationalizes substance use disorders as an abuse or dependence on alcohol or illicit drugs based on the DSM-IV criteria (CBHSQ, 2015). The participant is considered dependent on a substance if she reported that at least three out of seven symptoms occurred in a 12-month period: engaging in activities related to substance use, tolerance, withdrawal, larger or longer use, unsuccessful attempts to cut down, physical health or emotional problems, and reduced activities (APA, 1994). Substance abuse and dependence criteria are mutually exclusive. Substance abuse is defined as reporting at least one of four abuse criteria occurred in a 12-month period: roles obligations, hazardous use, legal problems, and social problem (APA, 1994). The validity of the NSDUH in assessing substance use disorders was supported (Jordan, Karg, Batts, Epstein, \& Wiesen, 2008). The test-retest reliability of substance dependence or abuse measures showed substantial agreement (Cohen's Kappa $=.67)($ SAMHSA, 2010). 
Receipt of mental health treatment. Mental health treatment receipt refers to any treatment received in an inpatient or outpatient setting, or use of prescription drugs for any problem related to mental health, emotions, or nerves in the past 12 months (yes/no). These measures demonstrated excellent test-retest reliability (Cohen's Kappa $=$ .85) (SAMHSA, 2010).

Unmet need for substance use treatment. The unmet need for substance use treatment is defined as having the need for treatment for alcohol or illicit drug use that met the $D S M-I V$ criteria for dependence or abuse, but not receiving that treatment at a specialty facility (i.e., hospital, rehabilitation facility, or mental health center) (USDHHS, SAMHSA, Office of Applied Studies, 2015). This measure was used in this study rather than the receipt of substance use treatment to have larger sample size and better powered statistical analysis when comparing trends over time by pregnancy status, especially since few numbers of pregnant women received the treatment for alcohol or illicit drug use despite their need.

Perceived barriers to mental health and substance use treatment. The NSDUH includes 28 items addressing reasons for not getting mental health treatment (14 items) and substance use treatment (14 items) among those who perceived treatment need (USDHHS, SAMHSA, Office of Applied Studies, 2015). Perceived barriers include factors such as treatment beliefs, readiness for treatment, lack of knowledge about treatment programs, confidentiality concerns, lack of openings in the substance use treatment programs, lack of time, and lack of transportation. The majority of items addressing the barriers to mental health treatment demonstrated good test-retest reliability 
(Cohen's Kappa $\geq .65$ ); however, the reliability of the items addressing substance use treatment was not reported (SAMHSA, 2010).

The classification of perceived barriers in this study was adapted from Ko et al. (2012). Any items measuring perceived barriers that were scored "yes" were classified into the following categories: (a) cost (three items for mental health treatment; two items for substance use treatment); (b) stigma (four items for mental health treatment; three items for substance use treatment); (c) opposition to treatment (four items for each treatment type); (d) time or transportation limitation (two items for each treatment type); (e) not knowing where to go (one item for each treatment type); and (f) lack of substance use treatment programs (two items for substance use treatment).

\section{Procedure}

The NSDUH has been conducted by the Federal Government since 1971 (SAMHSA, 2010) and is managed by SAMHSA's Office of Applied Studies. Participation in the NSDUH is voluntary and all randomly selected participants are encouraged to participate regardless of their substances use status. Interviews are completed in private, as participants answer most of the interview questions using a laptop computer; hence, the interviewer does not know the answers entered. No prior computer skills are required to answer the questions. The interviews last approximately one hour and the participant receives $\$ 30$ cash at the end of the interview (CBHSQ, 2015). Confidentiality of the answers is protected by law and participants do not give their full names (NSDUH, 2016).

Given that the current study used de-identified public use data from the 20082014 NSDUH, the study was exempt from the University of Louisville Institutional 
Review Board. In congruence with the terms of use of this dataset as proposed by the Interuniversity Consortium for Political and Social Research (ICPSR), the principal investigator (PI) analyzed the NSDUH only for the purpose of research and prevented any unauthorized access to the data by maintaining it in encrypted files on the PI's computer.

\section{Data Analysis}

Considering the complex survey design and weighting, statistical analysis was conducted using complex sample analysis with SPSS software, version 22.0 (IBM Corp., 2013). As multiple NSDUH survey years were used, the person-level analysis weight was divided by the numbers of years of survey data used in analyses (i.e., seven years) (CBHSQ, 2015). Because Bonferroni correction was deemed so conservative (Bland \& Altman, 1995), $p$-values $<.05$ were considered statistically significant for analyses even in the presence of multiple comparisons. Recoded and imputed demographic and substance use variables were analyzed. Missing data for mental health measures were excluded from analysis. The NSDUH uses an imputation methodology called "predictive mean neighborhoods (PMN)" which was developed for the survey in 1999 (CBHSQ, 2015, p.11). PMN combines a regression model imputation and a random nearest neighbor hot-deck procedure. The hot-deck procedure involves replacing the missing values with a corresponding value from a donor randomly selected from a set of candidate donors called the "neighborhood" (CBHSQ, 2015, p.12). The potential donors in the neighborhood have complete data with a predicted mean close to that of the item of the nonrespondent. 
Propensity score matching was conducted to match pregnant and nonpregnant women before analyzing the data. Propensity Score Matching for SPSS (Version 1.0; Thoemmes, 2012) was used to calculate propensity scores by regressing pregnancy status onto: age, ethnicity, marital status, education level, employment status, income, health insurance, and county urbanicity. One-to-two pairs of pregnant and non-pregnant women were matched. One-to-two pairs matching was selected because it is recommended when the sample size between the two groups differ substantially, hence reducing bias (Ming \& Rosenbaum, 2000). Compared to adjustment for covariates, propensity score matching helps in assessing covariate balance between groups without looking at outcomes and thereby protects against Type I error (Vittinghoff, Glidden, Shiboski, \& McCulloch, 2012). Good balance between matched and control groups was indicated in this study as the standardized mean differences between the groups' covariate means were of less than .25 (Ho, Imai, King, \& Stuart, 2007).

Descriptive statistics were conducted for the matched sample using weighted percentages and standard errors (SEs) to describe all categorical variables. Bivariate analyses using chi-square were conducted to examine differences between pregnant and nonpregnant women for covariates.

A total of eight logistic regression models were conducted to test the interaction between time and pregnancy status for the dichotomous outcomes of: MDE, anxiety disorder, any past-year mental illness, alcohol use disorder, illicit drug use disorder, pastmonth psychological distress, past-year receipt of mental health treatment, and the unmet need for past-year substance use treatment. The test of model coefficients was conducted for each model to determine goodness of fit (Vittinghoff et al., 2012). 
Among women with mental illness, a logistic regression model was run to test the interaction between time and pregnancy status to predict the receipt of mental health treatment controlling for severity of mental illness. Finally, weighted percentages were calculated for each type of barrier to mental health and substance use treatment and compared across two time periods, 2008-2010 and 2011-2014, using chi-square and rank ordering. The purpose of aggregating data into two time periods was to have an adequate sample size to describe different types of barriers. Because a small number of pregnant women reported perceived barriers to substance use treatment, these barriers were compared across 2008-2010 and 2011-2014 among the total sample of pregnant and nonpregnant women.

\section{Results}

There was a satisfactory balance with the propensity score matching using age, ethnicity, education, income, employment, health insurance, and county urbanicity (see Table 4). The majority of the matched sample was white, married, college educated, and employed. Most of women had an income level of less than $\$ 50,000$, had health insurance, and lived in a large urban area.

The rates of past-year MDE decreased slightly from $7.2 \%$ in 2008 to $5.9 \%$ in 2014 among pregnant women, and remained relatively stable from $2008(9.4 \%, 8.7 \%)$ to $2014(9.3 \%, 8.3 \%)$ among nonpregnant women and the total sample of women, respectively (see Figure 2). The rate of MDE was lowest at $2.7 \%$ in 2010 among pregnant women. However, the rates of anxiety disorder increased from 2008 to 2014 among pregnant women $(4.7 \%$ to $6.8 \%)$, nonpregnant women $(7.3 \%$ to $11.2 \%)$, and the total sample $(6.5 \%$ to $9.9 \%)$. Likewise, rates of past-month psychological distress increased 
from $5.4 \%, 4.9 \%$, and $5.6 \%$ in 2008 to $6.7 \%, 5.1 \%$, and $7.5 \%$ in 2014 among the entire sample as well as pregnant and nonpregnant women, respectively. The rates of past-year mental illness showed only a slight increase from 2008 to 2014 in the total sample ( $21.0 \%$ to $22.0 \%)$, pregnant $(17.5 \%$ to $18.3 \%)$ and nonpregnant women ( $22.7 \%$ to $23.6 \%)$ (see Figure 2).

Alcohol use disorder remained relatively stable at approximately $6 \%$ among the total sample of childbearing-aged women from 2008 to 2014 regardless of pregnancy status (see Figure 3). Although the rate of illicit drug use decreased in pregnant women from $3.6 \%$ in 2008 to $2.4 \%$ in 2014 , it increased in non-pregnant women from $2.0 \%$ to $3.3 \%$, reflecting an overall increase among the total sample by 1.2 fold.

The rates of the receipt of mental health treatment remained relatively stable from 2008 to 2014 among pregnant women, nonpregnant women, and the total sample, respectively, at approximately 12\%, 18\%, and 16\% (see Figure 4). Among those with mental illness, the rates of the receipt of mental health treatment increased from 2008 $(36.6 \%, 39.0 \%, 38.4)$ to $2014(39.6 \%, 44.5 \%, 43.2 \%)$ among pregnant, nonpregnant women, and the total sample, respectively. The rate of unmet need for substance use treatment remained stable at 7\% from 2008 to 2014 among pregnant women. However, among nonpregnant women as well as the total sample, respectively, the rates increased from $6.5 \%$ and $6.8 \%$ in 2008 to $6.8 \%$ and $8.3 \%$ in 2014 .

Comparing trends in mental health problems, substance use disorders, and treatment receipt over time by pregnancy status, there were no significant interactions between time and pregnancy status; thus, only main effects are reported (see Table 5). Of mental health problems, only trends in past-year anxiety disorder $(p=.003)$ and past- 
month psychological distress $(p=.009)$ were significant. For a one-year increase from 2008 to 2014, the odds of anxiety disorder increased by $7.0 \%$ (Adjusted Odds Ratio [AOR]: 1.07; 95\% Confidence Interval [CI]: 1.02-1.12), and pregnant women had lower odds of anxiety disorder (AOR: .62; 95\% CI: .51-.75) compared to nonpregnant women. Likewise, for a one-year increase, the odds of past-month psychological distress increased by 1.06 times (95\% CI: 1.01-1.10). Compared to nonpregnant women, pregnant women had lower odds of past-month serious psychological distress (AOR: .68; 95\% CI: .56-.82). The likelihood of past-year MDE (AOR: 1.01; 95\% CI: .96-1.05) and any mental illness (AOR: 1.02; 95\% CI: .98-1.05) did not change over the seven years; however, pregnant women had significantly lower odds of MDE (AOR: .53; 95\% CI: .43$.65)$ and any mental illness (AOR: .65; 95\% CI: .58-.74) compared to nonpregnant women.

There was a significant increase in the odds of illicit drug use disorder from 2008 to 2014 (for one-year increase) (AOR: 1.05; 95\% CI: 1.004-1.10); yet, the odds of illicit drug use disorder was not significantly higher in pregnant women than nonpregnant women (AOR: 1.06; 95\% CI: .83-1.35). There was no significant change in the probability of alcohol use disorder over time (AOR: 1.02; 95\% CI: .97-1.07) or by pregnancy status (AOR: 1.04; 95\% CI: .87-1.24). There were no significant trends in the mental health treatment receipt (AOR: $1.01 ; 95 \%$ CI: .98-1.04) and the unmet need for substance use treatment over time (AOR: 1.03; 95\% CI: .99-1.08). Pregnant women had lower odds of receipt of mental health treatment (AOR: .60; 95\% CI: .52-.69) compared to nonpregnant women; yet, there was no significant difference between pregnant and 
nonpregnant women in predicting the probability of the unmet need for substance use treatment (AOR: 1.01; 95\% CI: .86-1.18).

Seventeen percent of pregnant women versus $23.6 \%$ of nonpregnant women had past-year mental illness. There were no significant differences between pregnant and nonpregnant women with mental illness in any of the covariates (i.e., age, ethnicity, education, employment status, income level, county urbanicity), except marital status. Pregnant women $(50.2 \%)$ were less likely to be married compared to nonpregnant women $(56.7 \%)\left[\chi^{2}(1, N=3,637)=11.48, p=.031\right]$. However, marital status was not associated with the receipt of mental health treatment $\left[\chi^{2}(1, N=3,637)=3.955, p=.224\right]$, and thus was not including as a covariate in the regression model. Among those with mental illness, there was no significant interaction between time and pregnancy status and therefore only main effects are reported in Table 6 . The odds of mental health treatment did not significantly change over time (AOR: 1.04, 95\% CI: .98-1.09). Yet, pregnant women with mental illness had lesser odds of the receipt of mental health treatment compared to nonpregnant women (AOR: .66; 95\% CI: .52-.84). Women with moderate (AOR: 1.94; 95\% CI: 1.51-2.50) and severe mental illness (AOR: 3.87; 95\% CI: 3.044.92) had higher odds of the receipt of mental health treatment compared with women with mild mental illness.

Perceived barriers to mental health treatment among women of childbearing age ranked similar in 2008-2010 and 2011-2014 in regards: (a) cost (45.2\%, 50.6\%), (b) opposition to treatment $(41.9 \%, 41.4 \%)$, and (c) stigma $(28.2 \%, 24.7 \%)$ (see Figure 5). In 2008-2010, the perceived barrier of not knowing where to go ranked last (19.2\%), while time/transportation limitations had the lowest percentage in 2011-2014 (19.7\%). 
However, the order of perceived barriers to substance use treatment among childbearingaged women differed from 2008-2010 to 2011-2014. In 2008-2010, the perceived barriers ranked in the following order: cost (38.7\%), stigma (18.2\%), time/transportation limitations (17\%), opposition to treatment and lack of treatment programs (3\%), and finally not knowing where to go (.9\%). By 2011-2014, stigma ranked first (35.5\%), followed by cost (25.9\%), time/transportation limitations (22.2\%), lack of treatment programs (17.7\%), not knowing where to go (8.2\%), and opposition to treatment $(7.6 \%)$.

Perceived barriers to mental health treatment among pregnant women had the same order as the total sample in 2008-2010 across the two time periods, 2008-2010 and 2011-2014 (see Figure 6). Nonpregnant women had the same order of perceived barriers to mental health treatment in 2008-2010 and 2011-2014: cost (44.6\%, 49.3\%), opposition to treatment $(40.8 \%, 41.3 \%)$, stigma $(28.6 \%, 26.4 \%)$, not knowing where to go $(20.7 \%$, $21.6 \%)$, and time/transportation limitations $(19.7 \%, 20.1 \%)$.

There were no significant differences in the perceived barriers to mental health treatment across 2008-2010 to 2011-2014 among the total sample, and pregnant and nonpregnant women (see Table 7). However, in 2011-2014 women of childbearing age were significantly more likely to report not knowing where to go (8.2\% vs. .9\%) and a lack of treatment programs $(17.7 \%$ vs. $3.0 \%)$ as perceived barriers to substance use treatment than women in 2008-2010. Other perceived barriers to substance use treatment did not differ between the two time periods. In 2011-2014, women of childbearing age who perceived a need for substance use treatment were more likely to live in a nonmetro (23.2\% vs. $9.0 \%)$ or small county area $(32.7 \%$ vs. $13.5 \%)$ compared to their counterpart 
groups in 2008-2010 $(p<.001)$. There were no significant differences in other sociodemographic characteristics between the two groups in 2008-2010 and 2011-2014.

\section{Discussion}

The purpose of this study was to compare trends in mental health problems, substance use disorders, mental health treatment receipt, and unmet needs for substance use treatment by pregnancy status from 2008 to 2014. Among a matched sample of pregnant and non-pregnant women, there was no significant interaction between time and pregnancy status in predicting the probability of mental health, substance use disorders, and treatment receipt. This means that the proportional change in these outcome measures was the same for pregnant and nonpregnant women over time. However, to our knowledge, there are no comparable trend studies specifically addressing the difference between pregnant and nonpregnant women in having mental health problems and receiving mental health treatment over time.

This study showed that compared to nonpregnant women, pregnant women had lesser odds of MDE, anxiety disorder, past-year mental illness, and past-month psychological distress. This is inconsistent with a previous population-based study that showed no significant difference in the prevalence of psychiatric disorders between pregnant and nonpregnant women who participated in NESARC (Vesga-Lopez et al., 2008). Yet, another NESARC-based study (Mota et al., 2008) as well as NSDUH-based study (Ko et al., 2012) found that pregnant women were less likely to have major depression compared to nonpregnant women. However, Mota et al. (2008) found that pregnant women were as likely as nonpregnant women to have anxiety disorder. These discrepancies may be due to different measures of psychiatric disorders, sample 
characteristics, and controlling for different confounding variables. For instance, the NSDUH used one question addressing if a healthcare provider told the respondent she had anxiety disorder or not, while NESARC used structured clinical interviews in assessing anxiety disorders. Further, the current study analyzed the NSDUH among a matched sample of pregnant and nonpregnant women, while other population-based studies adjusted for confounding variables.

In addressing psychological distress symptoms, a population study based on the NSDUH (Glasheen et al., 2015) was in accord with the current study by suggesting that pregnant women had lesser odds of past-month psychological distress compared to nonpregnant women. These findings from general population samples suggest an interesting comparison with the evidence from clinical samples, as the later captured advanced clinical symptoms among only pregnant women who received treatments (Connelly et al., 2013; Fairbrother, Janssen, Antony, Tucker, \& Young, 2016; Fairbrother, Young, Janssen, Antony, \& Tucker, 2015; Gavin et al., 2011; Melville, Gavin, Guo, Fan, \& Katon, 2010; Qiu, Gelaye, Fida, \& Williams, 2012). Given that these clinical studies lack comparison groups of nonpregnant women, drawing a clear conclusion about the association between pregnancy and mental disorders is limited.

In the present study, there was a significant increase in the probability of past-year anxiety disorder and past-month psychological distress over the seven years among the total sample of pregnant and nonpregnant. Anxiety is among the most prevalent disorders in the United States and women are 1.5 times more likely to have an anxiety disorder compared to men (Kessler, Berglund, et al., 2005). Yet, a previous trend study showed no significant increase in any psychiatric disorder from 1990 to 2003 among the general 
population (Kessler, Demler, et al., 2005), whereas a recent trend study did not focus on examining trends in anxiety disorders (Mojtabai \& Jorm, 2015). This emphasizes the need for further studies to examine the magnitude of anxiety disorder among women of childbearing age, particularly pregnant women.

In the current study, there was a significant increase in the probability of pastmonth psychological distress but not past-year MDE or mental illness. Yet, Mojtabai and Jorm (2015) found no significant change in the proportion of past-month psychological distress or past-year MDE among the general population from 2001 to 2012. This suggests that childbearing-aged women in this study tended to report non-specific recent distress symptoms rather than past-year mental health conditions. Moreover, the increase in the probability of anxiety disorder and past-month psychological distress, as well as the absence of significant change in the proportion of MDE and mental illness may be related to unsubstantial increase in the receipt of mental health treatment. The link between trends in the receipt of mental health treatment and in mental health problems should be interpreted with caution. Previous trend studies revealed puzzling findings in which the receipt of mental health treatment increased while the proportion of mental health problems either did not change (Kessler, Demler, et al., 2005; Mojtabai \& Jorm, 2015) or increased (Mojtabai \& Jorm, 2015) over the same period of time. Therefore, the quality of mental health treatment provided to women may be more important in assessing the change in mental health problems.

Research suggests that although women have more frequent contact with health care providers, obstetric providers lack training in care of women with depression (ACOG, 2010) and anxiety (Leddy, Lawrence, \& Schulkin, 2011). Mental health care 
providers are also reluctant to treat depression during pregnancy (Byatt, Biebel, Debordes-Jackson, et al., 2013; Palladino et al., 2011). Literature also indicated an absence of standardized procedures for depression care (Palladino et al., 2011) as well as inadequate referral systems and coordinated follow-up care (Palladino et al., 2011; Price, Corder-Mabe, \& Austin, 2012), all of which may influence the status of mental health among women of childbearing age.

The nonsignificant increase in the receipt of mental health treatment in this study is incongruent with previous trend studies among the general population that showed an increase in the receipt of mental health treatment from 1990-2003 (Kessler, Demler, et al., 2005) and from 2000 to 2014 (Mojtabai \& Jorm, 2015). This suggests that women of childbearing age have specific mental health needs (USDHHS, 2009) and may experience unique multilevel barriers to access treatment (Byatt, Simas, Lundquist, Johnson, \& Ziedonis, 2012). A systematic review revealed that screening alone for depression among perinatal women was associated with only $22 \%$ mental health treatment receipt; yet, this rate was doubled in the presence of patient engagement interventions, on-site assessments, and training for perinatal care providers (Byatt, Levin, Ziedonis, Simas, \& Allison, 2015). This emphasizes the need for interventions that address strategies identified by both patient and health care providers to increase mental health treatment use (Byatt, Biebel, Friedman et al., 2013).

In contrast with previous trend studies that examined trends in the use of antipsychotic drugs during pregnancy (Hanley \& Mintzes, 2014; Toh et al., 2013), the current study has focused on the receipt of any mental health treatment including outpatient counseling, inpatient treatment, and prescription drugs for mental health 
problems. Hence, these studies are not comparable with the current study due to different measures of mental health treatment as well as the time of examining trends.

In the current study, pregnant women were as likely as nonpregnant women to have alcohol and illicit drug use disorders. This finding is in accord with previous population studies based on the 2001-2002 NESARC that found no significant difference between pregnant and nonpregnant women in developing illicit drug use disorders (Mota et al. 2008; Vesga-lopez et al., 2008). However, these studies revealed that pregnant women were less likely to have alcohol use disorders compared to nonpregnant women. It is noteworthy that these studies relied on an old national dataset that used structured clinical interviews in assessing substance use disorders rather than self-report questionnaires that may result in this discrepancy. Yet, there is a dearth of updated literature that compared substance use disorders among pregnant and nonpregnant women from the general population. Most of what is known about substance use problems is based on admission data that focused on illicit drug use among only pregnant women (Martin, Longinaker, Mark, et al., 2015; Martin, Longinaker, \& Terplan, 2015). One study included a comparison group of nonpregnant women and suggested that treatment admission rate for illicit drug abuse increased more profoundly among pregnant women compared to nonpregnant women from 1998 to 2008 (McCabe \& Arndt, 2012). However, these findings should not be generalized to the population as the majority of childbearing-aged women with substance use disorders do not receive treatment (Terplan et al., 2012).

The present study showed a significant increase in the probability of illicit drug use disorder from 2008 to 2014 among women of childbearing age. SAMHSA (2013) 
also reported based on TED an increase in the percentage of illicit drug abuse but not alcohol abuse among pregnant and nonpregnant women from 2000 to 2010 . These findings indicate a critical need for interventions to help women of childbearing age with substance use disorders, hence preventing devastating health consequences associated with substance use during pregnancy.

The present study showed that the gap between the need and receipt of substance use treatment did not change from 2008 to 2014 among both pregnant and nonpregnant women. The rate of treatment admission among pregnant women was relatively stable from $2000(4.4 \%)$ to $2010(4.8 \%)$ (SAMHSA, 2013). Women in this study experienced an unmet need for substance use treatment over the seven years, despite treatment initiatives (ACOG, 2015a, 2015b) and legislation (MHPAEA, 2008; PPACA, 2010). This emphasizes the need for prevention and interventional strategies tailored according to the specific needs of childbearing-aged women.

\section{Mental Illness and Trends in the Receipt of Mental Health Treatment}

Among women with mental illness, there was no significant interaction between time and pregnancy status in predicting the probability of mental health treatment receipt. This indicates that the change in the odds of the receipt of mental health treatment over time was similar for pregnant and nonpregnant women. Yet, pregnant women had a lower odds of the receipt of mental health treatment despite their mental illness. This is congruent with previous studies indicating that pregnant women with psychiatric disorders (Mota et al., 2008; Vesga-Lopez et al., 2008) or psychological distress (Glasheen et al., 2015) were less likely to receive mental health treatment compared to nonpregnant women. 
However, the present study found that pregnant women, regardless of having mental illness, had a lower odds of receipt of mental health treatment compared to nonpregnant women. This raises a question in regards the relationship between treatment need and the severity of mental illness. Given the fact that psychiatric disorders in women are rarely recognized (Ko et al., 2012) or treated (Glasheen et al., 2015; Ko et al., 2012; Vesga-Lopez et al., 2008), women of childbearing age may not access treatment due to structural, system, and personal barriers until their mental condition is advanced (Byatt et al., 2012). This is also of critical concern as the present study also showed no significant increase in the likelihood of mental health treatment receipt among women of childbearing age with mental illness from 2008 to 2014, while pregnant women had a lower odds of mental health treatment receipt compared to nonpregnant women.

Although this study covered a period of time that coincided with policy initiatives including MHPAEA (2008) and PPACA (2010), it did not show a substantial increase in the receipt of mental health treatment. This study did not specifically address the effect of these policies; however, it yielded a critical concern reflecting that there are complex integrated obstacles that may affect the receipt of both mental health and substance use treatment among women of childbearing age.

\section{Barriers to Mental health and Substance Use Treatment}

This study showed that the most common barriers to mental health treatment in 2008-2010 and 2011-2014 included cost, followed by opposition to treatment, and stigma. These barriers did not differ in their rank or percentages between 2008-2010 and 2011-2014 among pregnant and nonpregnant women. Other barriers included time and transportation limitations that had lower proportions than not where to go among 
pregnant women in the two time periods. One clinical study showed that perinatal women reported more concerns regarding structural barriers to depression care (i.e., insurance, inability to pay, transportation, and childcare) than knowledge (not sure whom to contact and not knowing the best treatment) and attitudinal barriers (lack of motivation and hopelessness that treatment would work) (O’Mahen \& Flynn, 2008). However, the same rank of barriers found in this study was reported in a previous population study based on 2005-2009 NSDUH of women of reproductive age (Ko et al., 2012), suggesting that strategies provided to enhance access to treatment for mental health problems among women of childbearing age might be inadequate over the nine years.

Despite the enactment of PPACA in 2010, cost had the highest percentage as a perceived barrier to mental health treatment across 2008-2010 and 2011-2014. Findings from 2013 Kaiser Women's Health Survey, conducted just before the start of the PPACA's major coverage expansion, showed that cost was a major obstacle to getting mental health care among $23 \%$ of uninsured women, $6 \%$ of women with private insurance, and 9\% of Medicaid covered women (Salganicoff, Ranji, Beamesderfer, \& Kurani, 2014). Beyond coverage and affordability, this national representative survey suggested that logistical barriers such as time, transportation, sick leave, and childcare also impeded access to care. Interestingly, between summer 2013 and winter 2014-2015, the Health Reform Monitoring Survey revealed that the uninsurance rate decreased from $19.6 \%$ to $13.3 \%$ among women of childbearing age and the unmet need for care due to cost decreased by 10.4\% (Shartzer et al., 2015). This coverage improvement was not translated into significant enhancement in the access to care, and nearly one in four lowincome women was uninsured in winter 2014-2015. This suggests the need for efforts to 
enroll uninsured women on the one hand, and on the other hand to design interventions and strategies to overcome other structural, attitudinal, and knowledge barriers to mental health care.

The present study showed that the rank of barriers to substance use treatment among women of childbearing age changed from: cost, stigma, time/transportation limitation, opposition to treatment/lack of treatment programs, and not knowing to go in 2008-2010 to: stigma, cost, time/transportation limitation, lack of treatment programs, not knowing where to go, and opposition to treatment in 2011-2014. Beyond the limited health insurance coverage of substance use problems (CSAT, 2009) women perceived stigma as the most important barrier to substance use treatment in 2011-2014. Given that these women also reported opposition to treatment as the least important barrier, this suggests that even when women are willing to accept treatment; the stigma linked with their substance use impeded them. According to the CSAT (2009), stigma toward substance use women is greater than that toward men, and women have feelings of shame, guilt, and low self-esteem because of their substance use, all of which create more treatment needs to be addressed. Congruently, WHO (2014) and SAMHSA (2014c) emphasized the importance of minimizing a judgmental attitude and stigmatization when providing care for women of childbearing age. According to SAMHSA (2014c), public institutions and health service systems need to adapt the framework of trauma-informed care to help resolve and not aggravate trauma related issues among women with substance use disorder.

Cost was rated as the second barrier to substance use treatment. Corresponding with the PPACA that requires the coverage of preventive measures such as substance use 
screening without cost sharing, the awareness about these rules is still inadequate and only $31 \%$ of women were screened for alcohol or drug use from 2011 to 2013 (Salganicoff et al., 2014).

Importantly, lack of treatment programs had a significantly higher percentage in 2010-2014 (17.7\%) than 2008-2010 (3.0\%). This is congruent with recent findings from qualitative studies revealing that the availability of substance use treatment services is a challenge to women seeking treatment (Jackson \& Shannon, 2012a; Otiashvili et al., 2013). Although the proportion of facilities that provided substance abuse treatment services for adult women and pregnant or postpartum women increased from $35 \%$ and 15\%, respectively, in 2010 (SAMHSA, 2011b) to $46 \%$ and $21 \%$ in 2014(SAMHSA, 2015), these rates are still low and a number of states have sought to increase the availability of drug treatment services especially for pregnant women (Guttmacher, 2017). In 2011-2014, childbearing-aged women in the current study were more likely to live in nonmetro and small county areas than women in 2008-2014. This suggests that these women were likely to face a massively different group of barriers than residents in large urban areas such as access to and perceived effectiveness of treatment (Fortney \& Booth, 2001).

Another significant finding from the current study is that more women in 20112014 than 2008-2010 did not know where to go to get substance use treatment. This is of critical concern as compared to men, women with substance use disorders have a higher incidence of poverty and childcare responsibilities (SAMHSA, 2011a). Unfortunately, only $3.4 \%$ of substance use treatment facilities in 2014 provided residential beds for clients' children (SAMHSA, 2015). Hence, even if women are highly motivated to get 
treatment, they face additional barriers in finding treatment programs that can address their specific needs (CSAT, 2009).

\section{Limitations}

A number of limitations should be considered when interpreting the results of this study. First, data were analyzed only over seven years because mental illness measures were only included in the NSDUH in 2008. Second, although this study used one-to-two matching between pregnant and nonpregnant women to increase the sample size and power of the analyses, perceived barriers to substance use treatment among pregnant women were not examined over time due to the small sample size of pregnant women reported perceived need for substance use treatment. Third, other variables not included in this study may have affected the propensity scores. Yet, the two groups were wellmatched as indicated by balanced statistics, suggesting that the variance in the control group was reduced. Fourth, pregnancy status was measured based on self-report; thus, it was susceptible to recall bias. Fifth, postpartum women could not be identified from other nonpregnant women using publicly available data. However, a study based on the 2008-2012 NSDUH reported that only approximately 8,000 postpartum women of 18-44 years old participated in the survey, indicating an approximate rate of less than $10 \%$ of nonpregnant women (Glasheen et al., 2015).

Sixth, measurement of MDE and substance use disorder in the NSDUH relied on questionnaires to operationalize the DSM-IV criteria rather than conducting clinical interviews. In addition, measurement of anxiety relied on one item which might also increase recall bias. Seventh, women answered questions about their mental health and substance use disorder and treatment receipt in the past year, while they specified their 
current pregnancy status. These events may be occurred during or before pregnancy. However, this study included past-month psychological distress to increase the possibility of assessing prenatal mental health, although this also cannot be captured if the woman was pregnant in the first few weeks. Yet, the majority of pregnant women in this study $(68.7 \%)$ were in their second and third trimester. Eighth, pregnant women might tend to under report their mental health and substance use problems and treatment receipt due to a social desirability effect; yet, the NSDUH uses ACASI to reduce this response bias. Finally, mental health problems may increase access to treatment which in turn may affect these problems. However, due to the cross-sectional nature of the NSDUH, a cause-effect relationship between treatment receipt and mental health cannot be concluded.

\section{Recommendations}

The findings from this study showed increased trends in anxiety disorder and past-month psychological distress, underscoring the need for preventive and interventional strategies addressing these mental health problems among women of childbearing age. Pregnant women tended to report fewer mental health problems than nonpregnant women; however, differences in the receipt of mental health treatment of pregnant and nonpregnant women suggested that screening and treatment should not be generalized across women of childbearing broadly. More programs and initiatives are needed to increase the receipt of mental health treatment among a vulnerable population of pregnant women especially since cost, stigma, and opposition to treatment continued to be the most important obstacles to mental health treatment over time. 
Trend data presented in this study emphasized the importance of addressing the needs of women with illicit drug use disorder. Women had higher concerns regarding availability of substance use treatment services in 2011-2014 than 2008-2010, emphasizing that parity legislation and treatment initiatives should seek to increase services tailored according to the need of childbearing-aged women. Findings from this study also highlight the importance of additional strategies addressing stigma, cost, and time/transportation limitations to improve access to substance use treatment. This study coincided with important health reforms, MHPAEA (2008) and PPACA (2010);

however, future research is needed to specifically explore how these policies affect the receipt of mental health and substance use treatment among pregnant women. 
Table 4

Sociodemographic Characteristics of Matched Samples of Pregnant and Non-pregnant Women Aged 18-44, NSDUH 2008- 2014 ( N = 16,560)

\begin{tabular}{|c|c|c|c|c|c|}
\hline Characteristics & $\begin{array}{l}\text { Total sample } \\
\text { Wtd. \% (SE) }\end{array}$ & $\begin{array}{c}\begin{array}{c}\text { Pregnant } \\
\text { women }^{\mathrm{a}}\end{array} \\
\text { Wtd.\% (SE) }\end{array}$ & $\begin{array}{c}\begin{array}{c}\text { Non-pregnant } \\
\text { women }^{\mathrm{b}}\end{array} \\
\text { Wtd.\% (SE) }\end{array}$ & $\chi^{2}$ & $p$-value \\
\hline \multicolumn{6}{|l|}{ Age } \\
\hline $18-25$ & $36.5(0.6)$ & $37.5(1.0)$ & $36.0(0.6)$ & 3.44 & .178 \\
\hline $26-44$ & $63.5(0.6)$ & $62.5(1.0)$ & $64.0(0.6)$ & & \\
\hline \multicolumn{6}{|l|}{ Ethnicity } \\
\hline White & $59.0(0.7)$ & $58.8(1.2)$ & $59.1(0.9)$ & 1.96 & .885 \\
\hline African American & $13.7(0.4)$ & $14.3(0.8)$ & $13.5(0.5)$ & & \\
\hline Other nonHispanics ${ }^{\mathrm{a}}$ & $8.9(0.4)$ & $8.7(0.6)$ & $9.0(0.5)$ & & \\
\hline Hispanics & $18.4(0.5)$ & $18.3(0.8)$ & $18.4(0.7)$ & & \\
\hline \multicolumn{6}{|l|}{ Marital status } \\
\hline Married & $61.2(0.7)$ & $60.7(1.1)$ & $61.5(0.7)$ & .88 & .497 \\
\hline Unmarried & $38.8(0.7)$ & $39.3(1.1)$ & $38.5(0.7)$ & & \\
\hline \multicolumn{6}{|l|}{ Education } \\
\hline $\begin{array}{l}\text { Less than high } \\
\text { school }\end{array}$ & $15.8(0.4)$ & $15.5(0.7)$ & $16.0(0.5)$ & 1.19 & .714 \\
\hline High school & $26.2(0.6)$ & $26.0(0.9)$ & $26.3(0.6)$ & & \\
\hline College graduate & $58.0(0.7)$ & $58.6(1.0)$ & $57.7(0.7)$ & & \\
\hline \multicolumn{6}{|l|}{ Employment } \\
\hline Employed full time & $43.0(0.7)$ & $42.8(1.1)$ & $43.1(0.8)$ & .85 & .935 \\
\hline Employed part time & $17.9(0.5)$ & $17.6(1.0)$ & $18.0(0.6)$ & & \\
\hline Other & $32.5(0.5)$ & $32.7(1.0)$ & $32.4(0.7)$ & & \\
\hline Unemployed & $6.7(0.3)$ & $6.9(0.5)$ & $6.6(0.3)$ & & \\
\hline \multicolumn{6}{|l|}{ Income } \\
\hline$<\$ 20,000$ & $22.6(0.5)$ & $22.4(0.9)$ & $22.7(0.7)$ & 1.96 & .885 \\
\hline$\$ 20,000-49,999$ & $29.8(0.7)$ & $30.4(1.2)$ & $29.5(0.8)$ & & \\
\hline$\geq \$ 50,000$ & $47.6(0.8)$ & $47.2(1.2)$ & $47.9(0.9)$ & & \\
\hline \multicolumn{6}{|l|}{ Health insurance } \\
\hline Insured & $89.9(0.4)$ & $90.2(0.5)$ & $89.8(0.5)$ & .62 & .546 \\
\hline Uninsured & $10.1(0.4)$ & $9.8(0.5)$ & $10.2(0.5)$ & & \\
\hline \multicolumn{6}{|l|}{ County type } \\
\hline Large & $52.8(0.9)$ & $53.2(1.2)$ & $52.6(0.9)$ & 2.24 & .526 \\
\hline Small & $31.6(0.7)$ & $31.8(1.0)$ & $31.5(0.7)$ & & \\
\hline Nonmetro & $15.6(0.5)$ & $15.0(0.7)$ & $15.9(0.6)$ & & \\
\hline
\end{tabular}

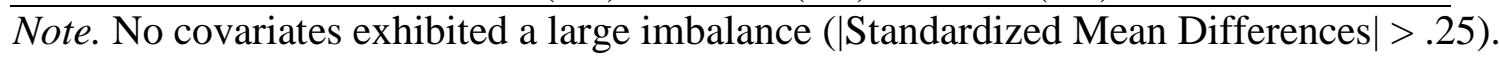
Imputed and recoded variables were used. NSDUH = National Survey on Drug Use and Health; Wt. \% = Weighted Percentage; SE = Standard Error.

${ }^{a}$ Other nonHispanics included Native American/Alaska Native, Native Hawaiian/Pacific Islander, Asian, and more than one race.

${ }^{\mathrm{a}} n=5,520 ;{ }^{\mathrm{b}} n=11,040$. 


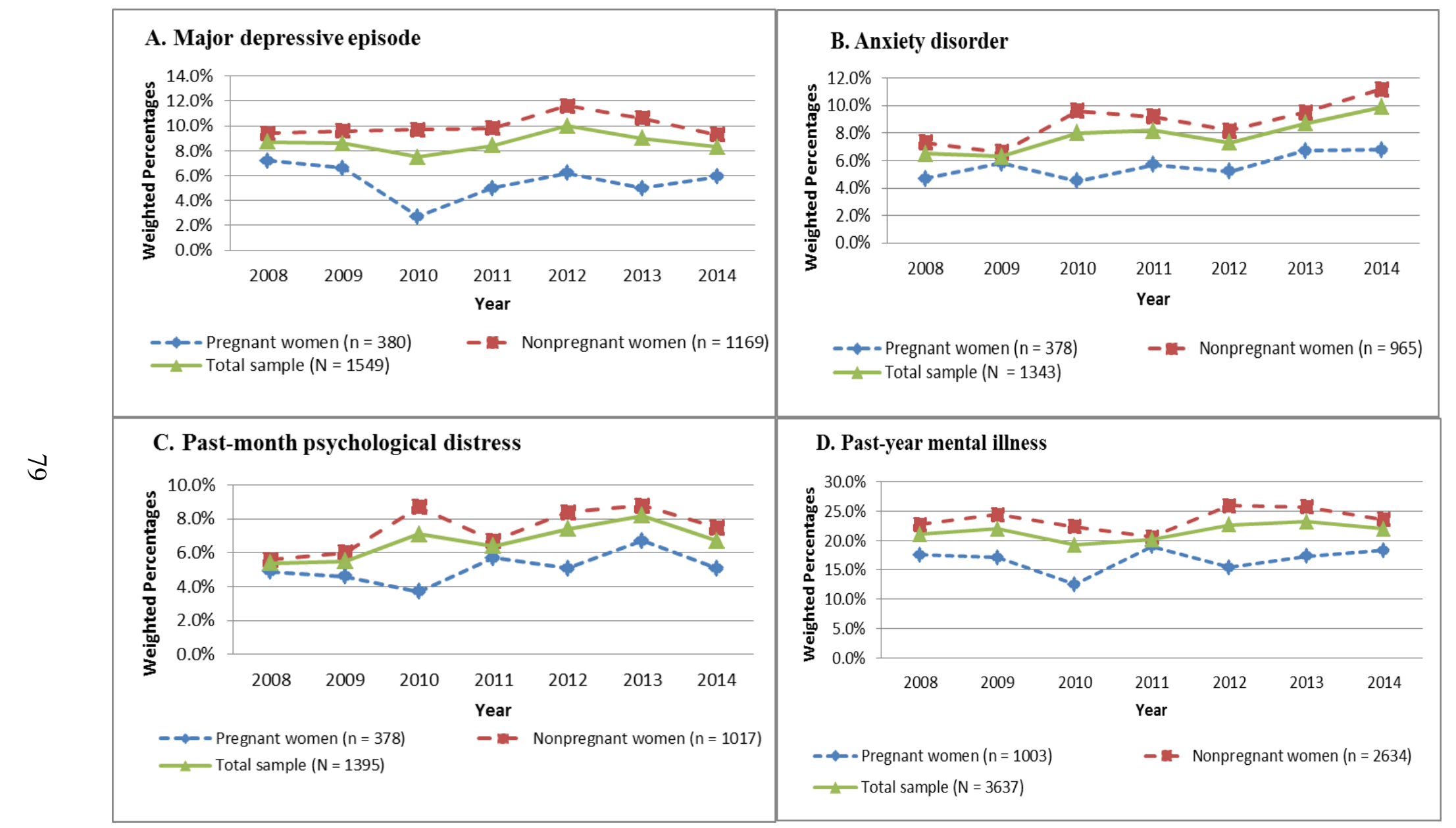

Figure 2. Trends in mental health problems rates from 2008 to 2014 among a matched sample of pregnant and nonpregnant women aged 18-44, National Survey on Drug Use and Health. Frequencies and weighted percentages do not include missing data addressing mental health. 


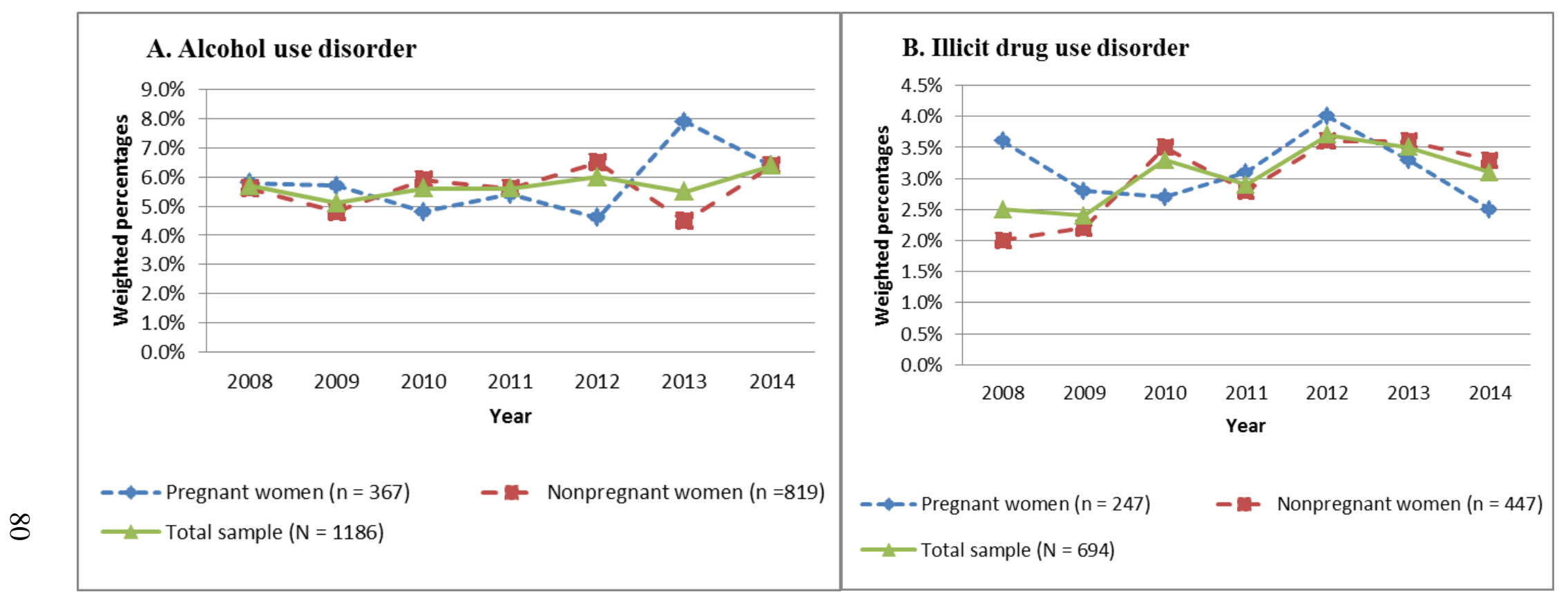

Figure 3. Trends in substance use disorders rates from 2008 to 2014 among a matched sample of pregnant and nonpregnant women, National Survey on Drug Use and Health. Imputed and recoded variables addressing substance use were used. Substance use disorder includes alcohol or illicit drug use dependence or abuse measured based on questions operationalized the Diagnostic and Statistical Manual of Mental Disorders (DSM-IV) criteria. Illicit drugs include heroin, marijuana, cocaine, inhalants, sedatives, tranquilizers, hallucinogens, stimulants, and analgesics 

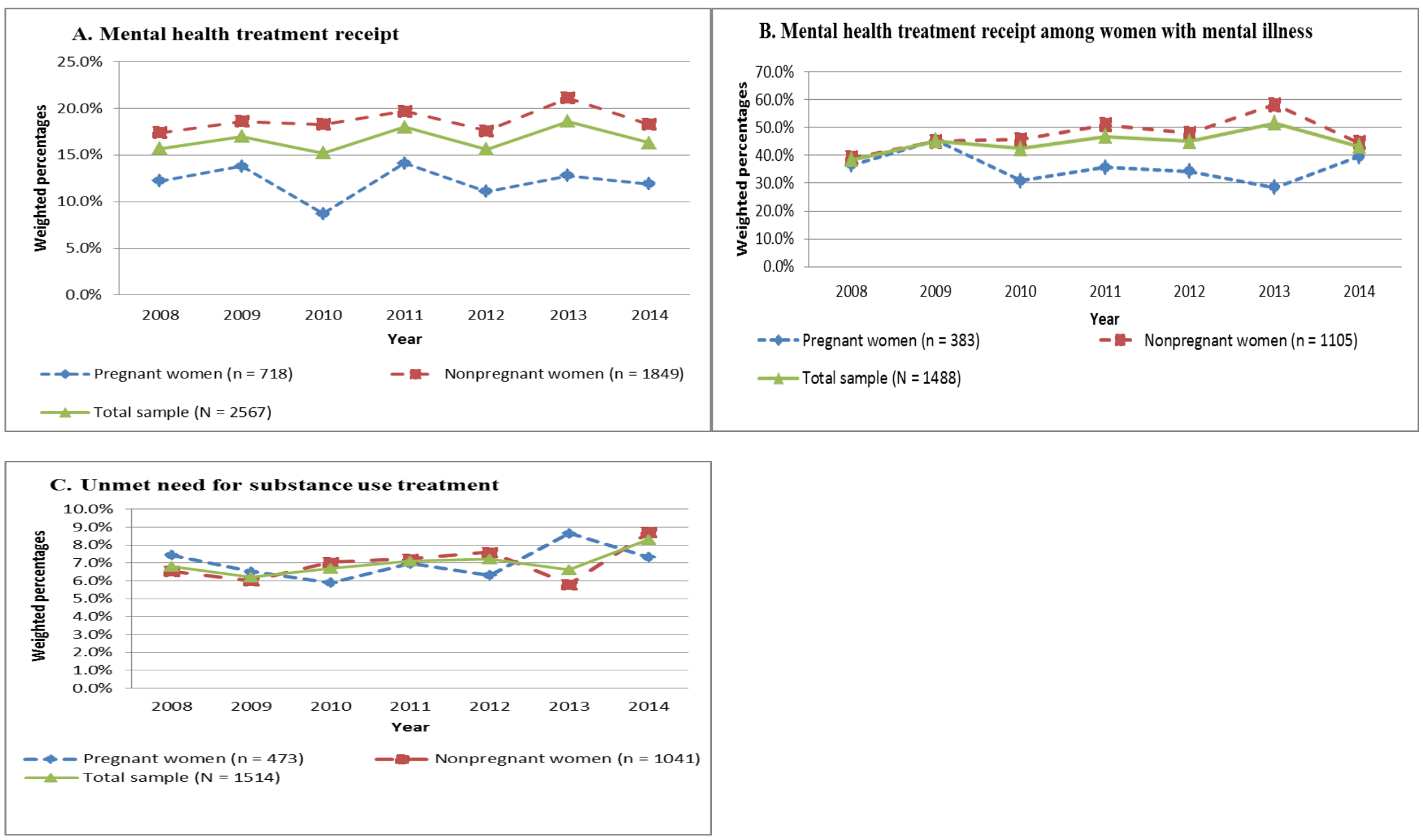

Figure 4. Trends in rates of treatment receipt for mental health and substance use disorders from 2008-2014 among a matched sample of pregnant and nonpregnant women, National Survey on Drug Use and Health. Imputed and recoded variables were used. Frequencies and weighted percentages do not include missing data addressing mental health. 
Table 5

Logistic Regression Modeling the Probability of Mental Health and Substance Use Disorders and Treatment Receipt from 20082014 among a Matched Sample of Pregnant and Nonpregnant Women, $\operatorname{NSDUH}(N=16,560)$

\begin{tabular}{|c|c|c|c|c|c|c|}
\hline \multirow[b]{2}{*}{ Model/Outcomes } & \multicolumn{3}{|c|}{ Pregnant vs. Nonpregnant Women ${ }^{\mathrm{a}}$} & \multicolumn{3}{|c|}{ Time (one-year increase) } \\
\hline & AOR & $95 \% \mathrm{CI}$ & p-value & $\mathrm{AOR}$ & $95 \% \mathrm{CI}$ & p-value \\
\hline 1. Major depressive episode & .53 & $.43-.65$ & $<.001$ & 1.01 & $.96-1.05$ & .791 \\
\hline 2. Anxiety disorder & .62 & $.51-.75$ & $<.001$ & 1.07 & $1.02-1.12$ & .003 \\
\hline $\begin{array}{l}\text { 3. Serious psychological } \\
\text { distress (past month) }\end{array}$ & .68 & $.56-.82$ & $<.001$ & 1.06 & $1.01-1.10$ & .009 \\
\hline 4. Past-year mental illness & .65 & $.58-.74$ & $<.001$ & 1.02 & $.98-1.05$ & .331 \\
\hline 5. Alcohol use disorder ${ }^{b}$ & 1.04 & $.87-1.24$ & .660 & 1.02 & $.97-1.07$ & .375 \\
\hline 6. Illicit drug use disorder ${ }^{\mathrm{b}, \mathrm{c}}$ & 1.06 & $.83-1.35$ & .645 & 1.05 & $1.004-1.10$ & .034 \\
\hline 7. Mental health treatment & .60 & $.52-.69$ & $<.001$ & 1.01 & $.98-1.04$ & .445 \\
\hline 8. Unmet need for substance use & 1.01 & $.86-1.18$ & .939 & 1.03 & $.99-1.08$ & .125 \\
\hline
\end{tabular}

Note. Imputed and recoded variables were used. Frequencies and weighted percentages do not include missing data addressing mental health. NSDUH = National Survey on Drug Use and Health.

${ }^{a}$ Nonpregnant women were the reference group. ${ }^{b}$ Substance use disorder includes substance use dependence or abuse measured based on questions operationalized the Diagnostic and Statistical Manual of Mental Disorders (DSM-IV) criteria. ${ }^{\mathrm{c}}$ Illicit drugs include heroin, marijuana, cocaine, inhalants, sedatives, tranquilizers, hallucinogens, stimulants, and analgesics. 
Table 6

Logistic Regression Modeling the Probability of the Receipt of Mental Health Treatment by Pregnant and Nonpregnant Women with Mental Illness from 2008 to 2014, Controlling for Severity of Illness, NSDUH $(N=3,637)$

\begin{tabular}{llll}
\hline Characteristics & AOR & $95 \%$ CI & p-value \\
\hline Pregnancy status & & & \\
$\quad$ Nonpregnant women & Reference & Reference & .001 \\
$\quad$ Pregnant women & .66 & $.52-.84$ & \\
Time (one year increase) & 1.04 & $.98-1.09$ & .176 \\
Severity of mental illness & & & \\
$\quad$ Mild mental illness & Reference & Reference & $<.001$ \\
$\quad \begin{array}{l}\text { Moderate mental illness } \\
\text { Severe mental illness }\end{array}$ & 1.94 & $1.51-2.50$ & \\
\end{tabular}

Note. Imputed and recoded variables were used. Frequencies and weighted percentages do not include missing data addressing mental health. NSDUH = National Survey on Drug Use and Health. 
A. Perceived barriers to mental health treatment among women of childbearing age $(N=1,436)$

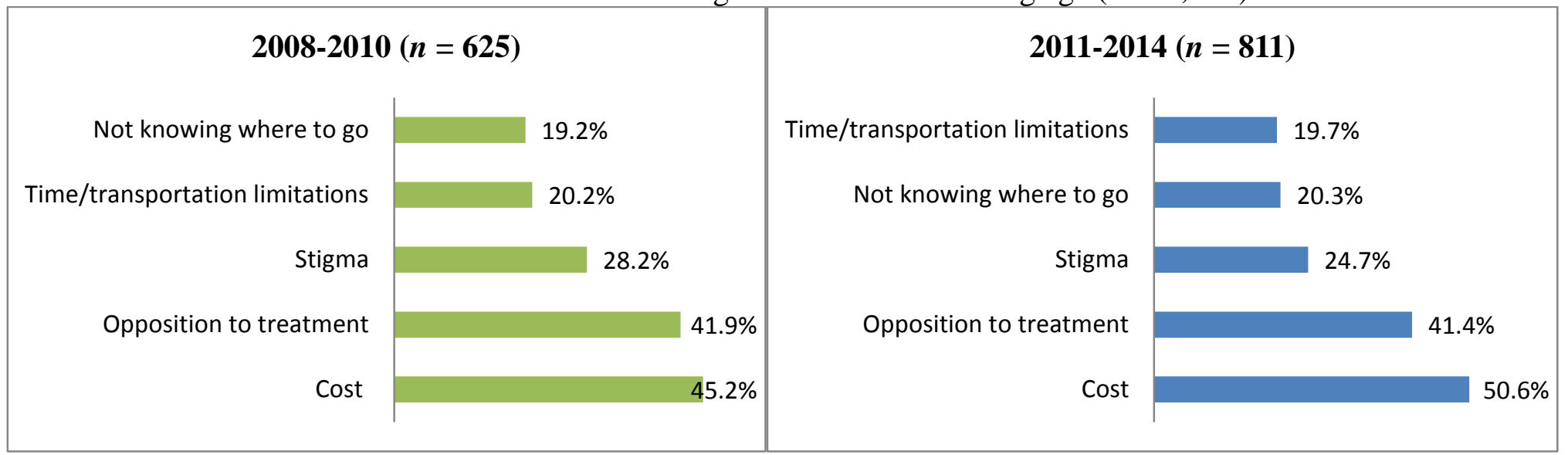

B. Perceived barriers to substance use treatment among women of childbearing age $(N=103)$

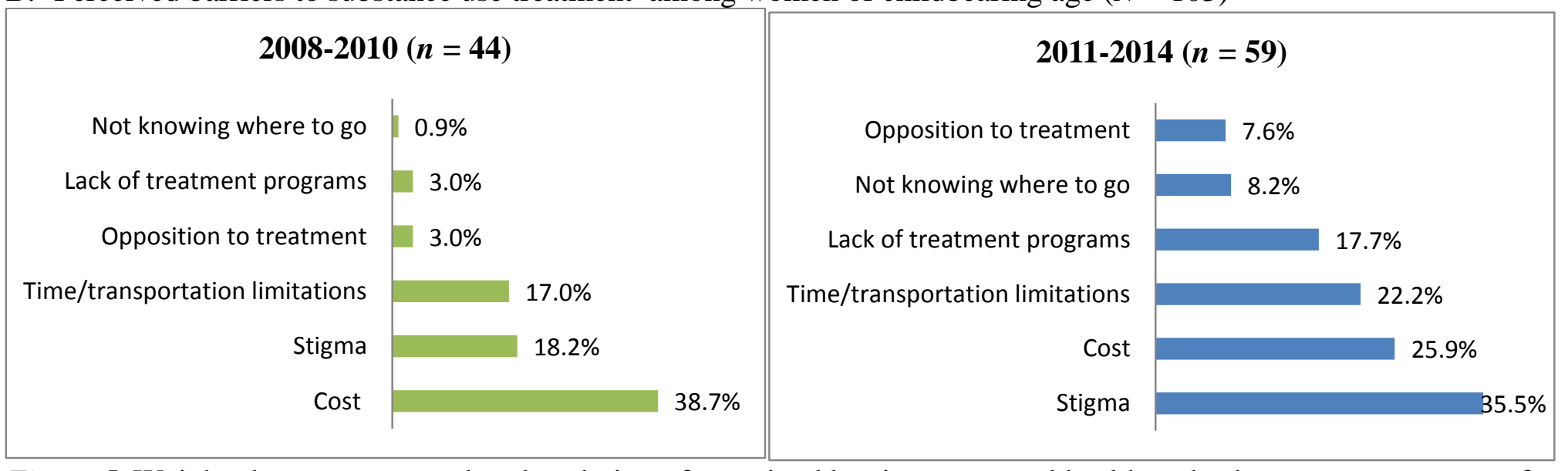

Figure 5. Weighted percentages and rank ordering of perceived barriers to mental health and substance use treamtent from 2008-2010 to 2011-2014 among women of childbearing age perceived need for treatment, National Survey on Drug Use and Health. Imputed and recoded variables were used. Frequencies and weighted percentages do not include missing data addressing mental health. 
A. Perceived barriers to mental health treatment among pregnant women $(N=390)$

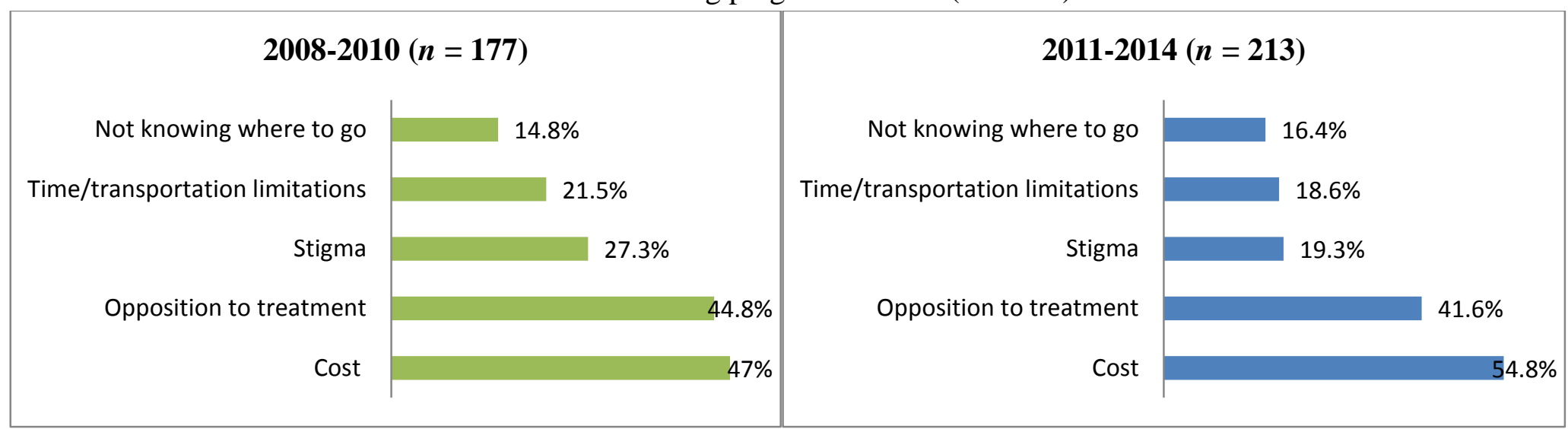

B. Perceived barriers to mental health treatment among nonpregnant women $(N=1046)$

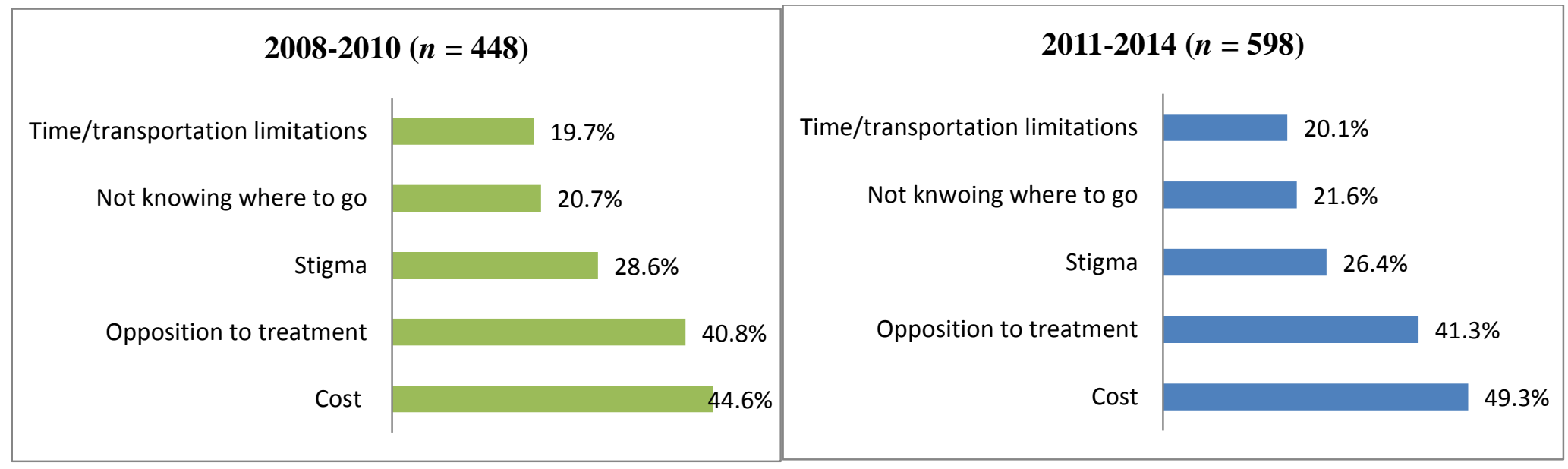

Figure 6. Weighted percentages and rank ordering of perceived barriers to mental health treatment from 2008-2010 to 20112014 among pregnant and nonpregnant women perceived need for treatment, National Survey on Drug Use and Health. Frequencies and weighted percentages do not include missing data addressing mental health. 
Table 7

Perceived Barriers to Mental Health Treatment and Substance Use Treatment in Pregnant and Nonpregnant Women

Perceived Need for Treatment from 2008-2010 to 2011-2014 (NSDUH)

\begin{tabular}{|c|c|c|c|c|c|c|c|c|c|c|c|c|}
\hline \multirow[b]{2}{*}{ Perceived Barriers } & \multicolumn{2}{|c|}{ Total Sample } & \multirow[b]{2}{*}{$\chi^{2}$} & \multirow[b]{2}{*}{$p$} & \multicolumn{2}{|c|}{ Pregnant ${ }^{\mathrm{a}, \mathrm{b}}$} & \multirow[b]{2}{*}{$\chi^{2}$} & \multirow[b]{2}{*}{$p$} & \multicolumn{2}{|c|}{ Nonpregnant $^{\mathrm{c}, \mathrm{d}}$} & \multirow[b]{2}{*}{$\chi^{2}$} & \multirow[b]{2}{*}{$p$} \\
\hline & $\begin{array}{c}\text { Time } \\
1 \\
\text { Wt. } \%\end{array}$ & $\begin{array}{c}\text { Time } \\
2 \\
\text { Wt. \% }\end{array}$ & & & $\begin{array}{c}\text { Time } \\
1 \\
\text { Wt. } \%\end{array}$ & $\begin{array}{c}\text { Time } \\
2 \\
\text { Wt. } \%\end{array}$ & & & $\begin{array}{c}\text { Time } \\
1 \\
\text { Wt. } \%\end{array}$ & $\begin{array}{c}\text { Time } \\
2 \\
\text { Wt. } \%\end{array}$ & & \\
\hline \multicolumn{13}{|l|}{$\begin{array}{l}\text { Mental health treatment } \\
(N=1,436)\end{array}$} \\
\hline Cost & 45.2 & 50.6 & 3.95 & .261 & 47.0 & 54.8 & 2.30 & .317 & 44.6 & 49.3 & 2.13 & .400 \\
\hline Stigma & 28.2 & 24.7 & 2.24 & .368 & 27.3 & 19.3 & 3.40 & .185 & 28.6 & 26.4 & .59 & .636 \\
\hline Opposition to treatment & 41.9 & 41.4 & .03 & .914 & 44.8 & 41.6 & .40 & .711 & 40.8 & 41.3 & .03 & .926 \\
\hline Time/transportation & 20.2 & 19.7 & .05 & .899 & 21.5 & 18.6 & .50 & .643 & 19.7 & 20.1 & .09 & .941 \\
\hline Not knowing where to go & 19.2 & 20.3 & .28 & .768 & 14.8 & 16.4 & .18 & .768 & 20.7 & 21.6 & .11 & .851 \\
\hline \multicolumn{13}{|l|}{$\begin{array}{l}\text { Substance Use Treatment } \\
(N=103)\end{array}$} \\
\hline Cost & 38.7 & 25.9 & 1.80 & .356 & 42.8 & 41.9 & NA & NA & 37.0 & 20.3 & 2.30 & .325 \\
\hline Stigma & 18.2 & 35.5 & 3.30 & .211 & 18.6 & 63.3 & NA & NA & 18.0 & 25.7 & .53 & .616 \\
\hline Opposition to treatment & 3.0 & 7.6 & .88 & .286 & 5.5 & .30 & NA & NA & 1.9 & 10.2 & 1.56 & .098 \\
\hline Time/transportation & 17.0 & 22.2 & .37 & .758 & 5.5 & 16.7 & NA & NA & 21.9 & 24.1 & .04 & .921 \\
\hline Not knowing where to go & .90 & 8.2 & 4.45 & .003 & 6.9 & 6.4 & NA & NA & 1.4 & 21.6 & 5.06 & $<.001$ \\
\hline $\begin{array}{l}\text { Lack of treatment } \\
\text { programs }\end{array}$ & 3.0 & 17.7 & 2.28 & .014 & 0.0 & 7.3 & NA & NA & 1.2 & 8.5 & 1.44 & .055 \\
\hline
\end{tabular}




\section{CHAPTER IV}

\section{PREDICTORS OF MENTAL HEALTH AND SUBSTANCE USE TREATMENT RECEIPT AND ETHNIC DISPARITIES IN MENTAL HEALTH TREATMENT IN A NATIONAL SAMPLE OF PREGNANT WOMEN WITH MENTAL HEALTH AND/OR SUBSTANCE USE DISORDERS \\ Introduction}

The purpose of this study was to examine factors associated with the receipt of mental health and substance use treatment and determine ethnic disparities in mental health treatment among pregnant women with mental health and/or substance use disorders. Pregnant women with mental health and/or substance use disorders are a vulnerable population. Depression affects $8.2 \%$ to $12.4 \%$ of pregnant women in the United States (Cook et al., 2010; Le Strat, Dubertret, \& Le Foll, 2011; Vesga-Lopez et al., 2008) and is associated with co-occurring anxiety and substance use disorders (Le Strat et al., 2011).

Poor mental health during pregnancy is linked with reduced quality of life (Goodman, Chenausky, \& Freeman, 2014), preterm delivery (Grigoriadis et al., 2013), high risk for postpartum depression (Goodman et al., 2014), impaired maternal-child bonding (Grigoriadis et al., 2013; Rossen et al., 2016), and behavioral and cognitive disorders in children of depressed mothers (Csaszar, Melichercikova, \& Dubovicky, 2014). These adverse health consequences may become more complex and prevalent for 
the mother and her child when are associated with prenatal substance use (Connelly, Hazen, Baker-Ericzen, Landsverk, \& Horwitz, 2013; Homish, Cornelius, Richardson, \& Day, 2004; Jaaskelainen, Holmila, Notkola, \& Raitasalo, 2016). In 2012 and 2013, 5.4\% of pregnant women used illicit drugs and $9.4 \%$ of them used alcohol in the past month (Substance Abuse and Mental Health Services Administration [SAMHSA], 2014b).

Despite effective treatments for mental health and substance use disorders (Baker et al., 2010; Marais et al., 2011; May et al., 2013; Meyer, Johnston, Crocker, \& Heil, 2015 ), only $10.3 \%$ to $39 \%$ of pregnant women with these complex health issues receive treatment (Cook et al., 2010; Glasheen, Colpe, Hoffman, \& Warren, 2015; Le Strat et al., 2011, Rosen, Tolman, \& Warner, 2004; Song, Sands, \& Wong, 2004; Vesga-Lopez et al., 2008). Low rates of treatment for mental health problems occur despite ongoing medical recommendations (American College of Obstetricians and Gynecologists [ACOG], 2015b) and state screening initiatives (Agency for Healthcare Research and Quality, 2016). Moreover, pregnant women who use substances are often involved with the law before they are screened or referred to treatment by health care providers (McCabe \& Arndt, 2012; Terplan, Smith, Kozloski, \& Pollack, 2010). Inadequate treatment for prenatal substance use is associated with prolonged hospitalizations of prenatally affected infants (Patrick, Davis, Lehmann, \& Cooper, 2015) and expensive child protective services (Ondersma, Simpson, Brestan, \&Ward, 2000), making prenatal substance use a significant public health problem.

Pregnant women face barriers (e.g., stigmatization) to access treatment for mental health problems (Ko, Farr, Dietz, \& Robbins, 2012), and those who are ethnic and racial minorities continue to experience health care disparities (Chang, Tabet, Elder, Kiel, \& 
Flick, 2016). However, little is known regarding factors associated with mental health/substance use treatment receipt, perceived barriers to mental health treatment, and ethnic care disparities in a general population of pregnant women.

Numerous studies have focused on the correlates of mental health problems during pregnancy (Fairbrother, Janssen, Antony, Tucker, \& Young, 2016; Fairbrother, Young, Janssen, Antony, \& Tucker, 2015; Le Strat et al., 2011; Melville, Gavin, Guo, Fan, \& Katon, 2010; Witt et al., 2010), but few have given attention to factors associated with mental health treatment receipt. Mental health treatment may motivate pregnant women with substance use disorders to access treatment for substance use issues (Rade et al., 2015). Hence, addressing factors associated with the receipt of mental health treatment can be used to establish preventive and interventional strategies to overcome under-utilization of mental health treatment and thereby improve access to substance use treatment. This is of critical concern because the growing literature, despite its importance, has focused on factors related to retention in treatment programs for substance use disorders (Brigham, Winhusen, Lewis, \& Kropp, 2010; Kissin, Svikis, Moylan, Haug, \& Stitzer, 2004; Knight, Logan, \& Simpson, 2001; Ondersma, Winhusen, \& Lewis, 2010) rather than examining the rate and predictors of the receipt of treatment in a general population of pregnant women. A clear understanding of these factors, while addressing ethnic care disparities and reasons for the unmet need for mental health treatment, may help identify solutions to the under-treatment for mental health and substance use disorders in a vulnerable population of pregnant women. 


\section{Background}

Pregnant women with mental health and substance use disorders remain undertreated despite the adverse health consequences associated with their condition and the availability of different treatment modalities (Glasheen et al., 2015; Le Strat et al., 2011; Terplan, McNamara, \& Chisolm, 2012; Vesga-Lopez et al., 2008). Therefore, it is vital that pregnant women with these disorders are not only recognized but also treated. Much information remains to be understood regarding how pregnant women's sociodemographic and clinical characteristics influence the receipt of mental health and substance use treatment.

Previous population-based studies either only reported the prevalence of mental health treatment in pregnant women with psychiatric disorders (Cook et al., 2010; Le Strat et al., 2011; Vesga-Lopez et al., 2008) or examined predictors of the receipt of mental health (Glasheen et al., 2015) and substance use treatment (Terplan et al., 2012) in women of childbearing age while adjusting for pregnancy status. Several factors may specifically bear on whether pregnant women are able to receive treatment for mental health and substance use disorders including predisposing (e.g., age, ethnicity, marital status, and education level), enabling (e.g., income and health insurance), and need factors. The specific aims of this study were to:

1. Identify predictors of the receipt of mental health treatment and substance use treatment among pregnant women with mental health or substance use disorders given predisposing characteristics (i.e., age, ethnicity, marital status, education level, and employment status), enabling resources (i.e., income, health insurance, and county type), and perceived and actual need for treatment, controlling for time. 
2. Examine differences in the receipt of mental health treatment among White and nonWhite pregnant women with mental health (i.e., depression, anxiety, and serious psychological distress) and/or substance use disorders, controlling for time and confounding variables (i.e., age, marital status, education level, employment status, income, health insurance, county type, self-rated health status, and severity of distress symptoms).

3. Compare and contrast perceived barriers to mental health treatment among pregnant women who perceived need for treatment across mental health and/or substance use disorders and ethnicity.

\section{Predisposing Characteristics}

Pregnant women become more vulnerable because of reported disparities in antenatal depression (Cook et al., 2010; Mukherjee, Trepka, Pierre-Victor, Bahelah, \& Avent, 2016) and substance use problems (Cook et al., 2010; Connelly et al., 2013). However, there is sparse evidence on racial/ethnic differences in the receipt of mental health/substance use treatment among this population. Studies based on the National Epidemiologic Survey on Alcohol and Related Conditions (NESARC) did not report the differences across racial/ethnicity groups in the receipt of mental health treatment (Le Strat et al., 2011; Vesga-Lopez et al., 2008). Other studies examined race/ethnicity as a correlate of mental health treatment utilization among perinatal women, suggesting that Hispanic (Geier, Hills, Gonzales, Tum, \& Finley, 2015; Glasheen et al., 2015) and Black women reported receipt of mental health treatment proportionately less than their counterparts (Glasheen et al., 2015). 
A few studies focused explicitly on examining racial/ethnic differences in the receipt of mental health treatment (Chang et al., 2016; Song et al., 2004). Using data from the Florida Healthy Start prenatal screening program 2008-2012, Chang et al. (2016) reported that White pregnant women with depressive symptoms had the highest rates of mental health services utilization compared to Mexicans and other Hispanics. Ethnic minority pregnant women who entered substance use treatment also reported unmet need for mental health treatment (Coleman-Cowger, 2012). Because mental health treatment receipt is a key factor in enhancing the participation in substance use treatment (Rade et al., 2015), further research is needed to address racial disparities in mental health care among pregnant women with a broad range of psychiatric problems.

Compared to Whites, African American pregnant women with substance use problems were less likely both to be motivated to enroll in (Mitchell, Severtson, \& Latimer, 2008) and receive substance use treatment (McCabe \& Arndt, 2012). These ethnic differences in the receipt of substance use treatment showed a significant trend among pregnant women between 1998 (34.4\% Blacks vs. 54.1\% Whites) to 2008 (20.5\% Blacks vs. 60.3\% Whites) (McCabe \& Arndt, 2012).

Prior research revealed inconsistent findings regarding the associations among the receipt of mental health treatment and maternal age (Flynn, Blow, \& Marcus, 2006; Glasheen et al., 2015; Rosen et al., 2004), educational level (Flynn et al., 2006; Glasheen et al., 2015; Goodman, 2009; Smith et al., 2009), employment status (Flynn et al., 2006; Glasheen et al., 2015; Smith et al. 2009), and marital status (Chang et al., 2016; Flynn et al., 2006; Glasheen et al., 2015; Smith et al., 2009), reflecting the heterogeneity in the design and sample across studies. 
The relationship between predispositional characteristics and substance use treatment is also unclear. One study found that unmarried women were more likely to receive treatment than married women (Messer, Clark, \& Martin, 1996), whereas Kotelchuck et al. (2017) found them less likely to receive treatment; other studies showed no significant association between marital status and treatment receipt in pregnant (Haller, Miles, \& Dawson, 2001) and childbearing-aged women (Terplan et al., 2012). Although a few population-based studies revealed that women of reproductive age who had at least a high school education (Kotelchuck et al., 2017; Terplan et al., 2012) and who were employed had higher odds of receipt of substance use treatment (Terplan et al., 2012), other studies did not find a significant relationship among pregnant women who received current (Haller et al., 2001; Messer et al., 1996) or lifetime substance use treatment (Walton-Moss \& McCaul, 2006). Maternal age in a few population-based and clinical studies did not influence the receipt of substance use treatment (Messer et al., 1996; Rosen et al., 2004). Yet, McCabe and Arndt (2012) reported that pregnant women aged 21-24 years had an $8.5 \%$ point increase in the receipt of substance use treatment from 1998 to 2008.

\section{Enabling Factors}

Economically disadvantaged pregnant women are unlikely to access mental health (Song et al., 2004) and substance use treatment (Center for Substance Abuse Treatment [CSAT], 2009). However, a few studies showed that income was not associated with the receipt of mental health (Glasheen et al., 2015; Goodman, 2009; Smith et al., 2009) or substance use treatment (Haller et al., 2001). These findings may be related to the homogeneity of the clinical samples (Haller et al., 2001; Smith et al., 2009) or the 
influence of other mediators or moderators on the relationship between income and treatment receipt that were not examined. Uninsured women of childbearing age also demonstrated unmet need for mental health (Farr, Bitsko, Hayes, \& Dietz, 2010) and substance use treatment (CSAT, 2009). A population-based study showed that health insurance coverage was associated with and predicted mental health treatment receipt in perinatal women and childbearing-aged women, respectively (Glasheen et al., 2015). However, another study showed that health insurance coverage did not increase the probability of the receipt of substance use treatment in women of childbearing age after adjusting for other socio-demographic characteristics (Terplan et al., 2012).

Unfortunately, substance use treatment services impose additional financial requirements that may not be covered by health insurance, thus creating other financial barriers to treatment (CSAT, 2009).

Rural women received mental health treatment later in the development of their health condition and therefore need more intensive treatments (United States Department of Health and Human Services [USDHHS], 2003). However, Heil, Sigmon, Jones, and Wagner (2008) found that rural opioid-using pregnant women when compared with urban women might have characteristics associated with better treatment outcomes; however, they face more barriers to access treatment due to larger distance from treatment service. In qualitative studies of rural pregnant women, barriers to mental health (e.g., dissatisfaction with the health care system and lack of trust) (Jesse, Dolbier, \& Blanchard, 2008) and substance use treatment (e.g., availability, stigma, and lack of transportation) (Jackson \& Shannon, 2012a) were identified. To date, very few population-based studies 
examined the relationship between urban residency and mental health or substance use treatment receipt in women of childbearing age (Rosen et al., 2004).

\section{Perceived and Clinical Needs for Mental Health/Substance Use Treatment}

Approximately, 39\% of women of childbearing age with past major depressive episode (MDE) reported unmet treatment needs (Ko et al., 2012) and less than $20 \%$ of women who needed substance use treatment received it (Terplan et al., 2012). Yet, little is known about the relationship among the perceived need for and receipt of treatment for mental health and substance use disorders in pregnant women.

Research on pregnant women's mental health gives little attention to how mental health or substance use issues differentiate the receipt of treatment in the general population. A study based on the NESARC showed that pregnant women with major depression and any other psychiatric disorders had higher odds of the receipt of mental health treatment compared to those without these disorders (Le Strat et al., 2011). Moreover, a study based on the National Survey on Drug Use and Health (NSDUH) revealed that history of depression or anxiety disorders was associated with the receipt of mental health treatment in perinatal women with serious psychological distress (Glasheen et al., 2015). Yet, these population-based studies did not indicate that substance use problems were associated with the receipt of mental health treatment. However, Rosen et al. (2004) reported that comorbid mental health and substance use disorders increased the probability of receipt of substance use and mental health treatment in women aged 18-54 years. Nevertheless, the authors did not specify pregnancy status or the correlates of each type of mental health and substance use treatment. 
A few clinical studies suggest that substance-related factors play a vital role in pregnant women's utilization of substance use treatment. The type of substance used appears to influence this relationship; illicit drug use was related to substance use treatment acceptance, but alcohol use showed an inconsistent pattern in this relationship (Haller et al., 2001; Messer et al., 1996; Walton-Moss \& McCaul, 2006). For instance, Haller et al. (2001) found that the drug severity composite score was related to treatment among pregnant women who used drugs while alcohol use did not affect receipt of treatment. Pregnant women with comorbid mental health and substance use problems were more likely to receive substance use treatment (Haller et al., 2001; Rade et al., 2015). However, these findings of these clinical studies cannot be generalized to the general population. To date, little is known regarding how need factors are related to the receipt of substance use treatment in pregnant women from the general population.

\section{Perceived Barriers to Mental Health Treatment}

The receipt of mental health treatment among perinatal women is a complex phenomenon involving individual, healthcare provider, and health system barriers (Battle, Salisbury, Schofield, \& Ortiz-Hernandezet, 2013; Kim et al., 2010). Clinical studies that specifically examined perceived barriers to mental health treatment among pregnant women indicated the most common barriers include: cost/lack of insurance (Kim et al., 2010; Kopelman et al., 2008), stigma (Battle et al., 2013; Goodman, 2009; Jesse et al., 2008), lack of time (Goodman, 2009; Kim et al., 2010; Kopelman et al., 2008) and transportation (Kopelman et al., 2008), opposition to treatment (Jesse et al., 2008), dissatisfaction with the health care (Jesse et al., 2008; Kopelman et al., 2008), and not knowing where to go (Kopelman et al., 2008). The only population-based study of 
perceived barriers to mental health treatment among childbearing-aged women revealed consistent findings in which cost $(54.8 \%)$, opposition to treatment $(41.7 \%)$, stigma (26.3\%), lack of time or transportation (18.1\%), and not knowing where to go for treatment (16.7\%) were the common barriers to mental health treatment (Ko et al., 2012). These perceived barriers did not differ by pregnancy status.

To date, research has focused on women with depression; hence, whether perceived barriers to treatment differ between mental health and/or substance use disorders is not known nor have ethnic differences in mental health treatment barriers been fully explored in pregnant women (O’Mahen, Henshaw, Jones, \& Flynn, 2011). Recent research identified important barriers to mental health care for comorbid women (e.g., cost and fear from treatment) (Rosen et al., 2004) and ethnic minority pregnant women (e.g., stigma and lack of trust) (Jesse et al., 2008). However, O’Mahen and Flynn (2008) did not find differences between White and African American perinatal women regarding perceived structural (e.g., insurance, cost, transportation, and childcare), knowledge, and attitudinal barriers with respect to treatment of depression.

\section{Theoretical Framework}

This study used the Behavioral Model of Health Service Use (Andersen, 1995) to explain ethnic/racial care disparities and predictors of the receipt of mental health and substance use treatment among pregnant women (see Figure 7). Andersen's (1995) behavioral model incorporates individual and contextual determinant of health services use.

This model postulates that there are three components of individuals' health services utilization. First, predisposing factors include: (a) demographic characteristics of 
age and sex representing "biological imperatives" (p. 2); (b) social factors such as education, ethnicity, and employment; and (c) attitudes, values, and knowledge related to health and health services that might affect individuals' subsequent perceptions of need and use of health services. According to Andersen's (1995) model, social factors determine the persons' ability to cope with problems and influence their enabling resources which in turn facilitate or impede health services' use. Second, enabling factors include: (a) availability and accessibility of services; (b) income; (c) health insurance status; (d) transportation; and (e) travel time to and waiting times for health care. The third component is the individual's treatment needs which involve perceived and evaluated need.

Andersen's (1995) behavioral model has been extensively used in studies addressing health services utilization (Babitsch, Gohl, \& von Lengerke, 2012). In this study predisposing characteristics (i.e., age, ethnicity, marital status, education level, and employment status), enabling resources (i.e., income, health insurance, and county type), and perceived and actual need for treatment were examined as predictors of the receipt of mental health and substance use treatment (see Figure 8).

\section{Methods}

\section{Design}

Secondary analysis of existing data from the NSDUH 2008-2014 was conducted. The NSDUH is a national cross-sectional survey funded by SAMHSA (Center for Behavioral Health Statistics and Quality [CBHSQ], 2015). This large population-based survey provides information about mental health and substance use problems along with treatment for mental health and substance disorders among the civilian, 
noninstitutionalized population aged 12 years old or older (CBHSQ, 2015). Data were aggregated for seven years to obtain a large sample size, thus enabling the detection of rare events such as substance use treatment among pregnant women as well as ethnic care disparities.

\section{Sample}

An independent, multistage probability stratified sample was used to collect data from participants in each of the 50 states and the District of Columbia (CBHSQ, 2015). The data were collected using both face-to-face interviews and audio computer-assisted self-interviews (ACASI) (CBHSQ, 2015). The sample for this study was restricted to pregnant women aged 18 to 44 years old who had mental health or substance use disorders. Pregnant women aged 12 to 17 years were excluded because the NSDUH included a different mental health module administered only to adults aged 18 and over. A total of 5,520 pregnant women participated in the survey from 2008 to 2014, including 1,106 pregnant women with mental health problems and 521 women with substance use disorders.

\section{Measures}

Pregnancy status. Women who participated in the NSDUH were classified based on their self-report of pregnancy status (yes/no). The self-report of pregnancy status showed substantial test-retest reliability (Cohen's Kappa $=.85)($ SAMHSA, 2010).

Predisposing characteristics. Predisposing characteristics included: (a) age category (18-25; 26-44); (b) ethnicity (Hispanic, White, African American, and other nonHispanics, i.e., Native American/Alaska Native, Native Hawaiian/Pacific Islander, Asian, and more than one race; (c) education level (less than high school, high school 
graduate, and college graduate); (d) marital status (married and unmarried, i.e., never been married, divorced or separated, and widowed), and (e) employment status (unemployed and employed, i.e., full-time, part-time, and not in labor force).

Enabling factors. Enabling factors included: (a) total family income $(<\$ 20,000$; $\$ 20,000-49,999 ; \$ 50,000-\$ 74,999$; and $\geq \$ 75,000$ ); (b) health insurance (uninsured and insured); and (c) county urbanicity (large, small, and nonmetro). The socio-demographic characteristics were grouped accordingly based on the sample size in each category. The demographic variables demonstrated almost perfect test-retest reliability (Cohen's Kappa ranging from .95 to 1.0) (SAMHSA, 2010).

Need factors. Need factors included self-rated health status (poor/fair and excellent/good/very good), mental health and substance use disorders, as well as perceived need for treatment.

Substance use disorders. The NSDUH includes structured questions designed to operationalize the Diagnostic and Statistical Manual of Mental Disorders: DSM-IV (American Psychiatric Association [APA], 1994) criteria for abuse and dependence of alcohol and illicit drugs (CBHSQ, 2015). Dependence on a substance is defined as reporting at least three out of seven dependence symptoms occurred in a 12-month period (i.e., engaging in activities related to substance use, tolerance, withdrawal, larger or longer use, unsuccessful attempts to cut down, physical health or emotional problems, and reduced activities) (APA, 1994). Substance abuse involves not meeting the criteria for dependence on that substance but reporting at least one of four abuse criteria occur in a 12-month period (i.e., roles obligations, hazardous use, legal problems, and social problem) (APA, 1994). The validity of the NSDUH in assessing substance use disorders 
was supported (Jordan, Karg, Batts, Epstein, \& Wiesen, 2008). In addition, the test-retest reliability of substance dependence or abuse measures showed substantial agreement $($ Cohen's Kappa = .67) (SAMHSA, 2010).

Mental health problems (i.e., major depressive episode, anxiety disorder, or serious psychological distress). The NSDUH adapted questions from the National Comorbidity Survey Replication (NCS-R) to measure symptoms of MDE (yes/no) consistently with the DSM-IV criteria (CBHSQ, 2015). The adult MDE measure demonstrated moderate test-retest reliability (Cohen's Kappa $=.52)($ SAMHSA, 2010). Anxiety disorder (yes/no) was measured using a single item addressing whether a doctor or other medical professional told participants that they had anxiety disorder in the past 12 months. This measure demonstrated substantial test-retest reliability (Cohen's Kappa $=.73)($ SAMHSA, 2010).

The NSDUH uses Kessler-6 (K6) Psychological Distress Scale (Kessler, Barker, et al., 2003) to measure symptoms of psychological distress during the past year. The K6 Scale is a 6-item self-report instrument that ranks items on a 4-point scale ranging from "all of the time" to "none of the time." These items ask about the frequency of feeling: nervous, hopeless, restless or fidgety, sad or depressed, that everything was an effort, and no good or worthless. The range of the total scores is 0 to 24 ; higher scores indicate greater psychological distress. The cut-off score of 13 is the indicator of serious psychological distress (CBHSQ, 2015). The K6 predicted serious mental illness (Kessler, Barker, et al., 2003) thereby supporting its validity. Cronbach's alpha for the K6 in the present sample had excellent reliability $(\alpha=.91)$. In this study, serious psychological 
distress was examined as an outcome variable and included as a confounding variable to control severity of distress symptoms when addressing ethnic care disparities.

Perceived need for treatment. The NSDUH includes two items addressing whether participants perceived a need for the treatment for alcohol (one item) and illicit drugs (one item) (yes/no). The recorded variable addressing the perceived need for treatment for alcohol or illicit drug use was used in this study. The perceived need for mental health treatment was measured using a single item addressing whether participants perceived a need for mental health treatment or counseling during the past 12 months but did not get it (yes/no). Measures of perceived need for treatment demonstrated substantial test-retest reliability (Cohen's Kappa $=.86$ for substance use treatment; Cohen's Kappa $=.65$ for mental health treatment) $($ SAMHSA, 2010).

Receipt of mental health treatment. The NSDUH includes three items addressing whether participants received treatment for any problem with emotions, nerves, or mental health in the past 12 months in an inpatient or outpatient setting, or used prescription medication for mental health problems (yes/no). These measures demonstrated excellent test-retest reliability $($ Cohen's Kappas $=.85)($ SAMHSA, 2010).

Receipt of substance use treatment. The NSDUH includes 18 items (yes/no) addressing the receipt of treatment for alcohol (nine items) and illicit drugs use problems (nine items) during the past 12 months in any of the following venues: hospitals, inpatient or outpatient residential drug or alcohol rehabilitation facilities, outpatient mental health facilities, emergency departments, private doctor's offices, prisons/jails, self-help groups such as Alcoholics Anonymous (AA), Narcotics Anonymous (NA), or some other places. The substance use treatment measures showed strong test-retest reliability (Cohen's 
Kappa $=.87)($ SAMHSA, 2010). In this study, the recoded variable that indicates the receipt of treatment for alcohol or illicit drug use at any venue during the past 12 months was used.

Perceived barriers to mental health treatment. The NSDUH includes 14 items addressing reasons for not getting mental health treatment (USDHHS, SAMHSA, Office of Applied Studies, 2015). Perceived barriers include factors such as treatment beliefs, readiness for treatment, lack of knowledge about treatment programs, confidentiality concerns, lack of time, and lack of transportation. The majority of items addressing the barriers to mental health treatment demonstrated good test-retest reliability (Cohen's Kappa $\geq .65)($ SAMHSA, 2010).

The classification of perceived barriers used by Ko et al. (2012) was adapted for use in this study. Any items measuring perceived barriers that were scored "yes" were classified into the following categories: (a) cost (three items: could not afford cost, insurance did not cover at all, and insurance did not pay enough); (b) stigma (four items: fear of neighbors' negative opinion, fear of negative effects on job, confidentiality concerns, and did not want others to find out); (c) opposition to treatment (four items: didn't think treatment was needed at the time, could handle problems without treatment, didn't think treatment would help, and fear of being committed/medicated); (d) time or transportation limitation (two items: didn't have time, and no transportation or inconvenient); (e) and did not know where to go.

\section{Procedure}

This study used existing de-identified, publicly available data from the NSDUH 2008-2014. Hence, an exemption certification was received for the current study from the 
University of Louisville Institutional Review Board. Approval to use these data for the proposed research was obtained from SAMHSA through the Interuniversity Consortium for Political and Social Research (ICPSR). The principal investigator (PI) agreed to: (a) use the data only for research purposes; (b) report to the ICPSR if the identity of any subject is discovered accidentally; and (c) keep the data safe from unauthorized access. Thus, the data were saved as encrypted file on the investigator's computer.

\section{Data Analysis}

Statistical analysis was conducted using complex sample analysis with SPSS software, version 22.0 (IBM Corp., 2013). Considering the complex survey design and probability of sampling, a weighting variable was included by diving the final personlevel analysis weights by seven (i.e., the number of years of pooled data), according to the guidelines of the NSDUH (CBHSQ, 2015). $P$-values $<.05$ were considered statistically significant for all analyses. Bonferroni correction was deemed conservative (Bland \& Altman, 1995); hence, multiple comparisons were considered when interpreting ethnic care disparities across mental health and/or substance use disorders. The recoded and imputed variables for demographic and substance use variables were analyzed, while missing data for mental health variables were excluded from analyses.

Descriptive statistics were conducted for the entire sample using weighted percentages and standard errors (SEs) to describe all categorical variables; means and $S E \mathrm{~s}$ were used to describe psychological distress. Bivariate analyses using chi-square and $t$ test were performed to examine the associations/differences among predisposing, enabling, and need factors and receipt of treatment groups. 
Two logistic regression models were conducted to model the probability of the receipt of mental health treatment and substance use treatment. Unadjusted and adjusted odds ratios were calculated for best predictors. The full model contained characteristics with $p$-value less than .15 in bivariate analyses, confounding variables, and time. Multicollinearity was assessed by tolerance and variance inflation factor (VIF). A backward selection method was used to determine which variables to include in the final model. All models were compared using the likelihood ratio test and the Akaike Information Criterion (AIC) and Bayesian Information Criterion (BIC) fit statistics (Vittinghoff, Glidden, Shiboski, \& McCulloch, 2012).

Five separate logistic regression models were run to model the probability of the receipt of mental health treatment among each group of pregnant women with: major depression, anxiety disorder, serious psychological distress, and/or substance use disorders, controlling for time and confounding variables (i.e., age, income, education, marital status, employment status, health insurance, county type, self-rated health status, severity of distress symptoms, and time). Ethnicity was included as the main variable in each model. Finally, weighted percentages were calculated for each type of perceived barrier and compared across types of disorders and ethnicity using chi-square.

\section{Results}

\section{Sample Characteristics}

A total of 5,520 pregnant women of childbearing age (18-44 years) participated in the NSDUH 2008-2014. Most participants were white (58.8\%), college graduates (58.6\%), employed (93.1\%), and had a family income of less than $\$ 50,000$ (see Table 8). Approximately $17 \%$ of pregnant women had mental health problems in the past year (i.e., 
MDE, anxiety, or serious psychological distress), $7.6 \%$ of them met the DSM-IV criteria for the substance use disorders, and $4.1 \%$ of them had comorbid mental health and substance disorders. Only $44.5 \%$ and $13.1 \%$ of pregnant women with mental health or substance use disorders received treatment for mental health and substance use problems, respectively.

Among pregnant women with mental health problems (i.e., MDE, anxiety, or serious psychological distress) $(N=1,106)$, the majority aged $26-44$ years, were white, unmarried, college educated, employed, insured, had income of less than $\$ 50,000$, and lived in urban residency. Most of pregnant women with mental health problems perceived their health status as good or excellent. Approximately, 34\% of them had MDE or anxiety disorder in the previous year. Only, $20 \%$ of pregnant women had comorbid mental health and substance use disorders. Approximately $75 \%$ of pregnant women had serious psychological distress (K-6 score $\geq 13$ ); the mean score for the K-6 scale of 15.54 (see Table 9).

Most of pregnant women with substance use disorders $(N=521)$ aged 18 to 25 years, were white, unmarried, college educated, employed, had health insurance coverage, lived in urban residency, and had an income of less than $\$ 50,000$. The majority perceived their health as excellent or good and did not perceive a need for substance use treatment $(95.5 \%)$. Forty-one percent of pregnant women had alcohol abuse and $34.9 \%$ of them had alcohol dependence, while $10 \%$ and $31.1 \%$ met the DSM-IV criteria for illicit drug abuse and dependence, respectively. Around $28 \%$ of women had comorbid depression/anxiety and substance use disorders (see Table 10).

\section{Factors Associated with Mental Health/Substance Use Treatment}


Compared to pregnant women with mental health problems who did not receive mental health treatment, those who received the treatment were significantly more likely to be age 26 to 44 years $(p=.001)$, white $(p<.001)$, and married $(p=.13)$; have college education $(p=.002)$; have a higher income $(p=.008)$; and have health insurance coverage $(p=.036)$. Pregnant women who received mental health treatment were more likely to: perceive need for treatment $(p<.001)$; have a past-year $\operatorname{MDE}(p=.014)$; and have anxiety disorder $(p<.001)$ compared to those who did not receive treatment. They also had lower scores on serious psychological distress $(M=15.44, S E=.43)$ than nontreatment recipients $(M=15.62, S E=.29)(p<.001)($ see Table 9). Pregnant women with substance use disorders who received substance use treatment were significantly more likely to have illicit drug abuse or dependence $(p=.002)$ and have comorbid depression/anxiety and substance use disorders $(p=.007)$ compared to those who did not receive the treatment (see Table 10).

\section{Predictors of Mental Health/Substance Use Treatment}

A binary logistic regression analysis was conducted to examine the ability of variables to predict the likelihood of the receipt of mental health treatment. The full model contained 14 variables: five predisposing characteristics, three enabling, and six need factors. Using backward elimination, variables were removed one at a time according to the least significant $p$-value in the following order: income, age, self-rated health status, substance use disorders, urban residency, employment status, perceived need for treatment, and marital status. In the final model, ethnicity, educational level, health insurance status, past-year serious psychological distress, MDE, and anxiety 
disorder provided the best predictive model of the receipt of mental health treatment. Both the AIC and BIC were assessed to choose the more parsimonious final model.

The adjusted odds ratios in the final model (see Table 11) indicated that anxiety disorder was the strongest predictor of the receipt of mental health treatment. After controlling for other variables in the model, pregnant women with past-year anxiety disorder had over 17 times the odds of the receipt of mental health treatment compared with those who did not have anxiety (Adjusted Odds Ratio [AOR]: 17.34; 95\% Confidence Interval [CI]: 8.64-34.81). Compared to White pregnant women, African Americans (AOR: $.38 ; 95 \% \mathrm{CI}=.20-.74$ ) and other NonHispanics (AOR: .17; 95\% CI: .05-.59) had much lesser odds of mental health treatment receipt. Pregnant women who had a college education had almost three times the odds of mental health treatment receipt compared to those who had less than a high school education (AOR: 2.84; $95 \%$ CI $=1.36-5.91)$. MDE (AOR: 2.48; CI: 1.44-4.27) and health insurance coverage (AOR: 2.34; 95\% CI: 1.16-4.71) increased the likelihood of mental health treatment receipt. After adjusting other variables in the model, for a one-unit increase in the psychological distress score, the odds of mental health treatment receipt increased significantly by 1.06 times (95\% CI: $1.003-1.12)$.

To predict the likelihood of the receipt of substance use treatment, the full regression model contained 13 variables: five predisposing characteristics, three enabling factors, and five need factors. Backward elimination was used to remove one variable at a time based on the least significant $p$-value in the following order: educational level, employment, health insurance, marital status, perceived need, age, income, and self-rated health status. In the final model, ethnicity, urban residency, alcohol use disorders, illicit 
drug use disorders, and comorbid mental health and substance use disorders were the best predictors of the receipt of substance use treatment. The AIC and BIC were assessed to choose the best predictive model.

After controlling for other variables in the final model (see Table 12), illicit drug dependence was the strongest predictor of the likelihood of substance use treatment (AOR: 8.83, 95\% CI: 3.10-25.16), followed by illicit drug abuse (AOR: 7.89, 95\% CI: 1.81-34.4), large urban residency (versus small urban) (AOR: 4.40, 95\% CI: 1.82-10.62), comorbid depression/anxiety and substance use disorders (AOR: 3.13, 95\% CI: 1.407.02), alcohol use dependence (AOR: $2.99,95 \%$ CI: 1.37-6.49), and finally nonWhite ethnicity (vs. Whites) (AOR: .39, 95\% CI: .19-.80).

\section{Ethnic Disparities in Mental Health Treatment Receipt}

Regardless of mental health or substance use disorders and ethnicity background, a higher percentage of pregnant women received prescription drugs or outpatient counseling rather than inpatient treatment (see Table 13). Overall, nonWhite pregnant women with mental health and/or substance use disorders were less likely to receive any mental health treatment, outpatient mental health treatment, or prescription drugs than Whites. NonWhite pregnant women with serious psychological distress were significantly less likely to receive any mental health treatment $(23.8 \%$ vs. $47.3 \%)(p<$ $.001)$ or prescription drugs $(18.2 \%$ vs. $37.7 \%)(p<.001)$. Compared to nonWhites, White

pregnant women with substance use disorders $(31.3 \%$ vs. $18.5 \% ; p=.019)$ and comorbid mental health and substance use disorders $(54.8 \%$ vs. $30.7 \% ; p=.003)$ were more likely to receive any mental health treatment. 


\section{Bivariate associations with ethnicity and predisposing, enabling, and need}

factors. White pregnant women with any mental health problem were more likely to be age of $26-44$ years $(57.3 \%$ vs. $42.3 \%)(p=.008)$, married $(53.3 \%$ vs. $31.7 \%)(p<.001)$, and college graduates $(56.1 \%$ vs. $40 \%)(p=.005)$; have a family income of $\geq \$ 50,000$ $(48.2 \%$ vs. $19.1 \%)(p<.001)$; and live in nonmetropolitan and small urban areas $(62.5 \%$ vs. 40.5) ( $p<.001)$. The same pattern of the relationship was found between ethnicity (Whites vs. nonWhites) and age of $26-44$ (58.1\% vs. $41.4 \%(p=.018)$, married-marital status $(56.6 \%$ vs. $31.2 \%)(p<.001)$, college education $(60.1 \%$ vs. $41.3 \%)(p=.033)$, income of $\geq \$ 50,000(45.7 \%$ vs. $16.3 \%)(p<.001)$, and small urban and nonmetropolitan residency $(68.4 \%$ vs. $38.5 \%)(p=.001)$ in pregnant with MDE. Similarly, 26-44 years age $(54.1 \%$ vs. $39.2 \%)(p=.018)$, married-marital status $(51.3 \%$ vs. $30.5 \%)(p<.001)$, high income ( $45.7 \%$ vs. $16.3 \%)$ ( $p<.001)$, and large urban residency (39.1\% vs. $58.9 \%)$ $(p=.001)$ differentiated White and nonWhite ethnicity in pregnant women with serious psychological distress.

Likewise, compared to nonWhites, White pregnant women with substance use disorders were more likely to be $26-44$ years old $(54.0 \%$ vs. $35.5 \%)(p=.012)$, have a college education (59.7\% vs. $42.2 \%)(p=.030)$, and income of $\geq \$ 50,000$ (50.3\% vs. $27.0 \%)(p=.002)$, and live in small urban and nonmetropolitan residency (55.8\% vs. $37.8 \%)(p=.015)$. Yet, only large urban residency $(61.1 \%$ vs. $31.3 \%)(p=.002)$ and high income level (23.1\% vs. $48.8 \%)(p=.002)$ differentiated nonWhite and White ethnicity among women with comorbid mental health and substance use disorders, respectively. Finally, there was no significant association between ethnicity and self-rated health status 
and severity of distress symptoms in pregnant women, regardless of the type of mental health and/or substance use disorders.

Odds of mental health treatment receipt. Unadjusted and adjusted logistic regression models were constructed for MDE, anxiety disorder, serious psychological distress, substance use disorders, and comorbid mental health and substance use disorders to examine the effect of ethnicity on mental health treatment receipt. As indicated in Table 14, after controlling predisposing, enabling, and need factors in the model, nonWhite pregnant women with MDE (AOR: .49, 95\% CI: .27-.92), serious psychological distress (AOR: .34, 95\% CI: .20-.59), substance use disorders (AOR: .46, 95\% CI: .23-.93), and comorbid mental health and substance use disorders (AOR: .27, 95\% CI: .13-.57) had a much lower odds of receipt of mental health treatment compared to Whites.

\section{Perceived Barriers to Mental Health Treatment}

Among pregnant women who perceived need for treatment because of mental health, substance use disorders, and comorbid mental health and substance use disorders, respectively, cost $(52.8 \%, 57.5 \%, 54.8 \%)$, opposition to treatment $(40.6 \%, 45.2 \%$, $43.2 \%)$, and stigma $(22.6 \%, 38.1 \%, 36.7 \%)$ were the most frequent self-reported barriers to mental health treatment (see Table 15). Pregnant women with MDE were significantly more likely to self-report cost $(p=.025)$ and not knowing where to go $(p=.002)$ as barriers to mental health treatment compared to those without depressive episode. However, depressed pregnant women were less likely to have opposition to treatment compared to non-depressed women $(p=.012)$. Pregnant women with anxiety disorder were more likely to perceive time/transportation limitations to the receipt of mental 
health treatment compared with those without anxiety $(p=.014)$. Pregnant women who perceived a need for treatment and had substance use disorders $(p<.001)$ or comorbid mental health and substance use disorders $(p=.035)$ were significantly more likely to experience stigma to mental health treatment receipt in comparison with those without these disorders.

White and nonWhite pregnant women with mental health problems did not differ in the perceived barriers of: opposition to treatment, time/transportation limitations, and not knowing where to go (see Figure 9). However, White pregnant women were significantly more likely to perceive cost as a barrier to mental health treatment. Although Whites were less likely to self-report stigma as a barrier to mental health treatment compared to nonWhites, the difference was not significant. There were no significant differences in perceived barriers to mental health treatment among White and nonWhite pregnant women with substance use disorders (see Figure 10) or comorbid mental health and substance disorders (see Figure 11).

\section{Discussion}

Despite their needs, pregnant women with mental health and substance use disorders had low rates of mental health and substance use treatment receipt. In this study, $45 \%$ of pregnant women with mental health problems received mental health treatment and only $13 \%$ of those with substance use disorders received substance use treatment. These rates are comparable with rates reported in studies based on the NSDUH addressing mental health treatment (Glasheen et al., 2015; Ko et al., 2012) and substance use treatment (Terplan et al., 2010) and vary in comparison with other population-based studies focusing on mental health treatment (Cook et al., 2010; Le Strat et al., 2011; 
Rosen et al., 2004; Song et al., 2004; Vesga-Lopez et al., 2008). For instance, studies based on the NESARC reported lower rates of mental health treatment (6.1\% to $26.5 \%)$ (Le Strat et al., 2011; Vesga-Lopez, 2008).This discrepancy may be due to differences between the NSDUH and NESARC (as well as other surveys) in the survey design and measures used to assess mental health and substance use disorders (e.g., DSM-IV based self-report instrument in the NSDUH vs. diagnostic interview in the NESARC).

Nevertheless, the gap between the need for and receipt of treatment has been found consistently across studies of pregnant women with these complex health issues (Cook et al., 2010; Glasheen et al., 2015; Le Strat et al., 2011, Rosen et al., 2004, Song et al., 2004, Vesga-Lopez et al., 2008), suggesting an urgent call to address their needs.

\section{Predisposing and Enabling Predictors of Treatment Receipt}

Of the predisposing characteristics, only ethnicity predicted the receipt of both mental health treatment and substance use treatment. African Americans and other nonHispanics had a lower odds of the receipt of mental health treatment; nonWhite pregnant women with substance use disorders had .39 times the odds of substance use treatment receipt, yet only after controlling for other variables in the model. This ethnic disparity in treatment receipt is consistent with prior population-based studies (Chang et al., 2016; Geier et al., 2015; Glasheen et al., 2015; McCabe \& Arndt, 2012; Song et al., 2004).

Educational level and health insurance coverage predicted the receipt of mental health treatment but not substance use treatment. This supports findings of prior research, namely that perinatal women with mental health issues who received mental health treatment, compared to those who did not receive any treatment, were more likely to have a higher educational level (Glasheen et al., 2015) and health insurance coverage 
(Glasheen et al., 2015; Smith et al., 2009). In this study health insurance was not related to the receipt of substance use treatment which may be due to the homogenous sample of pregnant women who had health insurance. Other possible explanations for the differences in how health insurance differentiated the receipt of mental health treatment versus substance use treatment may include that: (a) health insurance benefits tend to cover mental health care rather substance use treatment (Clark, Power, Le Fauve, \& Lopez, 2008); and (b) some Medicaid programs do not cover treatment for substance use disorders which also hinders the access to treatment (CSAT, 2009).

The findings are congruent with prior clinical studies in indicating no significant relationship between educational level and substance use treatment receipt (Haller et al., 2001; Messer et al., 1996; Wolton-Moss et al., 2006), although in contrast, Terplan et al. (2012) found that higher educational level predicted receipt of substance use treatment. Although income was significantly associated with the receipt of mental health treatment, it was not one of the predictors of treatment receipt in the final model. This indicates that there were stronger predictors (e.g., health insurance) that increased the likelihood of the receipt of mental health treatment in this study sample.

After controlling for other predisposing and need factors, large urban residency increased the probability of substance use treatment receipt. This finding extends the growing evidence on the effect of residency on pregnant women's ability to access treatment (Heil et al., 2008; Jackson \& Shannon, 2012b). Interestingly, the urban residency was not associated with the receipt of mental health treatment, suggesting that substance use treatment programs are less available than mental health services and therefore this creates a greater challenge to access treatment (CSAT, 2009). A review of 
literature indicates that individuals residing in rural areas have distinctive beliefs, attitudes, and financial constrains that might influence their access to substance use treatment (Fortney \& Booth, 2001). There is a need for more research that sheds the lights on factors influencing the likelihood rural pregnant women seek treatment.

Maternal age was not associated with substance use treatment, yet it differentiated the receipt of mental health treatment but not after controlling other variables in the regression model. Similarly, previous studies of the relationships of receipt of mental health and substance use treatment with maternal age (Flynn et al., 2006; Glasheen et al., 2015; McCabe \& Arndt, 2012; Messer et al., 1996; Rosen et al., 2004), employment status (Flynn et al., 2006; Glasheen et al., 2015; Goodman, 2009; Haller et al., 2001; Messer et al., 1996; Smith et al. 2009; Terplan et al., 2012), and marital status (Flynn et al., 2006; Glasheen et al., 2015; Messer et al., 1996; Smith et al. 2009; Terplan et al., 2012) are inconclusive. The current study adds to the literature by shedding light on these relationships.

\section{Need Factors Predicting Treatment Receipt}

To date, little is known regarding how perceived need for treatment contributes to the receipt of treatment in pregnant women. In a clinical sample of perinatal women, only $40 \%$ of those who perceived a need for treatment of depression or anxiety received that treatment (Goodman \& Tyer-Viola, 2010). Yet, perceived need for mental health treatment in the present study failed to be in the final best predictive model, suggesting that other predisposing, enabling, and need factors are more significant predictors of the receipt of mental health treatment. Unfortunately, in the present study, the majority of pregnant women with substance use disorders (96\%) did not perceive a need for 
treatment and did not receive it. Importantly, pregnant women with substance use disorders continue to deny their needs for treatment which serves as an obstacle to treatment (CSAT, 2009).

Need factors markedly differentiated the receipt of mental health and substance use treatment. Anxiety disorder was the strongest predictor of the receipt of mental health treatment, accounting for other predisposing and enabling factors in the model. It had almost 17 times the odds of receipt of mental health treatment, while MDE and serious psychological distress (for one-unit increase) had 2.48 and 1.06 times the odds of treatment receipt, respectively. There are no previous population-based studies comparable to this study with respect to the design and sample to contrast these findings. The only NSDUH-based study that has focused on examining predictors of mental health treatment receipt among childbearing-aged women with past-month serious psychological distress showed that anxiety disorder had 3.5 times the odds of mental health treatment while depression disorder had 5.5 times the odds, controlling for pregnancy status (Glasheen et al., 2015). However, depression disorder was measured in this study based on the self-report of receiving a diagnosis of depression rather than meeting the $D S M-I V$ criteria for MDE, and therefore the differences in the measures and sample may contribute to the discrepancy in the results between our study and Glasheen's et al. (2015) study. Of studies conducted solely among pregnant women, Byatt, Xiao, Dinh, and Waring (2016) found that pregnant women with depressive symptoms who participated in the National Health and Nutrition Examination Survey 2005-2012 had higher odds of mental health care compared to those without depressive symptoms. 
Consistent with another population-based study (Le Strat et al., 2011), comorbid mental health and substance use disorders were not associated with the receipt of mental health treatment in childbearing-aged women. However, in this study, pregnant women with comorbid mental health and substance use disorders had 3.13 the odds of substance use treatment receipt. This is reflected in a clinical study that showed that despite pregnant women's need for mental health treatment they only received a substance usefocused treatment (Coleman-Cowger, 2012).

The results of this study also echo those of other studies that examined the associations among the type and severity of substance use and substance use treatment, namely that drug use disorders increased the likelihood of substance use treatment in pregnant women (Haller et al., 2001; Messer et al. 1996; Wolton-Moss et al., 2006). In this study, illicit drug dependence rather than abuse was the strongest predictor of the receipt of substance use treatment. It had 8.83 the odds of the receipt of treatment while abuse had 7.89 the odds. Furthermore, only alcohol dependence but not abuse predicted the receipt of treatment. A study based on the Treatment Episode Data Set (TEDS) 19982008 showed that there was an increase in the treatment rate for illicit drug disorder while a decline for alcohol use disorder in women of childbearing age and particularly among pregnant women (McCabe \& Arndt, 2012). The link between substance dependence diagnoses and treatment receipt was anticipated because dependence is associated with more problems related to substance use (Dawson, Saha, \& Grant, 2010). On the other hand, this may indicate that pregnant women did not access treatment until the severity of their substance use became paramount, suggesting a delayed access to treatment due to numerous barriers (CSAT, 2009). Given that alcohol abuse was the most common 
substance use disorder among pregnant women in the current study, screening and brief intervention are recommended to help pregnant women decrease antenatal alcohol consumption (Marais et al., 2011).

\section{Ethnic Disparities in Mental Health Treatment}

Consistent with previous research (Chang et al., 2016; Coleman-Cowger, 2012;

Geier et al., 2015; Glasheen et al., 2015; Song et al., 2004), nonWhite pregnant women were less likely to receive any mental health treatment compared to Whites. Interestingly, the data in the present study showed that nonWhite pregnant women compared with Whites were less likely to receive prescription drugs for mental health and substance use problems and this relationship was significant among those with serious psychological distress. Research findings also indicate that ethnic minorities in the general population (Cooper et al., 2003) and in pregnant women (Goodman, Dimidjian, \& Williams, 2013; Yamamoto, McCormick, \& Burris, 2015) are less likely to find prescription drugs acceptable to treat mental health problems, suggesting negative cultural beliefs toward treatment.

Aggregating data for seven years of the NSDUH enabled examination of ethnic differences in the receipt of any mental health treatment, controlling for predisposing, enabling, and need factors. Among White and nonWhite pregnant women with mental health and/or substance use disorders, the findings indicated differential pattern in the receipt of mental health treatment. NonWhite pregnant women were less likely to receive any mental health treatment for MDE and serious psychological distress. These differences were reflected in other studies in which ethnicity was examined as a correlates of treatment receipt (Geier et al., 2015; Glasheen et al., 2015) and in another 
study that focused explicitly on ethnic care disparities among pregnant women with depressive symptoms (Chang et al., 2016). However, in the current study there were no differences between White and nonWhite pregnant women with anxiety disorder in the receipt of mental health treatment. This can be due to recall bias in reporting anxiety disorder, as this study relied only on one item addressing whether participants received a diagnosis of anxiety disorder in the past year. In addition, this can be also explained by the fact that ethnic minorities, particularly African Americans, tend to voluntary seek treatment specifically for anxiety-like symptoms, whether from a physician or mental health specialists, or in an emergency room (Snowden, 2001). Therefore, this might account for the discrepancy between the two groups.

This study also extends prior research that has studied ethnic care disparities (Chang et al .2016; Song et al., 2004) in emphasizing that nonWhite pregnant women are less likely to use mental health treatment for substance use disorders and comorbid mental health and substance use disorders. This finding is consistent with those of a study in which Black women with substance use disorders did not receive mental health treatment despite their needs compared to Whites (Coleman-Cowger, 2012).

The current study showed that the greatest ethnic care discrepancy was for comorbid mental health and substance use disorders. NonWhite pregnant women had .27 times the odds of receipt of treatment compared to Whites. Taking the inverse of these odds, White pregnant women were almost four times more likely to receive mental health treatment compared to nonWhites. It is noteworthy, that even after applying the formal correction for multiple comparison, the differences in mental health treatment for comorbid mental health and substance use disorders would still have been significant $(p=$ 
.001). Furthermore, it is of particular interest that ethnic disparities in the receipt of mental health treatment persisted after controlling other characteristics and particularly indicators of socioeconomic status. This perennial problem of mental health disparities for ethnic and racial minorities has remained for decades in the United States (Leong \& Kalibatseva, 2011; Snowden, 2012), suggesting that significant changes should be made in the mental health care system, especially for pregnant women.

\section{Perceived Barriers to Mental health treatment}

The common barriers reported by pregnant women in this study included perceived cost, opposition to treatment, and stigma, regardless of their disorder, i.e., mental health and/or substance use disorders, and ethnicity. This perception is also common among pregnant women from clinical samples (Battle et al., 2013; Goodman, 2009; Jesse et al., 2008; Kim et al., 2010; Kopelman et al., 2008) and the general population (Ko et al., 2012).

Pregnant women who perceived a need for mental health treatment because of MDE were significantly more likely to report cost and not knowing where to go as barriers to mental health treatment. This is congruent with research reports that focused specifically on women with depressive symptoms (Kim et al., 2010; Kopelman et al., 2008). However, in contrast with these studies, the current study showed that pregnant women with MDE compared to those without depression but with a perceived need for treatment were significantly less likely to have an opposition to treatment. This suggests that depressive symptoms may motivate pregnant women to accept treatment. However, research suggests that depression or anxiety disorders of pregnant women, despite their perceived need for mental health treatment, are unidentified by clinicians (Goodman \& 
Tyer-Viola, 2010). Moreover, findings from clinical samples proposed that care providers themselves are reluctant to provide mental health treatment to pregnant women, particularly pharmacotherapy, which creates additional barriers to treatment receipt (Byatt, Biebel, Debordes-Jackson, et al., 2013; Weinreb, Byatt, Moore Simas, Tenner, \& Savageau, 2014).

Although little is known regarding barriers to mental health treatment specifically in pregnant women with anxiety disorders, this study extends prior research in demonstrating that time/transportation limitations are significant barriers perceived by these women. Similarly, time was the most common barrier to receive treatment for anxiety or depression among a clinical sample of perinatal women (Goodman, 2009). In addition, results from the NCS-R showed that transportation significantly impeded the receipt of mental health treatment in respondents from the general population with moderate to severe mental illness (Mojtabai et al., 2011).

Pregnant women with substance use disorders and comorbid substance use disorders were more likely to perceive stigma as a barrier to mental health treatment. The CSAT (2009) also reported that stigma linked with substance use among pregnant women impeded the access to treatment. The current study signifies the role of stigma when these women have specific mental health needs because of substance use issues.

Despite ethnic disparities in the receipt of mental health treatment, perceived barriers to treatment were similar among White and nonWhite pregnant women with substance use disorders and comorbid mental health and substance use disorders. However, compared to nonWhites, White pregnant women with mental health problems were more likely to perceive cost as a barrier to mental health treatment. Although 
nonWhite pregnant women had lower income compared to Whites, those who are poor are eligible to Medicaid (American Pregnancy Association, 2017) and therefore this may lessen their perception of financial constrains with respect to mental health treatment. In addition, regardless of health insurance status, ethnic minorities often believe that they can treat their mental illness through willpower and evading morbid thoughts rather than seeking mental health treatment (Snowden, 2001). Moreover, most of the White pregnant women in this sample were married which means that they may face more financial constrains when they are in need to access mental health treatment. Consistently, Mojtabai et al. (2011) found that married respondents in the NCS-R had higher odds of reporting structural barriers (e.g., financial barrier) to mental health treatment than unmarried respondents from the general population.

A higher percentage of nonWhite pregnant women with mental health problems perceived stigma as a barrier to mental health treatment than Whites, although the difference between these two groups was not significant. This is similar to the perception in the general population in the United States (Leong \& Kalibatseva, 2011). Yet, the data in this study showed an opposite pattern in which White pregnant women with substance use disorders perceived stigma as a greater barrier than nonWhites. Although the difference was not significant, it is consistent with one population-based study that reported nonBlacks with alcohol use disorders were more likely to report stigma as a reason for not seeking substance use treatment than Blacks (Grant, 1997). The findings of the current study provide an interesting perspective in regards how ethnicity and type of disorder relate to the perception of stigma as a barrier to mental health treatment. Further clinical and population-based studies are needed to examine how cultural and 
predisposing beliefs shape the access to treatment across ethnic groups of pregnant women.

\section{Limitations}

The NSDUH measured pregnant at the time of interview but assessed mental health and substance use disorders in the past year so that these problems may not have occurred during pregnancy. Second, the diagnosis of pregnancy was based on self-report; thus, recall bias may affect the estimation of the number of pregnant women in this survey. Social desirability effect might cause pregnant women to be reluctant to disclose issues related to mental health and substance use issues. However, the NSDUH uses computer-assisted interviews to lessen this bias. Fourth, the NSDUH measures MDE and substance use disorders using a $D S M-I V$ based self-report instrument rather than clinical interview which may introduce bias. This bias may be increased in measuring anxiety disorder as this depended on one self-report item--receiving a diagnosis from a health care provider.

Although aggregating data allowed examination predictors of mental health receipt, caution should be taken when interpreting the predictors of substance use treatment due to the small sample size of pregnant women who received the treatment. In addition, even though this study sheds light on ethnic care disparities, the small sample sizes in ethnic groups led us to group them in only two categories (nonWhites vs. Whites). This study also focused on any mental health treatment rather than specific treatment modalities when examining predictors of treatment and ethnic care disparities. Finally, the NSDUH is a cross-sectional survey; thus, cause-effect relationships cannot be drawn. 


\section{Recommendations}

These findings reinforce that low rates of treatment receipt for mental health and substance use disorders remain a significant public health problem among pregnant women in the United States. Given that anxiety disorder and illicit drug dependence are the best predictors of mental health and substance use treatment, respectively, pregnancy provides a unique opportunity not only to screen but also to intervene with pregnant women who have these and other mental health and substance use problems. The findings from the present study document ethnic care disparities, suggesting the need for public education and preventive and interventional strategies to address the needs of ethnic minority pregnant women.

Expansion of health insurance coverage for mental health treatment is essential as cost was the most common barrier to treatment. Screening, outreach, and treatment efforts should focus on pregnant women with substance use disorders to increase recognition and early treatment. As stigma is attached to substance use disorders, it is important to educate health care providers regarding prenatal substance use and traumainformed care (SAMHSA, 2014c), thus facilitating the receipt of treatment.

Further research is needed to understand cultural and belief barriers to mental health treatment as perceived by ethnic minorities. In addition, future research is recommended to examine the association between the receipt of mental health and substance use treatment.

Finally, the Behavioral Model of Health Services Use of Andersen (1995) was useful in predicting the receipt of mental health/substance use treatment given predisposing, enabling, and need factors among pregnant women with mental health/ 
substance use disorder. It also identified ethnic disparities in the receipt of mental health treatment among these women and thereby can be used to guide future research addressing a vulnerable population of pregnant women. 
Table 8

Socio-demographic Characteristics of Pregnant Women Aged 18-44, NSDUH 2008$2014(N=5,520)$

\begin{tabular}{|c|c|c|c|}
\hline Characteristics & Categories & Weighted \% & $\mathrm{SE}$ \\
\hline \multirow[t]{2}{*}{ Age in years } & $18-25$ & 37.4 & 1.0 \\
\hline & $26-44$ & 62.6 & 1.0 \\
\hline \multirow[t]{4}{*}{ Ethnicity } & White & 58.8 & 1.2 \\
\hline & African American & 14.2 & 0.8 \\
\hline & Other nonHispanic ${ }^{a}$ & 8.6 & 0.6 \\
\hline & Hispanic & 18.3 & 0.9 \\
\hline \multirow[t]{2}{*}{ Marital status } & Married & 60.7 & 1.1 \\
\hline & Unmarried & 39.3 & 1.1 \\
\hline \multirow[t]{3}{*}{ Education } & $\begin{array}{l}\text { Less than high } \\
\text { school }\end{array}$ & 15.4 & 0.7 \\
\hline & High school & 26.0 & 0.9 \\
\hline & College graduate & 58.6 & 1.0 \\
\hline \multirow[t]{2}{*}{ Employment status } & Employed & 93.1 & 0.5 \\
\hline & Unemployed & 6.9 & 0.5 \\
\hline \multirow[t]{4}{*}{ Family income } & $<\$ 20,000$ & 22.4 & 0.9 \\
\hline & $\$ 20,000-49,999$ & 30.4 & 1.1 \\
\hline & $\$ 50,000-\$ 74,999$ & 17.1 & 0.7 \\
\hline & $\geq \$ 75,000$ & 30.1 & 1.1 \\
\hline \multirow[t]{2}{*}{ Health insurance } & Insured & 90.2 & 0.5 \\
\hline & Uninsured & 9.8 & 0.5 \\
\hline \multirow[t]{3}{*}{ County urbanicity } & Large urban & 53.2 & 1.2 \\
\hline & Small urban & 31.8 & 1.0 \\
\hline & Nonmetro & 15.0 & 0.7 \\
\hline \multirow[t]{2}{*}{$\begin{array}{l}\text { Self-rated health } \\
\text { status }\end{array}$} & $\begin{array}{l}\text { Excellent/very } \\
\text { good/good }\end{array}$ & 95.1 & 0.4 \\
\hline & Fair/poor & 4.9 & 0.4 \\
\hline
\end{tabular}

Note. Imputed and recoded variables were used. Frequencies and weighted percentages do not include missing data addressing mental health. NSDUH = National Survey on Drug Use and Health; SE = Standard Error.

${ }^{a}$ Other nonHispanics included Native American/Alaska Native, Native Hawaiian/Pacific Islander, Asian, and more than one race. 
Table 9

Characteristics Associated with Receipt of Mental Health Treatment among Pregnant Women with Mental Health Problems Aged 18-44 Years, NSDUH 2008-2014 $(N=1,106)$

\begin{tabular}{|c|c|c|c|c|c|}
\hline \multirow[b]{2}{*}{ Characteristics } & \multirow[b]{2}{*}{$\begin{array}{c}\text { Total Sample } \\
\text { Wt. \% (SE) }\end{array}$} & \multicolumn{2}{|c|}{$\begin{array}{c}\text { Receipt of Mental Health } \\
\text { Treatment }\end{array}$} & \multirow[b]{2}{*}{$\chi^{2}$} & \multirow[b]{2}{*}{$\begin{array}{c}p- \\
\text { value }\end{array}$} \\
\hline & & $\begin{array}{c}\text { Yes }(n=453) \\
\text { Wt. \% (SE) }\end{array}$ & $\begin{array}{l}\text { No }(n=650) \\
\text { Wt. } \%(\mathrm{SE})\end{array}$ & & \\
\hline \multicolumn{6}{|l|}{ Age in years } \\
\hline $18-25$ & $47.7(2.4)$ & $39.3(3.4)$ & $54.5(3.0)$ & 25.15 & .001 \\
\hline $26-44$ & $52.3(2.4)$ & $60.7(3.4)$ & $45.5(3.0)$ & & \\
\hline \multicolumn{6}{|l|}{ Ethnicity } \\
\hline White & $66.9(2.2)$ & $79.7(2.9)$ & $56.7(3.1)$ & 66.82 & $<.001$ \\
\hline African American & $12.7(1.6)$ & $6.8(1.6)$ & $17.3(2.5)$ & & \\
\hline Other NonHispanic ${ }^{a}$ & $5.2(0.9)$ & $2.8(0.9)$ & $7.1(1.5)$ & & \\
\hline Hispanic & $15.2(1.5)$ & $10.7(2.1)$ & $18.8(2.3)$ & & \\
\hline \multicolumn{6}{|l|}{ Marital status } \\
\hline Married & $46.3(2.8)$ & $54.4(3.6)$ & $39.8(4.3)$ & 23.31 & .013 \\
\hline Unmarried & $53.7(2.8)$ & $45.6(3.6)$ & $60.2(4.3)$ & & \\
\hline \multicolumn{6}{|l|}{ Education } \\
\hline$<$ High school & $18.3(1.4)$ & $14.0(2.2)$ & $21.7(2.1)$ & 31.39 & .002 \\
\hline High school & $31.0(2.1)$ & $25.9(3.2)$ & $35.1(3.0)$ & & \\
\hline College graduate & $50.7(2.1)$ & $60.1(3.7)$ & $43.2(2.9)$ & & \\
\hline \multicolumn{6}{|l|}{ Employment status } \\
\hline Employed & $90.4(1.1)$ & $91.1(1.6)$ & $89.9(1.6)$ & .47 & .593 \\
\hline Unemployed & $9.6(1.1)$ & $8.9(1.6)$ & $10.1(1.6)$ & & \\
\hline \multicolumn{6}{|l|}{ Family income } \\
\hline$<\$ 20,000$ & $28.8(2.2)$ & $24.7(2.8)$ & $32.1(3.1)$ & 31.83 & .008 \\
\hline$\$ 20,000-\$ 49,999$ & $32.5(2.2)$ & $27.6(2.8)$ & $36.5(3.2)$ & & \\
\hline$\$ 50,000-\$ 74,999$ & $15.6(1.8)$ & $18.0(3.2)$ & $13.7(2.1)$ & & \\
\hline$\geq \$ 75,000$ & $23.0(2.3)$ & $29.7(3.5)$ & $17.7(2.9)$ & & \\
\hline \multicolumn{6}{|l|}{ Health insurance } \\
\hline Insured & $88.0(1.6)$ & $91.3(1.9)$ & $85.4(2.3)$ & 8.93 & .036 \\
\hline Uninsured & $12.0(1.6)$ & $8.7(1.9)$ & $14.6(2.3)$ & & \\
\hline \multicolumn{6}{|l|}{ County urbanicity } \\
\hline Nonmetropolitan & $18.8(1.6)$ & $21.2(2.4)$ & $16.9(2.0)$ & 3.52 & .445 \\
\hline Small & $36.4(2.5)$ & $36.2(3.5)$ & $36.6(3.3)$ & & \\
\hline Large & $44.7(2.5)$ & $42.6(3.8)$ & $46.5(3.5)$ & & \\
\hline
\end{tabular}




\begin{tabular}{|c|c|c|c|c|c|}
\hline \multirow[b]{2}{*}{ Characteristics } & \multirow[b]{2}{*}{$\begin{array}{l}\text { Total Sample } \\
\text { Wt. \% (SE) }\end{array}$} & \multicolumn{2}{|c|}{$\begin{array}{c}\text { Receipt of Mental Health } \\
\text { Treatment }\end{array}$} & \multirow[b]{2}{*}{$\chi^{2}$} & \multirow[b]{2}{*}{$\begin{array}{c}p- \\
\text { value }\end{array}$} \\
\hline & & $\begin{array}{l}\text { Yes }(n=453) \\
\text { Wt. \% (SE) }\end{array}$ & $\begin{array}{c}\text { No }(n=650) \\
\text { Wt. } \%(\mathrm{SE})\end{array}$ & & \\
\hline \multicolumn{6}{|l|}{$\begin{array}{l}\text { Self-rated health } \\
\text { status }\end{array}$} \\
\hline Poor/fair & $10.4(1.4)$ & $9.0(2.0)$ & $11.5(2.1)$ & 1.84 & .400 \\
\hline Excellent/very/good & $89.6(1.4)$ & $91.0(2.0)$ & $88.5(2.1)$ & & \\
\hline \multicolumn{6}{|l|}{$\begin{array}{l}\text { Perceived need for } \\
\text { treatment }\end{array}$} \\
\hline Yes & $28.1(2.5)$ & $36.2(3.6)$ & $21.6(2.7)$ & 28.69 & $<.001$ \\
\hline No & $71.9(2.5)$ & $63.8(3.6)$ & $78.4(2.7)$ & & \\
\hline $\begin{array}{l}\text { Serious psychological } \\
\text { distress (Mean, SE) }\end{array}$ & $15.54(.24)$ & $15.44(.43)$ & $15.62(.29)$ & 65.68 & $<.001$ \\
\hline \multicolumn{6}{|l|}{$\begin{array}{l}\text { Major depressive } \\
\text { episode }\end{array}$} \\
\hline Yes & $33.9(2.3)$ & $39.6(3.5)$ & $29.4(2.6)$ & 12.50 & .014 \\
\hline No & $66.1(2.3)$ & $60.4(3.5)$ & $70.6(2.6)$ & & \\
\hline \multicolumn{6}{|l|}{ Anxiety disorder } \\
\hline Yes & $33.6(2.0)$ & $59.1(3.3)$ & $13.2(1.8)$ & 256.05 & $<.001$ \\
\hline No & $66.4(2.0)$ & $40.9(3.3)$ & $86.8(1.8)$ & & \\
\hline \multicolumn{6}{|l|}{$\begin{array}{l}\text { Substance use } \\
\text { disorder }^{\text {b }}\end{array}$} \\
\hline Yes & $20.0(1.7)$ & $20.3(2.4)$ & $19.8(2.2)$ & .03 & .893 \\
\hline No & $80.0(1.7)$ & $79.7(2.4)$ & $80.2(2.2)$ & & \\
\hline \multicolumn{6}{|c|}{ 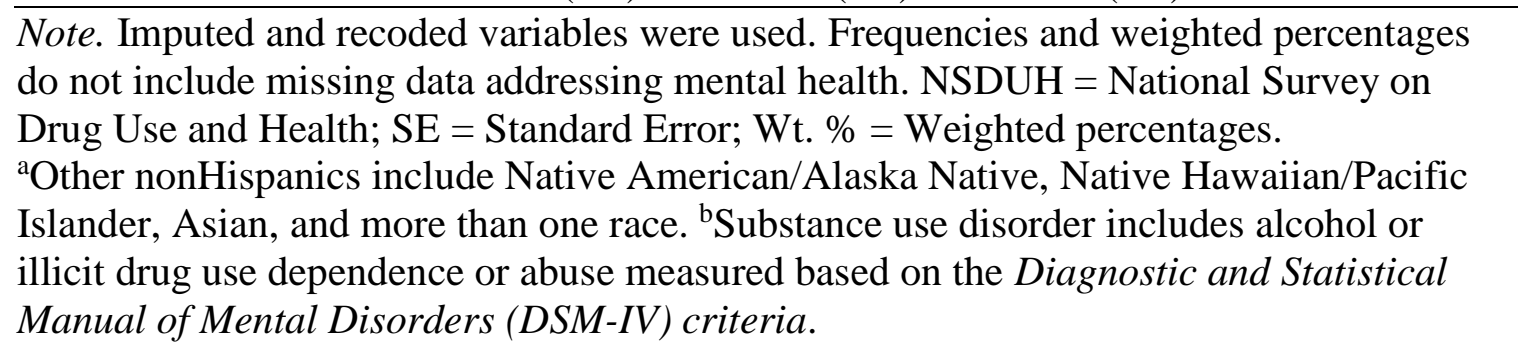 } \\
\hline
\end{tabular}


Table 10

Characteristics Associated with Receipt of Substance Use Treatment among Pregnant

Women with Substance Use Disorders Aged 18-44 Years, NSDUH 2008-2014 (N = 521)

\begin{tabular}{|c|c|c|c|c|c|}
\hline \multirow[b]{2}{*}{ Characteristics } & \multirow[b]{2}{*}{$\begin{array}{l}\text { Total Sample } \\
\text { Wt. \% (SE) }\end{array}$} & \multicolumn{2}{|c|}{$\begin{array}{c}\text { Receipt of Substance Use } \\
\text { Treatment }\end{array}$} & \multirow[b]{2}{*}{$\chi^{2}$} & \multirow[b]{2}{*}{$\begin{array}{c}p- \\
\text { value }\end{array}$} \\
\hline & & $\begin{array}{l}\text { Yes }(n=68) \\
\text { Wt. } \%(\mathrm{SE})\end{array}$ & $\begin{array}{c}\text { No }(n=453) \\
\text { Wt. \% }(\mathrm{SE})\end{array}$ & & \\
\hline \multicolumn{6}{|l|}{ Age in years } \\
\hline $18-25$ & $53.2(3.5)$ & $51.1(9.2)$ & $53.5(3.5)$ & \multirow[t]{2}{*}{.15} & \multirow[t]{2}{*}{.789} \\
\hline $26-44$ & $46.8(3.5)$ & $48.9(9.2)$ & $46.5(3.5)$ & & \\
\hline \multicolumn{6}{|l|}{ Ethnicity } \\
\hline White & $60.9(3.1)$ & $66.1(7.3)$ & $60.1(3.4)$ & \multirow[t]{2}{*}{.89} & \multirow[t]{2}{*}{.480} \\
\hline NonWhite $^{\mathrm{a}}$ & $39.1(3.1)$ & $33.9(7.3)$ & $39.9(3.4)$ & & \\
\hline \multicolumn{6}{|l|}{ Marital status } \\
\hline Married & $30.7(3.2)$ & $18.9(8.8)$ & $32.5(3.4)$ & \multirow[t]{2}{*}{5.14} & \multirow[t]{2}{*}{.218} \\
\hline Unmarried & $69.3(3.2)$ & $81.1(8.8)$ & $67.5(3.4)$ & & \\
\hline \multicolumn{6}{|l|}{ Education } \\
\hline$<$ High school & $20.4(2.1)$ & $29.4(8.2)$ & $19.1(2.1)$ & \multirow[t]{3}{*}{4.63} & \multirow[t]{3}{*}{.281} \\
\hline High school & $26.6(2.6)$ & $27.9(6.6)$ & $26.4(2.6)$ & & \\
\hline College graduate & $52.9(3.3)$ & $42.8(8.5)$ & $54.5(3.6)$ & & \\
\hline \multicolumn{6}{|l|}{ Employment } \\
\hline Employed & $89.5(1.8)$ & $88.7(3.8)$ & $89.6(2.0)$ & \multirow[t]{2}{*}{.05} & \multirow[t]{2}{*}{.817} \\
\hline Unemployed & $10.5(1.8)$ & $11.3(3.8)$ & $10.4(2.0)$ & & \\
\hline \multicolumn{6}{|l|}{ Family Income } \\
\hline$<\$ 20,000$ & $29.3(2.9)$ & $39.4(8.6)$ & $27.8(3.2)$ & \multirow[t]{3}{*}{4.92} & \multirow[t]{3}{*}{.297} \\
\hline$\$ 20,000-49,999$ & $29.5(2.5)$ & $30.2(7.7)$ & $29.4(2.7)$ & & \\
\hline$\geq \$ 50,000$ & $41.2(3.1)$ & $30.4(7.9)$ & $42.8(3.2)$ & & \\
\hline \multicolumn{6}{|l|}{ Health insurance } \\
\hline Insured & $91.8(1.1)$ & $92.6(3.6)$ & $91.7(1.3)$ & \multirow[t]{2}{*}{.07} & \multirow[t]{2}{*}{.831} \\
\hline Uninsured & $8.2(1.1)$ & $7.4(3.6)$ & $8.3(1.3)$ & & \\
\hline \multicolumn{6}{|l|}{ County urbanicity } \\
\hline Nonmetropolitan & $19.3(2.2)$ & $19.1(5.6)$ & $19.3(2.5)$ & \multirow[t]{3}{*}{8.48} & \multirow[t]{3}{*}{.059} \\
\hline Small urban & $29.5(2.9)$ & $15.3(4.4)$ & $31.7(3.2)$ & & \\
\hline Large urban & $51.2(3.3)$ & $65.5(7.4)$ & $49.1(3.7)$ & & \\
\hline \multicolumn{6}{|l|}{$\begin{array}{l}\text { Self-rated health } \\
\text { status }\end{array}$} \\
\hline Poor/Fair & $9.4(2.0)$ & $10.8(6.5)$ & $9.2(2.0)$ & .19 & .796 \\
\hline Excellent/very/good & $90.6(2.0)$ & $89.2(6.5)$ & $90.8(2.0)$ & $(\mathrm{Co}$ & ued) \\
\hline
\end{tabular}




\begin{tabular}{|c|c|c|c|c|c|}
\hline \multirow[b]{2}{*}{ Characteristics } & \multirow[b]{2}{*}{$\begin{array}{l}\text { Total Sample } \\
\text { Wt. \% (SE) }\end{array}$} & \multicolumn{2}{|c|}{$\begin{array}{c}\text { Receipt of Substance Use } \\
\text { Treatment }\end{array}$} & \multirow[b]{2}{*}{$\chi^{2}$} & \multirow[b]{2}{*}{$\begin{array}{c}p- \\
\text { value }\end{array}$} \\
\hline & & $\begin{array}{l}\text { Yes }(n=68) \\
\text { Wt. \% (SE) }\end{array}$ & $\begin{array}{l}\text { No }(n=453) \\
\text { Wt. \% (SE) }\end{array}$ & & \\
\hline \multicolumn{6}{|c|}{$\begin{array}{l}\text { Perceived need for } \\
\text { treatment }\end{array}$} \\
\hline Yes & $4.5(1.0)$ & $7.6(4.6)$ & $4.0(0.9)$ & 1.79 & .316 \\
\hline No & $95.5(1.0)$ & $92.4(4.6)$ & $96.0(0.9)$ & & \\
\hline \multicolumn{6}{|c|}{ Alcohol use disorder } \\
\hline None & $23.8(2.7)$ & $26.8(6.6)$ & $23.3(2.8)$ & 8.09 & .128 \\
\hline Abuse $^{b}$ & $41.3(3.6)$ & $26.1(8.1)$ & $43.6(3.9)$ & & \\
\hline Dependence $^{c}$ & $34.9(3.3)$ & $47.2(8.8)$ & $33.1(3.5)$ & & \\
\hline \multicolumn{6}{|l|}{$\begin{array}{l}\text { Illicit drug use } \\
\text { disorder }^{\mathrm{d}}\end{array}$} \\
\hline None & $58.9(2.9)$ & $27.7(8.8)$ & $63.6(3.2)$ & 31.81 & .002 \\
\hline Abuse $^{b}$ & $10.0(1.6)$ & $19.3(6.6)$ & $8.6(1.9)$ & & \\
\hline Dependence $^{c}$ & $31.1(2.4)$ & $53.0(8.3)$ & $27.8(2.4)$ & & \\
\hline \multicolumn{6}{|c|}{$\begin{array}{l}\text { Depression/anxiety } \\
\text { disorders }\end{array}$} \\
\hline Yes & $27.8(2.7)$ & $49.5(8.6)$ & $24.7(3.1)$ & 16.86 & .007 \\
\hline No & $72.2(2.7)$ & $50.5(8.6)$ & $75.3(3.1)$ & & \\
\hline
\end{tabular}

Note. Imputed and recoded variables were used. Frequencies and weighted percentages do not include missing data addressing mental health. NSDUH = National Survey on Drug Use and Health; SE $=$ Standard Error; Wt. Percentages $=$ Weighted Percentages. ${ }^{a}$ Other nonHispanics include Native American/Alaska Native, Native Hawaiian/Pacific

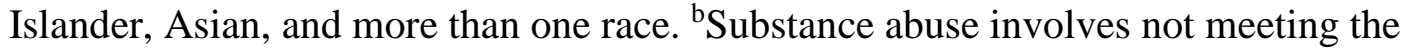
criteria for dependence on that substance but reporting at least one of four abuse criteria occur in a 12-month period (i.e., roles obligations, hazardous use, legal problems, and social problem). ${ }^{c}$ Dependence on a substance involves reporting at least three out of seven dependence symptoms occur in a 12-month period (i.e., engaging in activities related to substance use, tolerance, withdrawal, larger or longer use, unsuccessful attempts to cut down, physical health or emotional problems, and reduced activities). ${ }^{\mathrm{d}}$ Illicit drugs include heroin, marijuana, cocaine, inhalants, sedatives, tranquilizers, hallucinogens, stimulants, and analgesics. 
Table 11

Logistic Regression Using Backward Elimination to Identify the Best Predictive Model of the Probability of Mental Health Treatment Receipt among Pregnant Women Aged 18-44 years with Mental Health Problems, Controlling for Time, NSDUH 2008-2014 ( N = $1,106)$

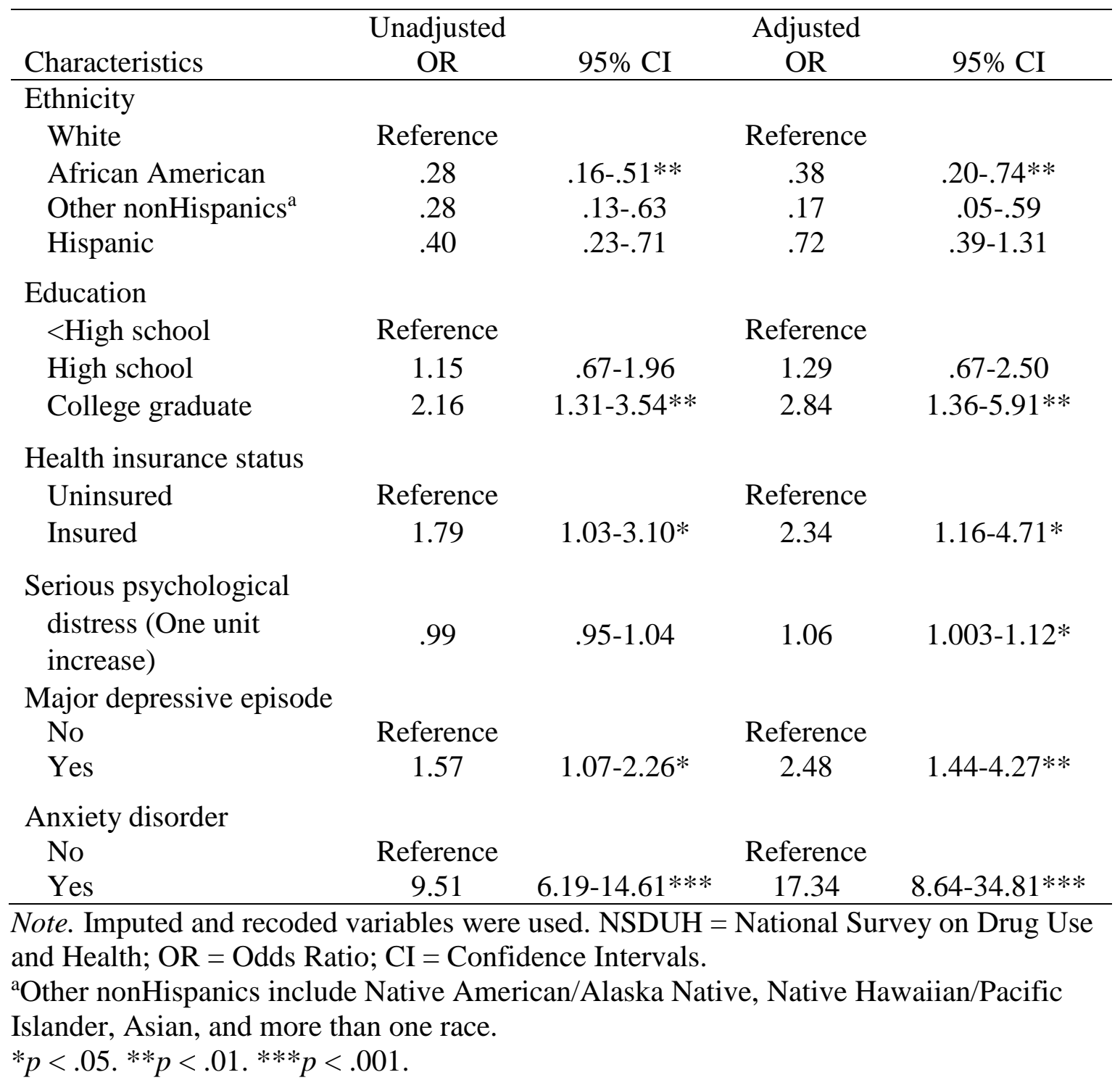


Table 12

Logistic Regression Using Backward Elimination to Identify the Best Predictive Model of the Probability of Substance Use Treatment Receipt among Pregnant Women Aged 18-44 years with Substance Use Disorders, NSDUH 2008-2014, Controlling Time $(N=521)$

\begin{tabular}{|c|c|c|c|c|}
\hline Characteristics & $\begin{array}{c}\text { Unadjusted } \\
\text { OR }\end{array}$ & $95 \% \mathrm{CI}$ & $\begin{array}{l}\text { Adjusted } \\
\text { OR }\end{array}$ & $95 \% \mathrm{CI}$ \\
\hline \multicolumn{5}{|c|}{ County urbanicity } \\
\hline Small urban & Reference & & Reference & \\
\hline Nonmetro & 2.05 & $.85-4.95$ & 2.570 & $.89-7.43$ \\
\hline Large urban & 2.76 & $1.24-6.15^{*}$ & 4.40 & $1.82-10.62 * *$ \\
\hline \multicolumn{5}{|l|}{ Ethnicity } \\
\hline Whites & Reference & & Reference & \\
\hline NonWhites $^{\mathrm{a}}$ & .77 & $.38-1.59$ & .39 & $.19-.80 *$ \\
\hline \multicolumn{5}{|c|}{ Alcohol use disorder } \\
\hline None & Reference & & Reference & \\
\hline Abuse $^{\mathrm{b}}$ & .52 & $.21-1.32$ & 2.84 & $.95-8.48$ \\
\hline Dependence $^{\mathrm{c}}$ & 1.24 & $.57-2.71$ & 2.99 & $1.37-6.49 *$ \\
\hline \multicolumn{5}{|c|}{ Illicit drug use disorder ${ }^{\mathrm{d}}$} \\
\hline None & Reference & & Reference & \\
\hline Abuse $^{\mathrm{b}}$ & 5.16 & $1.35-19.78 * *$ & 7.89 & $1.81-34.40 * * *$ \\
\hline Dependence $^{c}$ & 4.38 & $1.77-10.82$ & 8.83 & $3.10-25.16$ \\
\hline \multicolumn{5}{|c|}{ Depression/Anxiety disorders } \\
\hline No & Reference & & Reference & \\
\hline Yes & 2.98 & $1.32-6.71 * *$ & 3.13 & $1.40-7.02 * *$ \\
\hline \multicolumn{5}{|c|}{ 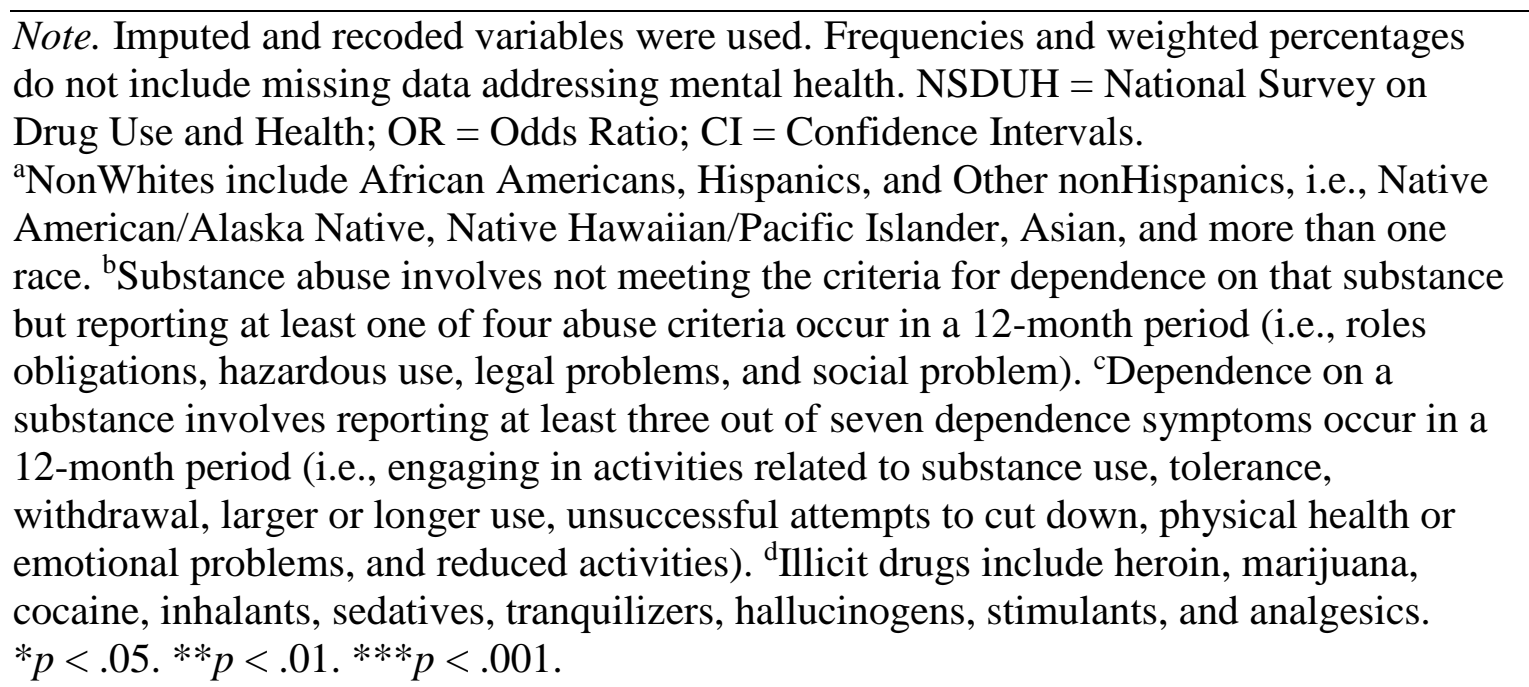 } \\
\hline
\end{tabular}


Table 13

Percentages of Mental Health Treatment Modalities in Non-Hispanic White and Nonwhite Pregnant Women with Mental Health and Substance Use Disorders and Aged 18-44 Years, NSDUH 2008-2014

\begin{tabular}{|c|c|c|c|c|c|}
\hline \multirow[b]{2}{*}{ Mental health treatment } & \multicolumn{3}{|c|}{ Women with Depression $(N=381)$} & \multirow[b]{2}{*}{$\chi^{2}$} & \multirow[b]{2}{*}{$p$-value } \\
\hline & $\begin{array}{l}\text { Total sample } \\
\text { Wt. \% (SE) }\end{array}$ & $\begin{array}{c}\text { Whites }(n=227) \\
\text { Wt. \% (SE) }\end{array}$ & $\begin{array}{c}\text { NonWhites }^{\mathrm{a}}(n=154) \\
\text { Wt.\% (SE) }\end{array}$ & & \\
\hline Any treatment $(n=179)$ & $51.8(3.2)$ & $55.8(4.1)$ & $42.9(5.0)$ & 5.38 & .062 \\
\hline Outpatient treatment $(n=105)$ & $33.3(3.7)$ & $35.2(4.8)$ & $29.2(4.6)$ & 1.32 & .373 \\
\hline Inpatient treatment $(n=21)$ & $3.9(1.0)$ & $3.3(1.1)$ & $5.2(1.9)$ & .80 & .347 \\
\hline \multirow[t]{3}{*}{ Prescription drugs $(n=142)$} & $40.5(3.0)$ & $44.8(3.9)$ & $30.9(5.2)$ & 6.53 & .054 \\
\hline & \multicolumn{3}{|c|}{ Women with Anxiety $(N=379)$} & & \\
\hline & $\begin{array}{l}\text { Total sample } \\
\text { Wt. \% (SE) }\end{array}$ & $\begin{array}{c}\text { Whites }(n=296) \\
\text { Wt. \% (SE) }\end{array}$ & $\begin{array}{c}\text { NonWhites }(n=83) \\
\text { Wt. \% (SE) }\end{array}$ & & \\
\hline Any treatment $(n=271)$ & $78.2(2.7)$ & $79.4(3.1)$ & $73.7(7.0)$ & 1.22 & .461 \\
\hline Outpatient treatment $(n=141)$ & $45.7(3.6)$ & $46.6(3.8)$ & $42.7(8.5)$ & .39 & .673 \\
\hline Inpatient treatment $(n=17)$ & $3.0(0.9)$ & $2.5(0.9)$ & $4.9(2.3)$ & 1.20 & .241 \\
\hline \multirow[t]{4}{*}{ Prescription drugs $(n=241)$} & $67.9(3.4)$ & $69.6(3.7)$ & $61.6(8.6)$ & 1.90 & .388 \\
\hline & \multicolumn{3}{|c|}{ Women with Serious Psychological Distress $(N=842)$} & & \\
\hline & Total sample & Whites $(n=482)$ & NonWhites $(n=360)$ & & \\
\hline & Wt. \% (SE) & Wt. \% (SE) & Wt. \% (SE) & & \\
\hline Any treatment $(n=308)$ & $38.6(2.5)$ & $47.3(3.4)$ & $23.8(3.4)$ & 45.70 & $<.0001$ \\
\hline Outpatient treatment $(n=178)$ & $24.5(2.3)$ & $29.7(3.6)$ & $15.7(2.3)$ & 20.61 & .003 \\
\hline Inpatient treatment $(n=35)$ & $3.5(0.9)$ & $3.2(1.0)$ & $4.0(1.5)$ & .45 & .593 \\
\hline Prescription drugs $(n=247)$ & $30.4(2.4)$ & $37.7(3.3)$ & $18.2(3.1)$ & 35.08 & $<.0001$ \\
\hline
\end{tabular}




\begin{tabular}{lcccccc}
\hline & \multicolumn{2}{c}{ Women with Substance Use Disorders $(N=521)$} & & \\
& Total sample & Whites $(n=284)$ & NonWhites $(n=237)$ & & \\
& Wt. \% (SE) & Wt. \% (SE) & Wt. \% (SE) & $\chi^{2}$ & $p$-value \\
\hline Any treatment $(n=140)$ & $26.4(2.9)$ & $31.3(4.1)$ & $18.5(3.4)$ & 10.40 & .019 \\
Outpatient treatment $(n=76)$ & $14.8(2.1)$ & $16.7(3.0)$ & $11.8(2.8)$ & 2.32 & .249 \\
Inpatient treatment $(n=21)$ & $2.8(1.0)$ & $2.4(1.1)$ & $3.5(2.1)$ & .54 & .619 \\
Prescription drugs $(n=104)$ & $19.1(2.5)$ & $21.7(3.5)$ & $14.9(3.0)$ & 3.63 & .145
\end{tabular}

Women with Comorbid Mental Health and Substance Use

Disorders $(N=244)$

\begin{tabular}{ccccc}
\cline { 1 - 3 } Total sample & Whites $(n=89)$ & \multicolumn{2}{c}{$\begin{array}{c}\text { NonWhites }(n=112) \\
\end{array}$} & \\
Wt. \% (SE) & Wt. \% (SE) & Wt. \% (SE) & & \\
\cline { 1 - 3 } $44.9(3.8)$ & $54.8(4.3)$ & $30.7(5.7)$ & 13.83 & .003 \\
$26.6(3.6)$ & $30.6(4.9)$ & $20.9(4.6)$ & 2.89 & .161 \\
$6.2(2.4)$ & $5.5(2.6)$ & $7.3(4.3)$ & .34 & .696 \\
$33.4(3.6)$ & $39.1(4.8)$ & $25.2(5.4)$ & 5.12 & .074
\end{tabular}

Any treatment $(n=110)$

Outpatient treatment $(n=65)$

Inpatient treatment $(n=18)$

$33.4(3.6)$

$39.1(4.8)$

$25.2(5.4)$

5.12

Note. Imputed and recoded variables were used. Frequencies and weighted percentages do not include missing data addressing mental health. NSDUH $=$ National Survey on Drug Use and Health; Wt. \%= Weighted Percentages; SE = Standard Error.

${ }^{a}$ NonWhites include African Americans, Hispanics, and Other nonHispanics, i.e., Native American/Alaska Native, Native Hawaiian/Pacific Islander, Asian, and more than one race. ${ }^{b}$ Substance use disorders include alcohol or illicit drug use dependence or abuse measured based on the Diagnostic and Statistical Manual of Mental Disorders (DSM-IV) criteria. 
Table 14

Logistic Regression Model of the Probability of the Receipt of Mental Health Treatment in Pregnant Women Aged 18-44Years by type of Mental Health and/or Substance Use Disorders and Ethnicity, NSDUH 2008-2014

\begin{tabular}{|c|c|c|c|c|}
\hline Model/Disorder & $\begin{array}{c}\text { Unadjusted } \\
\text { OR }\end{array}$ & $95 \% \mathrm{CI}$ & $\begin{array}{c}\text { Adjusted } \\
\text { OR }\end{array}$ & $95 \% \mathrm{CI}$ \\
\hline $\begin{array}{l}\text { 1. Major depression }(N=381) \\
\text { NonWhites }^{\text {a }} \text { vs. Whites }\end{array}$ & .60 & $.34-1.03$ & .49 & $.27-.92 *$ \\
\hline $\begin{array}{l}\text { 2. Anxiety disorder }(N=379) \\
\text { NonWhites vs. Whites }\end{array}$ & .73 & $.31-1.73$ & .91 & $.37-2.27$ \\
\hline $\begin{array}{r}\text { 3. Serious psychological } \\
\text { distress }^{\mathrm{b}}(N=842) \\
\text { NonWhites vs. Whites }\end{array}$ & .35 & $.22-.56 * * *$ & .34 & $.20-59 * * *$ \\
\hline $\begin{array}{l}\text { 4. Substance use } \\
\text { disorders }{ }^{\mathrm{c}}(N=521) \\
\text { NonWhites vs. Whites }\end{array}$ & .50 & $.27-.89 *$ & .46 & $.23-.93 *$ \\
\hline $\begin{array}{l}\text { 5. Comorbid } \\
\text { disorders }{ }^{\mathrm{d}}(N=244) \\
\text { NonWhites vs. Whites }\end{array}$ & .37 & $.19-.70 * *$ & .27 & $.13-.57 * *$ \\
\hline
\end{tabular}

Note. Control variables include predisposing factors (i.e., age, education, marital status, employment status); enabling factors (i.e., income, health insurance, and county type); need factors (i.e., self-rated health status and severity of distress symptoms); and time. Imputed and recoded variables were used. Frequencies and weighted percentages do not include missing data addressing mental health. NSDUH = National Survey on Drug Use and Health; $\mathrm{OR}=$ Odds Ratio; $\mathrm{CI}=$ Confidence Intervals.

${ }^{a}$ NonWhites include African Americans, Hispanics, and Other nonHispanics, i.e., Native American/Alaska Native, Native Hawaiian/Pacific Islander, Asian, and more than one race. ${ }^{\mathrm{b}}$ Included those who had a score of 13 or above on the Kessler-6 Psychological Distress Scale. 'Substance use disorders include alcohol or illicit drug use dependence or abuse measured based on the Diagnostic and Statistical Manual of Mental Disorders $(D S M-I V)$ criteria. ${ }^{\mathrm{d}}$ Comorbid disorders involve mental health (i.e, major depressive episode, anxiety disorder, or serious psychological distress) and substance use disorders. $* p<.05 . * * p<.01 . * * * p<.001$. 
Table 15

Differences in Perceived Barriers to Mental Health Treatment among Pregnant Women with Mental Health and/or Substance Use Disorders and Perceived Need for Treatment, NSDUH (2008-2014) $(N=391)$

\begin{tabular}{|c|c|c|c|c|c|c|}
\hline Disorders & & $\begin{array}{c}\text { Cost } \\
\text { Wt.\% (SE) }\end{array}$ & $\begin{array}{c}\begin{array}{c}\text { Opposition to } \\
\text { Treatment }\end{array} \\
\text { Wt.\% (SE) } \\
\end{array}$ & $\begin{array}{c}\text { Stigma } \\
\text { Wt.\% (SE) }\end{array}$ & $\begin{array}{c}\text { Time/transportation } \\
\text { limitations } \\
\text { Wt.\% (SE) } \\
\end{array}$ & $\begin{array}{l}\begin{array}{c}\text { Not knowing } \\
\text { where to go }\end{array} \\
\text { Wt.\% (SE) } \\
\end{array}$ \\
\hline \multicolumn{7}{|l|}{ Any mental health problem: } \\
\hline & Yes & $52.8(3.8)$ & $40.6(3.4)$ & $22.6(3.4)$ & $21.1(2.7)$ & $16.6(2.6)$ \\
\hline & No & $49.2(7.0)$ & $48.6(7.3)$ & $22.4(5.4)$ & $16.0(4.9)$ & $13.2(3.4)$ \\
\hline \multirow[t]{2}{*}{ Major depression: } & Yes & $61.1(5.2)^{*}$ & $33.4(3.3)^{*}$ & $23.7(5.2)$ & $17.8(3.3)$ & $24.2(4.7)^{* *}$ \\
\hline & No & $46.2(3.9)$ & $48.1(4.6)$ & $22.1(4.0)$ & $20.5(3.2)$ & $11.2(2.0)$ \\
\hline \multirow[t]{2}{*}{ Anxiety disorder: } & Yes & $51.7(6.7)$ & $35.9(6.1)$ & $17.7(4.1)$ & $31.1(5.5)^{*}$ & $13.0(3.5)$ \\
\hline & No & $52.0(4.3)$ & $45.2(4.0)$ & $24.4(3.9)$ & $15.4(2.4)$ & $16.8(2.8)$ \\
\hline \multirow[t]{2}{*}{$\begin{array}{l}\text { Serious psychological } \\
\text { distress: }{ }^{a}\end{array}$} & Yes & $52.3(4.4)$ & $39.5(4.0)$ & $22.9(4.1)$ & $17.9(3.3)$ & $18.0(2.9)$ \\
\hline & No & $51.0(5.6)$ & $48.5(6.5)$ & $21.6(4.7)$ & $22.8(4.4)$ & $11.5(2.6)$ \\
\hline \multirow[t]{2}{*}{ Substance use disorders: ${ }^{b}$} & Yes & $57.5(6.0)$ & $45.2(6.3)$ & $38.1(6.3)^{* * *}$ & $15.0(4.3)$ & $18.0(6.0)$ \\
\hline & No & $49.5(4.1)$ & $41.8(4.3)$ & $16.2(3.3)$ & $21.6(3.1)$ & $14.7(3.0)$ \\
\hline \multirow[t]{2}{*}{ Comorbid disorders: ${ }^{c}$} & Yes & $54.8(6.0)$ & $43.2(4.0)$ & $36.7(4.1)^{*}$ & $16.3(3.3)$ & $14.8(2.9)$ \\
\hline & No & $44.1(7.9)$ & $47.5(8.2)$ & $18.1(6.0)$ & $17.3(5.6)$ & $8.7(3.5)$ \\
\hline
\end{tabular}

Note. Imputed and recoded variables were used. Frequencies and weighted percentages do not include missing data addressing mental health. NSDUH = National Survey on Drug Use and Health; CI= Confidence Intervals.

${ }^{\mathrm{a}}$ Included those who had a score of 13 or above on the Kessler-6 Psychological Distress Scale. ${ }^{\mathrm{b}}$ Substance use disorders include alcohol or illicit drug use dependence or abuse measured based on the Diagnostic and Statistical Manual of Mental Disorders (DSM-IV) criteria. ${ }^{\circ}$ Comorbid disorders involve mental health (i.e., major depressive episode, anxiety disorder, or serious psychological distress) and substance use disorders.

$* p<.05 . * * p<.01 . * * * p<.001$. 


\section{$\begin{array}{llll} & \text { HNVIRONMENT } & \text { POPULATION CHARACTERISTICS } & \text { HEALTH } \\ & \text { BEHAVIOR } & \text { OUTCOMES }\end{array}$}

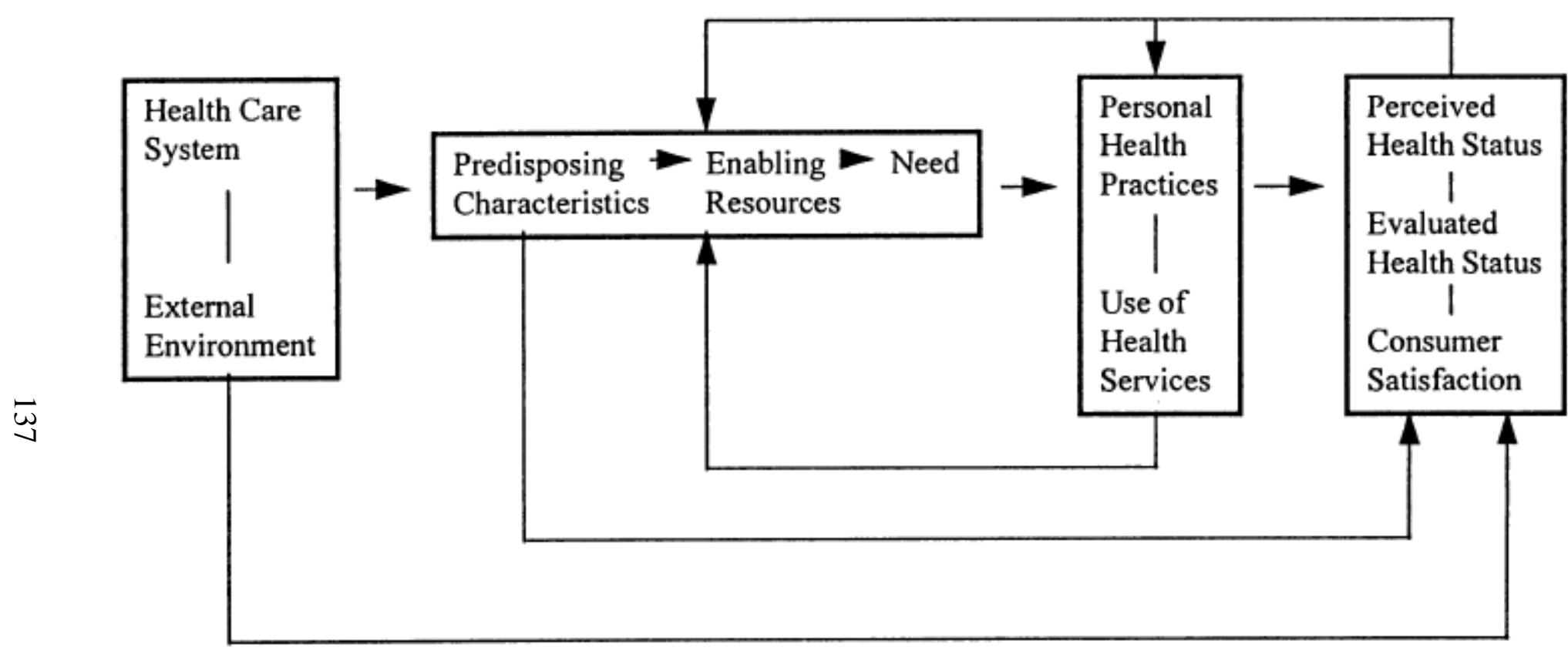

Figure 7. The Behavioral Model of Health Services Use. Adapted from "Revisiting the Behavioral Model and Access to Medical Care: Does it Matter?” by R.M. Andersen, 1995, Journal of Health and Social Behavior, 36(1), p. 8.

Permission for use in the dissertation is not required according to the American Sociological Association.

http://www.asanet.org/research-publications/journal-resources/reprint-permissions 


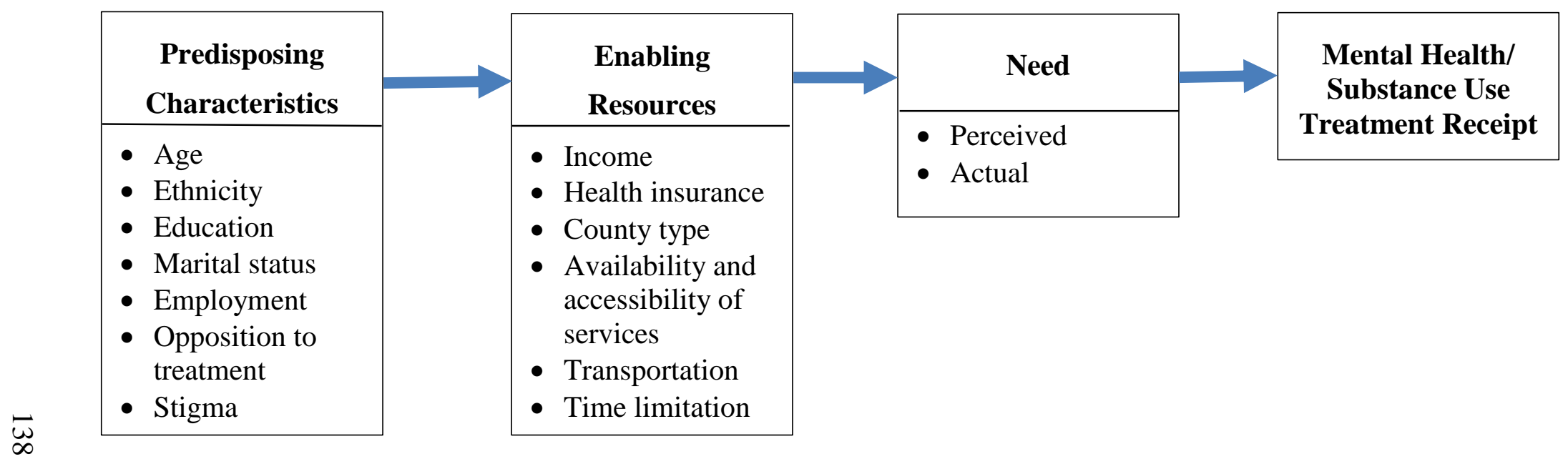

Figure 8. Theoretical framework adapted the Behavioral Model of Health Services Use. Adapted from "Revisiting the Behavioral Model and Access to Medical Care: Does it Matter?" by R.M. Andersen, 1995, Journal of Health and Social Behavior, 36(1), p. 8. 


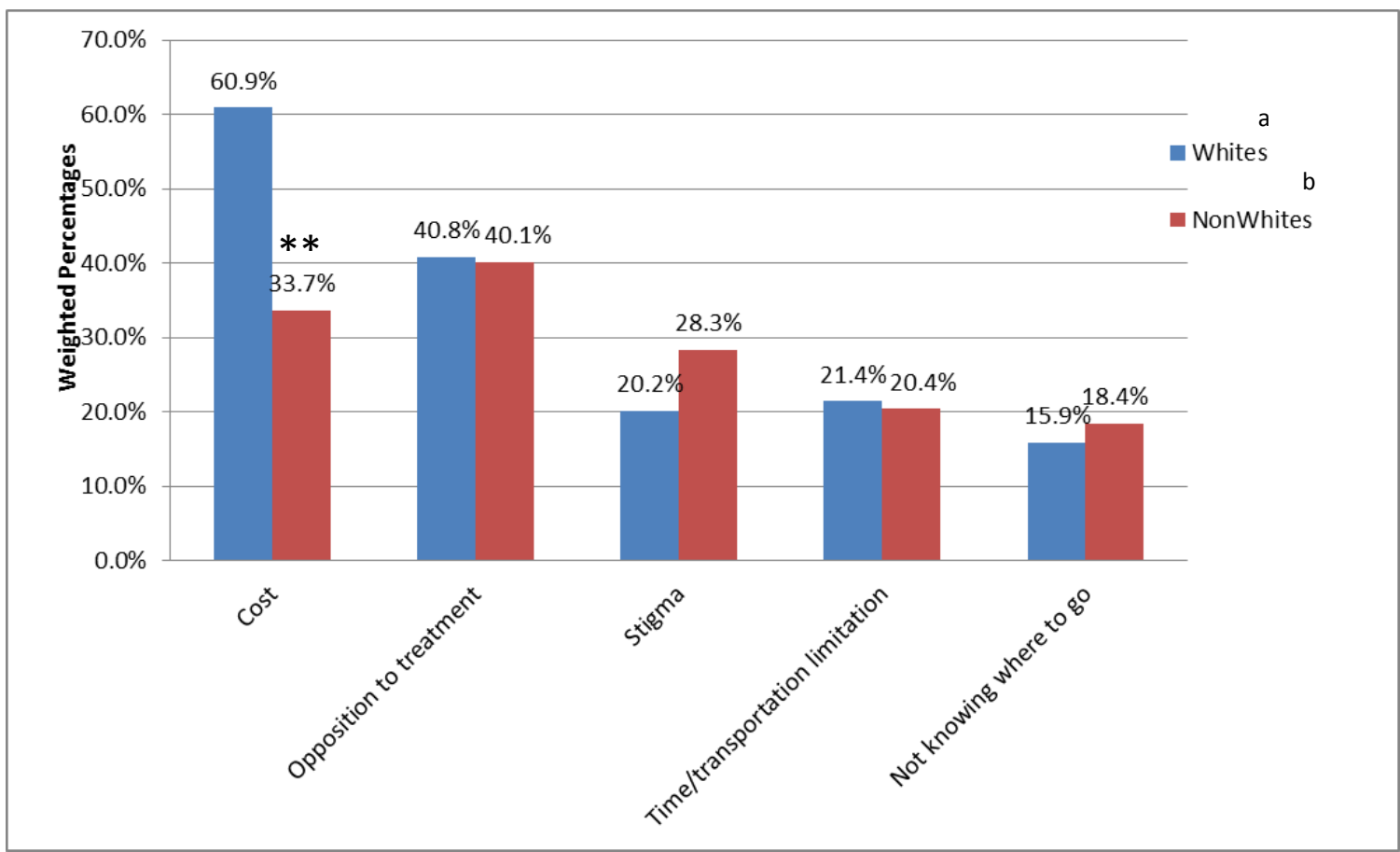

Figure 9. Perceived barriers to mental health treatment in White and NonWhite pregnant women with mental health problems who perceived need for treatment, National Survey on Drug Use and Health, 2008-2014 $(N=296)$. Imputed and recoded variables were used. Frequencies and weighted percentages do not include missing data addressing mental health. NonWhites include African Americans, Hispanics, and other nonHispanics, i.e., Native American/Alaska Native, Native Hawaiian/Pacific Islander, Asian, and more than one race.

${ }^{\mathrm{a}} n=195 .{ }^{\mathrm{b}} n=101$.

$* * p<.01$. 


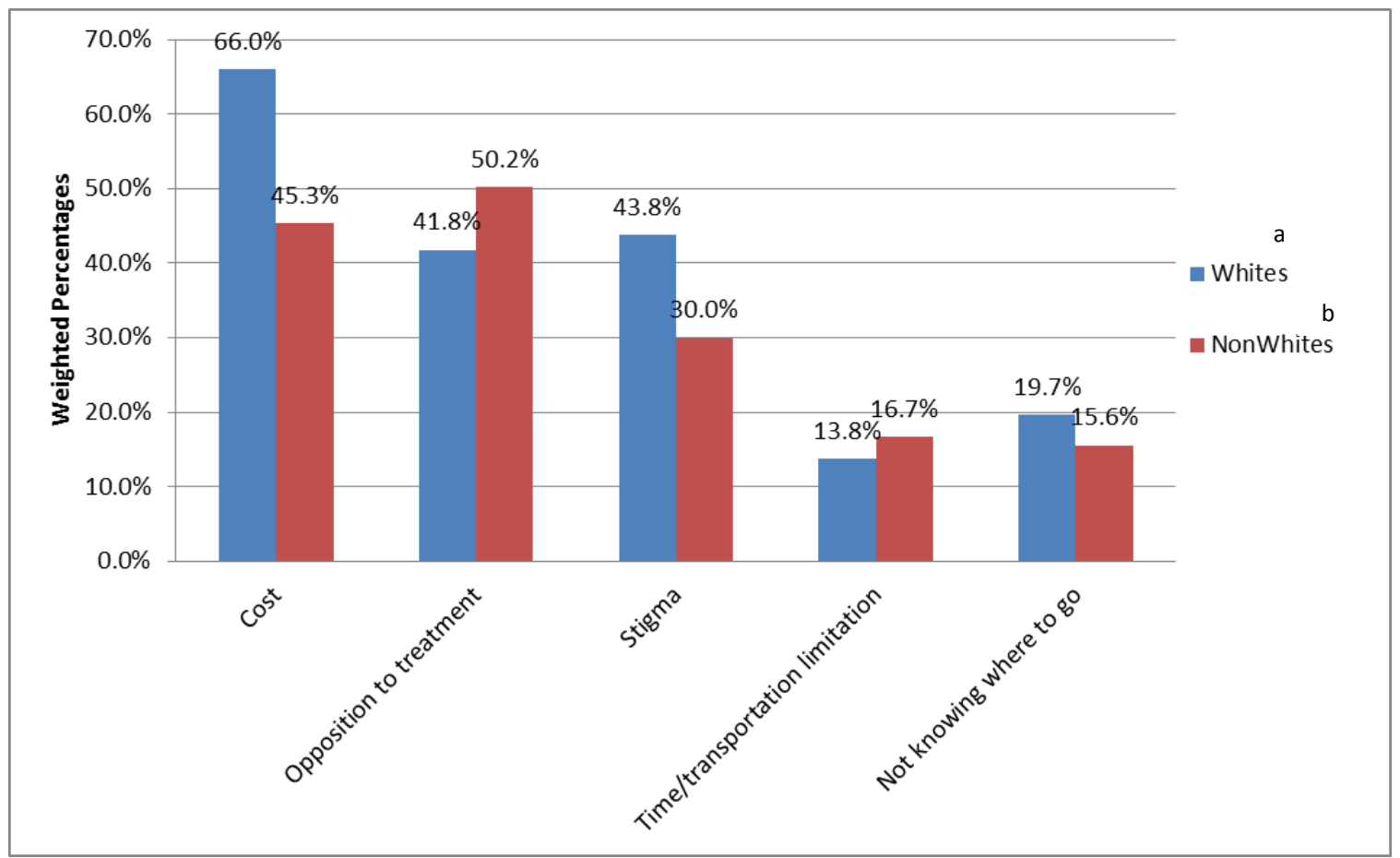

Figure 10. Perceived barriers to mental health treatment in White and NonWhite pregnant women with substance use disorders who perceived a need for treatment, National Survey on Drug Use and Health $(N=127)$. Imputed and recoded variables were used. Frequencies and weighted percentages do not include missing data addressing mental health. NonWhites include African Americans, Hispanics, and other nonHispanics, i.e., Native American/Alaska Native, Native Hawaiian/Pacific Islander, Asian, and more than one race. ${ }^{\mathrm{a}} n=72 .{ }^{\mathrm{b}} n=55$. 


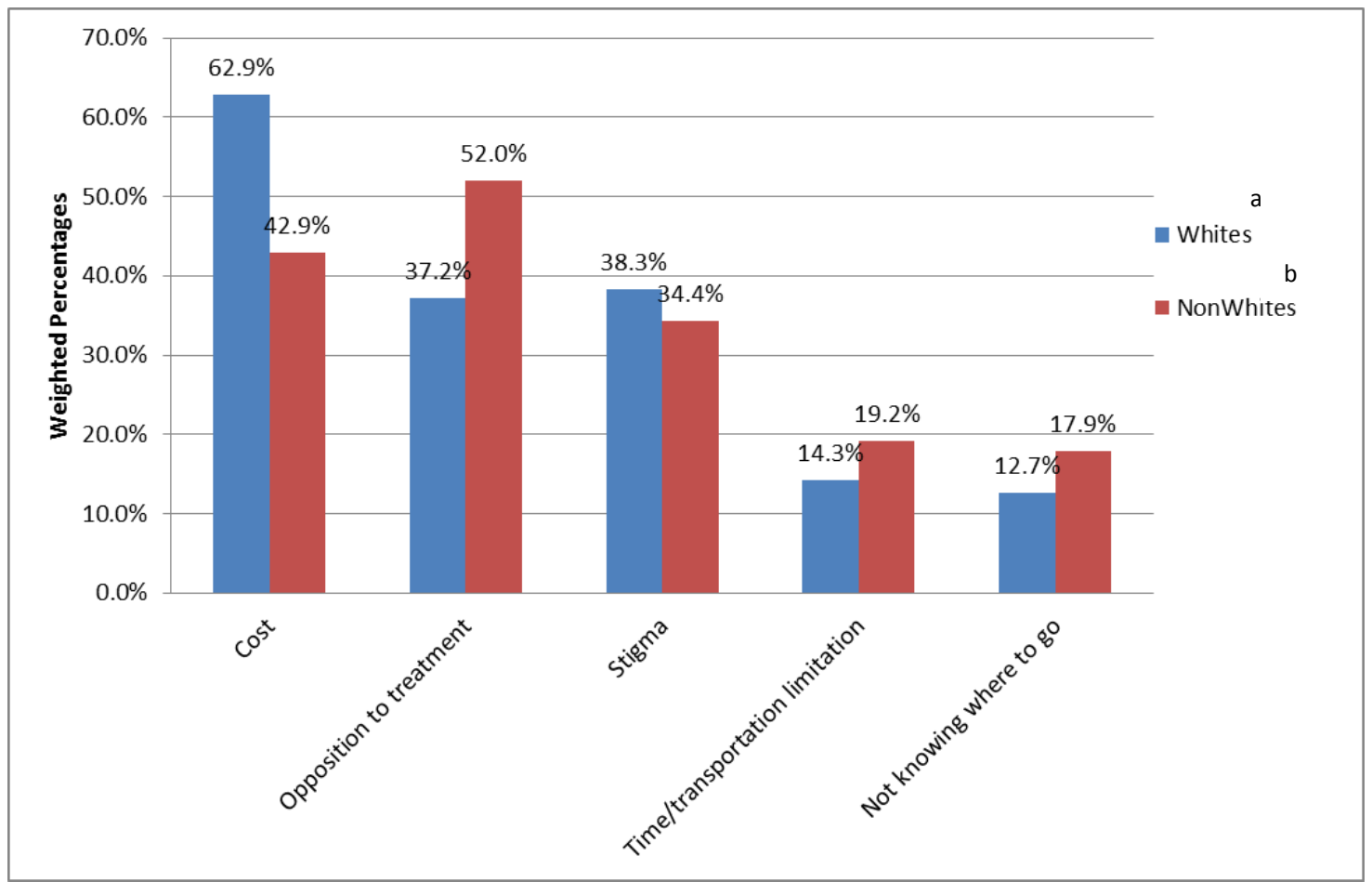

Figure 11. Perceived barriers to mental health treatment in pregnant women with comorbid mental health and substance use disorders who perceived a need for treatment, National Survey on Drug Use and Health, 2008-2014 $(N=114)$. NonWhites include African Americans, Hispanics, and other nonHispanics, i.e., Native American/Alaska Native, Native Hawaiian/Pacific Islander, Asian, and more than one race.

${ }^{\mathrm{a}} n=66 .{ }^{\mathrm{b}} n=48$. 


\section{CHAPTER V \\ DISCUSSION AND CONCLUSION}

The purposes of this dissertation were to: (1) systematically review literature of trend and population-based studies on mental health and substance use disorders and treatment receipt among pregnant women in the United States; (2) compare trends in mental health and substance use disorders and treatment receipt by pregnancy status from 2008 to 2014; and (3) identify predictors of treatment receipt for mental health and substance use disorders and examine ethnic care disparities in mental health treatment among pregnant women with mental health and/or substance use disorders in the United States.

\section{Synthesis of Findings and Implications}

\section{Trends in Mental Health and Substance Use Disorders}

Chapter Two was a systematic review of trend studies on mental health disorders, particularly depression, anxiety disorder, and psychological distress, among pregnant women in the United States. However, the review revealed a lack of recent evidence addressing trends in mental health disorders among pregnant women in the United States. Yet in Chapter Three, a significant increase was identified in the rates of past-year anxiety disorder and past-month serious psychological distress among women of childbearing age from 2008 to 2014. This is congruent with the increase in poor mental health for 15 days or more in the past month from 2001 to 2012 among the general 
population in the United States (Mojtabi \& Jorm, 2015). Interestingly, Chapter Four findings revealed that past-year anxiety disorder was the best predictor of receipt of mental health treatment among pregnant women. This emphasizes the need to screen and treat these mental health problems during prenatal period. In addition, evidence-based prevention strategies are required to reduce the negative health consequences of mental health disorders for the mother and her child.

The systematic review of trend studies on maternal substance use disorders revealed that maternal abuse of opioid, cannabis and hallucinogens, and methamphetamine increased from 1999 to 2008; however, cocaine abuse decreased significantly while alcohol abuse declined slightly (Pan \& Yi, 2013). Maeda et al. (2014) found that opioid use disorder increased from 1998 to 2011. Similarly, Chapter Three showed a significant linear trend in illicit drug use disorder from 2008 to 2014 among women of childbearing age. It is noteworthy that the studies reviewed did not compare trends in substance use disorders by pregnancy status; however, the findings in Chapter Three did not indicate a significant difference between pregnant and nonpregnant women in illicit drug or alcohol use disorders over time. Unfortunately, there is a paucity of studies specifically addressing trends in the national estimates of substance use disorders among pregnant and nonpregnant women in the United States. It is crucial to conduct such studies especially given that treatment admissions for illicit drug use disorders increased profoundly among pregnant women from 1998 to 2008 compared to nonpregnant women (McCabe \& Arndt, 2012). 


\section{Trends in Treatment Receipt}

The systematic review revealed an increase in antidepressant use among pregnant women from 1995 to 2010 (Andrade et al., 2008; Bobo et al., 2014; Meunier et al., 2013), whereas the rate of psychotropic medications use remained stable from 2006 to 2010 (Hanley \& Mintzes, 2014). These studies did not compare trends by pregnancy status. However, Hanley and Mintzes (2014) found that the rates of psychotropic medication use were higher before pregnancy than in the first and second trimesters of pregnancy.

Although antidepressant use during pregnancy is controversial (Yamamoto et al., 2015), there was only one study of a nationally representative sample on antidepressant use among pregnant women in the United States identified for review (Meunier et al., 2013). Hence, further research is needed to reflect recent trends in antidepressant use among nationally representative sample of pregnant women. The systematic review also showed there is a lack of evidence regarding trends in the receipt of any mental health treatment modalities including prescription drugs, outpatient counseling, or inpatient treatment among pregnant women. In contrast, trends in the receipt of any of these modalities were examined in Chapter Three; thus, the findings from Chapters Two and Three are not comparable in regards to the receipt of mental health treatment. Chapter Three revealed no significant increase in the receipt of mental health treatment among women of childbearing age from 2008 to 2014 . However, pregnant women had a lower likelihood of treatment receipt compared to nonpregnant women. The findings presented in Chapter Three revealed were similar. Trends in the receipt of mental health treatment among childbearing-aged women with mental illness were evaluated, controlling for severity of mental illness. The trends in receipt of mental health treatment among 
pregnant women were inconsistent with the increase over time in mental health treatment among the general population (Mojtabi \& Jorm, 2015). This suggests that women of childbearing age may have special mental health needs.

Interestingly, there was no significant interaction between pregnancy status and time in predicting mental health treatment receipt as discussed in Chapter Three; pregnant women had a lower odds of mental health treatment receipt compared to nonpregnant women. On the other hand, the systematic review revealed mixed findings regarding the difference between pregnant and nonpregnant women in the receipt of mental health treatment which may be due to the heterogeneity of samples and measures of mental health problems. The Chapter Three findings were in accord with a study based on the 2008-2012 NSDUH (Glasheen et al., 2015), although the two studies included different samples (e.g., women with past-year mental illness in Chapter Three versus women with past-month psychological distress in the study of Glasheen et al.). Thus, it is crucial to conduct more research about the difference between pregnant and nonpregnant women in the receipt of mental health treatment to tailor interventions according to the needs of pregnant women.

The systematic review indicated an increase in treatment admissions for illicit drug use disorder from 1998 to 2008 (McCabe \& Arndt, 2012), and for marijuana (Martin, Longinaker, Mark, et al., 2015) and opioid use disorders from 1992 to 2012 (Martin, Longinaker, \& Terplan, 2015). Yet, treatment admissions decreased over time for cocaine and alcohol use (Martin, Longinaker, Mark, et al., 2015; McCabe \& Arndt, 2012). Overall, treatment admissions for substance use disorders remained stable from 1992 to 2012 at 4\% among pregnant women (Martin, Longinaker, Mark, et al., 2015). 
This suggests that there was no improvement in the utilization of substance use treatment services among pregnant women. The findings in Chapter Three supported this as the rate of unmet need for substance use treatment remained stable at 7\% from 2008 to 2014 among pregnant women. This is of critical concern because several states enacted laws that stigmatized prenatal illicit substance use in pregnant women (Guttmacher Institute, 2017). Subsequently, many pregnant women do not seek treatment to avoid losing custody of their child (Tuchman, 2010). Legal and treatment initiatives should focus on the specific needs of pregnant women with substance use disorders. According to the CSAT (2009), an atmosphere of hope, acceptance, and support is essential for women to overcome the challenges of substance use disorder and receive substance use treatment.

\section{Factors Associated with Treatment Receipt}

The systematic review of population-based studies, although they were few, revealed that factors related to the receipt of mental health treatment included White ethnicity (Bennett et al., 2010; Byatt et al., 2016; Chang et al., 2016), older reproductive age, college education (Chang et al., 2016), having assistance/insurance coverage (Bennett et al., 2010; Chang et al., 2016), and having mental health problems (Byatt et al., 2016; Roberson et al., 2016). Multivariate analyses from Chapter Four supported these findings. The final predictive model for mental health treatment receipt contained six variables: White ethnicity, college education, health insurance coverage, past-year anxiety disorder, MDE, and serious psychological distress.

While the only national study focused on depressive symptoms among pregnant women (Byatt et al., 2016), Chapter Four findings added to the literature by identifying the best predictors of mental health treatment receipt given the need factors for treatment. 
Anxiety disorder was the strongest predictor, followed by MDE and serious psychological distress. These findings indicate the critical nature of screening and treatment initiatives for these mental health problems during pregnancy; emphasis on anxiety disorder is particularly warranted, especially since it is more often ignored than depression in pregnant women (Fairbrother et al., 2016; Fairbrother et al., 2015).

Only two population-based studies identified for the systematic review examined factors associated with substance use treatment receipt among childbearing-aged women (Terplan et al., 2012) and pregnant women (Kotelchuck et al., 2017). Factors related to treatment receipt in these studies included college education, older reproductive age, and governmental assistance/private health insurance. Compared to those who did not receive treatment, Kotelchuck et al. (2017) also found that Black or Hispanic women were less likely to receive substance use treatment whereas those with fewer health or psychiatric conditions were more likely to receive treatment. The best predictive model of substance use treatment receipt in Chapter Four indicated that White ethnicity and comorbid depression/anxiety increased the likelihood of substance use treatment receipt. Similarly, the review of trend studies in Chapter Two indicated that substance use treatment admissions of Whites and pregnant women with comorbid psychiatric illness increased over time (Martin, Longinaker, Mark, et al., 2015). This supports the importance of addressing mental health needs of pregnant women with substance use disorders. Increase access to substance use treatment among ethnic minority pregnant women is essential.

Chapter Four contributes to the literature by addressing how need factors for treatment differentiate the receipt of substance use treatment among pregnant women. Illicit drug dependence was the best predictor of treatment receipt followed by illicit drug 
abuse and alcohol use dependence. This is congruent with the trend studies reviewed in Chapter Two which revealed an increase in treatment admissions for illicit drug use disorder over time (Martin, Longinaker, Mark, et al., 2015; Martin, Longinaker, \& Terplan, 2015; McCabe \& Arndt, 2012). There is a need for evidence-based preventive strategies to minimize the burden of illicit drug use disorders for the mother, her child, and society. Given that substance use is a modifiable health behavior (Kuo et al., 2013; Massey et al., 2011), health care providers should screen and intervene early to prevent women from developing severe substance use disorders.

\section{Ethnic Care Disparities in Mental Health Treatment Receipt}

Only three population-based studies reviewed in Chapter Two explicitly addressed ethnic care disparities in the receipt of mental health treatment (Chang et al., 2016; Coleman-Cowger, 2012; Yamamoto et al., 2015). These studies indicated that White pregnant women were more likely to receive mental health treatment than nonWhites. A series of logistic regression models in Chapter Four also revealed that nonWhite ethnicity (versus White) decreased the likelihood of mental health treatment receipt in pregnant women with MDE, serious psychological distress, substance use disorders, and comorbid mental health and substance use disorders even after controlling for predisposing factors, enabling factors, and severity of distress symptoms. These findings indicate that ethnic minority pregnant women may have specific cultural beliefs and attitudes about seeking mental health treatment (O’Mahen \& Flynn, 2008). Further research is needed to address potential cultural differences. Screening initiatives and mental health program interventions targeting ethnic minority pregnant women are also necessary. 


\section{Barriers to Treatment Receipt}

Findings from the population-based studies reviewed indicated that barriers to mental health treatment included cost, opposition to treatment, stigma, time/transportation limitations, and not knowing where to go (Ko et al., 2012) as well as provider-patient conversation regarding depression (Farr et al., 2016) and providers' competency in treatment/referrals (Price et al., 2012). Chapter Three also indicated that cost, opposition to treatment, and stigma were the most common barriers among pregnant women. In addition, their rank order and percentages did not differ across two time periods, 2008-2010 and 2011-2014.

Chapter Four also expanded these findings and added to the literature by comparing perceived barriers to mental health treatment across types of mental health and/or substance use disorders and ethnicity. Compared to pregnant women without MDE, those with MDE were more likely to perceive cost and not knowing where to go as barriers to mental health treatment and less likely to have opposition to treatment. Pregnant women with anxiety disorder were more likely to report the lack of time/transportations as barriers to mental health treatment compared to those without anxiety. Those who had substance use disorders or comorbid mental health and substance use disorders were more likely to perceive stigma attached to the receipt of mental health treatment as a barrier compared to pregnant women without these disorders.

Furthermore, the findings in Chapter Four indicated there were no differences between White and nonWhite pregnant women with mental health problems, substance use disorders, and comorbid mental health and substance use disorders in the proportions of perceived opposition to treatment, stigma, time/transportation limitations, and not 
knowing where to go. These findings are congruent with those of one study in which there were no differences between White and African American perinatal women in the perceived structural (e.g., insurance, cost, and transportation), knowledge, and attitudinal barriers to depression treatment (O'Mahen \& Flynn, 2008). However, in Chapter Four, Whites were more likely to perceive cost as an obstacle to mental health treatment. Findings from the systematic review and the two data based manuscripts in this dissertation reflect the complexity of barriers to mental health treatment and provide information relevant to health reform on the importance of addressing such barriers and increasing the sensitivity of healthcare providers in regards unique mental health needs of pregnant women to enhance their access to treatment. Further research is needed to compare barriers to mental health treatment across different ethnic groups.

The systematic review demonstrated the paucity of studies addressing barriers to substance use treatment among pregnant women. In the first data based study, perceived barriers to substance use treatment among childbearing-aged women differed from 20082010 to 2011-2014. For instance, in 2008-2010, cost ranked first and followed by stigma, whereas stigma ranked first and followed by cost in 2011-2014. Interestingly, women of childbearing age in 2011-2014 were more likely to report not knowing where to go and a lack of treatment programs as obstacles to the receipt of substance use treatment than women in 2008-2010. Upstream efforts are needed to meet the needs of pregnant women with substance use disorders. These women are stigmatized and their specific needs are still unmet (CSAT, 2009). Legal and treatment initiatives are critical to increase the availability of treatment facilities that acknowledge the "biopsychosocial uniqueness" of 
women with substance use disorders (CSAT, 2009, p.1) and provide specific strategies to improve access to care such as trauma-informed care (SAMHSA, 2014c).

\section{Summary}

This dissertation is innovative because it: (a) includes a systematic review of trend and population-based studies on mental health and substance use disorders among pregnant women in the United States, (b) contains one of the first studies that compared trends in both mental health and substance use disorders and treatment receipt by pregnancy status, and (c) fills a gap in the literature by studying factors associated with the receipt of treatment for mental health and substance use disorders and addressing ethnic health care disparities and barriers to mental health treatment experienced by a national sample of pregnant women.

The findings clearly support the gap between the need for and the receipt of treatment among pregnant women with mental health and substance use disorders. Trends in the receipt of mental health treatment and the unmet need for substance use treatment did not change from 2008-2014 among childbearing-aged women, whereas anxiety disorders, past-month psychological distress, and illicit drug use disorder increased over the same time period. Further research is needed to address the seriousness of these disorders, particularly mental health problems, among pregnant women in the United States over time.

This research underscores that factors associated with both mental health and substance use treatment receipt are complex and involve predisposing (e.g., ethnicity), enabling (e.g., health insurance and urban residency), and need factors (e.g., anxiety disorder and illicit drug use disorder). This research also showed that numerous obstacles 
impede women of childbearing age in accessing mental health and substance use treatment. In addition, disparities in mental health treatment also exist among pregnant women with mental health and/or substance use disorders.

This dissertation provides new insights for improving maternal mental health. It has significant clinical implications because pregnancy provides an opportunity to screen and intervene with mental health and substance use problems. The information generated from this dissertation may help in designing programs according to the needs of pregnant women. There is a need for evidence-based preventive and treatment strategies to minimize the effects of mental health problems and substance use disorders for the mother, her child, and society. Health care providers play a significant role in screening and identifying pregnant women at risk for and those who have mental health and substance use disorders.

This research indicates needed changes in health policy to improve the health of a vulnerable population of pregnant women. There is a need to develop strategies addressing the unique barriers (e.g., cost, stigma, opposition to treatment, available treatment programs, and not knowing to go) that impede pregnant and nonpregnant women to access mental health and substance use treatment. Specific and evidence-based interventions tailored to the needs of ethnic minority pregnant women are essential. More research and clinical practice changes are required to focus on mental health needs of pregnant women with substance use disorders. Further research is needed to examine the association between the receipt of mental health and substance use treatment. Developing strategies integrating the two systems is also crucial. 
To improve maternal mental health and to disseminate a message of hope for pregnant women, collaboration among researchers, policy makers, and healthcare providers is required. Hopefully, this dissertation provides a contribution for a better understanding of the needs of pregnant women with mental health and substance use disorders. 


\section{REFERENCES}

Accortt, E. E., Cheadle, A. C., \& Dunkel Schetter, C. (2015). Prenatal depression and adverse birth outcomes: An updated systematic review. Maternal and Child Health Journal, 19(6), 1306-1337. doi: 10.1007/s10995-014-1637-2

Advocates for Pregnant Women. (2011). Medical and public health statements addressing prosecution and punishment of pregnant women. Retrieved from http://advocatesforpregnantwomen.org/Health\%20Statements\%20re.\%20Punitive \%20Policies\%20NAPW\%202015.pdf

Agency for Healthcare Research and Quality. (2016). Screening for Depression. Retrieved from http://www.ahrq.gov/professionals/prevention-chroniccare/healthier-pregnancy/preventive/depression.html

American College of Obstetricians and Gynecologists. (2010). Committee opinion no. 453: Screening for depression during and after pregnancy. Obstetrics and Gynecology, 115(2 Pt 1), 394.

American College of Obstetricians and Gynecologists. (2015a). Committee opinion no. 633: Alcohol abuse and other substance use disorders: ethical issues in obstetric and gynecologic practice. (2015). Obstetrics and Gynecology, 125(6), 1529-1537. doi: 10.1097/01.AOG.0000466371.86393.9b

American College of Obstetricians and Gynecologists. (2015b). Screening for perinatal depression. Retrieved from https://www.acog.org/-/media/Committee- 
Opinions/Committee-on-Obstetric-

ractice/co630.pdf?dmc=1\&ts=20160630T1521017957

American Nurses Association. (2011). Non-punitive alcohol and drug treatment for pregnant and breast-feeding women and their exposed children. Retrieved from http://www.nursingworld.org/MainMenuCategories/EthicsStandards/EthicsPosition-Statements/Non-punitive-Alcohol-and-Drug-Treatment-for-Pregnantand-Breast-feeding-Women-and-the-Exposed-Childr.pdf

American Pregnancy Association. (2017). Medicaid for pregnant women. Retrieved from http://americanpregnancy.org/planning/medicaid-for-pregnant-women/

American Psychiatric Association. (1994). Diagnostic and statistical manual of mental disorders: DSM IV (4th ed.). Washington, DC: Author.

Andersen, R. M. (1995). Revisiting the behavioral model and access to medical care: Does it matter? Journal of Health and Social Behavior, 36(1), 1-10.

Andrade, S. E., Raebel, M. A., Brown, J., Lane, K., Livingston, J., Boudreau, D., . . . Willy, M. E. (2008). Use of antidepressant medications during pregnancy: A multisite study. American Journal of Obstetrics and Gynecology, 198(2), 194. e191-194. e195.

Babitsch, B., Gohl, D., \& von Lengerke, T. (2012). Re-revisiting Andersen's Behavioral Model of Health Services Use: A systematic review of studies from 1998-2011. GMS Psycho-Social-Medicine, 9.

Baker, A. L., Kavanagh, D. J., Kay-Lambkin, F. J., Hunt, S. A., Lewin, T. J., Carr, V. J., \& Connolly, J. (2010). Randomized controlled trial of cognitive-behavioural 
therapy for coexisting depression and alcohol problems: Short-term outcome. Addiction, 105(1), 87-99. doi: 10.1111/j.1360-0443.2009.02757.x

Battle, C. L., Salisbury, A. L., Schofield, C. A., \& Ortiz-Hernandez, S. (2013). Perinatal antidepressant use: Understanding women's preferences and concerns. Journal of Psychiatric Practice, 19(6), 443-453. doi: 10.1097/01.pra.0000438183.74359.46

Bennett, I. M., Marcus, S. C., Palmer, S. C., \& Coyne, J. C. (2010). Pregnancy-related discontinuation of antidepressants and depression care visits among Medicaid recipients. Psychiatric Services, 61(4), 386-391.

Bland, J. M., \& Altman, D. G. (1995). Multiple significance tests: The Bonferroni method. British Medical Journal, 310(6973), 170.

Bobo, W. V., Epstein, R. A., Hayes, R. M., Shelton, R. C., Hartert, T. V., Mitchel, E., .. . $\mathrm{Wu}, \mathrm{P}$. (2014). The effect of regulatory advisories on maternal antidepressant prescribing, 1995-2007: An interrupted time series study of 228,876 pregnancies. Archives of Women's Mental Health, 17(1), 17-26.

Bowen, A., Duncan, V., Peacock, S., Bowen, R., Schwartz, L., Campbell, D., \& Muhajarine, N. (2014). Mood and anxiety problems in perinatal Indigenous women in Australia, New Zealand, Canada, and the United States: A critical review of the literature. Transcultural Psychiatry, 51(1), 93-111. doi: $10.1177 / 1363461513501712$

Brigham, G., Winhusen, T., Lewis, D., \& Kropp, F. (2010). Incentives for retention of pregnant substance users: A secondary analysis. Journal of Substance Abuse Treatment, 38(1), 90-95. doi: 10.1016/j.jsat.2009.05.005 
Byatt, N., Biebel, K., Debordes-Jackson, G., Lundquist, R. S., Simas, T. A. M., Weinreb, L., \& Ziedonis, D. (2013). Community mental health provider reluctance to provide pharmacotherapy may be a barrier to addressing perinatal depression: A preliminary study. Psychiatric Quarterly, 84(2), 169-174.

Byatt, N., Biebel, K., Friedman, L., Debordes-Jackson, G., Ziedonis, D., \& Pbert, L. (2013). Patient's views on depression care in obstetric settings: How do they compare to the views of perinatal health care professionals? General Hospital Psychiatry, 35(6), 598-604.

Byatt, N., Levin, L. L., Ziedonis, D., TA, M. S., \& Allison, J. (2015). Enhancing participation in depression care in outpatient perinatal care settings: A systematic review. Obstetrics and Gynecology, 126(5), 1048-1058.

Byatt, N., Simas, T. A. M., Lundquist, R. S., Johnson, J. V., \& Ziedonis, D. M. (2012). Strategies for improving perinatal depression treatment in North American outpatient obstetric settings. Journal of Psychosomatic Obstetrics and Gynecology, 33(4), 143-161.

Byatt, N., Xiao, R. S., Dinh, K. H., \& Waring, M. E. (2016). Mental health care use in relation to depressive symptoms among pregnant women in the USA. Archives of Women's Mental Health, 19(1), 187-191.

Center for Behavioral Health Statistics and Quality. (2015). 2014 National Survey on Drug Use and Health: Methodological summary and definitions. Rockville, MD: Substance Abuse and Mental Health Services Administration. 
Centers for Disease Control and Prevention. (2013).Vital signs: Overdoses of prescription opioid pain relievers and other drugs among women--United States, 1999-2010. MMWR. Morbidity and Mortality Weekly Report, 62(26), 537.

Center for Substance Abuse Treatment. (2009). Substance abuse treatment: Addressing the specific needs of women. Retrieved from http://store.samhsa.gov/shin/content//SMA15-4426/SMA15-4426.pdf

Chang, J. J., Tabet, M., Elder, K., Kiel, D. W., \& Flick, L. H. (2016). Racial/ethnic differences in the correlates of mental health services use among pregnant women with depressive symptoms. Maternal and Child Health Journal, 20(9), 19111922. doi: 10.1007/s10995-016-2005-1

Clark, H. W., Power, A. K., Le Fauve, C. E., \& Lopez, E. I. (2008). Policy and practice implications of epidemiological surveys on co-occurring mental and substance use disorders. Journal of Substance Abuse Treatment, 34(1), 3-13. doi: 10.1016/j.jsat.2006.12.032

Coleman-Cowger, V. H. (2012). Mental health treatment need among pregnant and postpartum women/girls entering substance abuse treatment. Psychology of Addictive Behaviors, 26(2), 345-350. doi: 10.1037/a0025355

Connelly, C. D., Hazen, A. L., Baker-Ericzen, M. J., Landsverk, J., \& Horwitz, S. M. (2013). Is screening for depression in the perinatal period enough? The cooccurrence of depression, substance abuse, and intimate partner violence in culturally diverse pregnant women. Journal of Women's Health, 22(10), 844-852. doi: 10.1089/jwh.2012.4121 
Cook, C. A., Flick, L. H., Homan, S. M., Campbell, C., McSweeney, M., \& Gallagher, M. E. (2010). Psychiatric disorders and treatment in low-income pregnant women. Journal of Women's Health (Larchmt), 19(7), 1251-1262. doi:

$10.1089 /$ jwh.2009.1854

Cooper, L. A., Gonzales, J. J., Gallo, J. J., Rost, K. M., Meredith, L. S., Rubenstein, L. V., . . Ford, D. E. (2003). The acceptability of treatment for depression among African-American, Hispanic, and White primary care patients. Medical Care, 4l(4), 479-489. doi: 10.1097/01.mlr.0000053228.58042.e4

Csaszar, E., Melichercikova, K., \& Dubovicky, M. (2014). Neuroendocrine and behavioral consequences of untreated and treated depression in pregnancy and lactation. Neuro Endocrinology Letters, 35(2), 169-174.

Dawson, D. A., Saha, T. D., \& Grant, B. F. (2010). A multidimensional assessment of the validity and utility of alcohol use disorder severity as determined by Item Response Theory models. Drug and Alcohol Dependence, 107(1), 31-38. doi: 10.1016/j.drugalcdep.2009.08.019

Endicott, J., Spitzer, R. L., Fleiss, J. L., \& Cohen, J. (1976). The Global Assessment Scale: A procedure for measuring overall severity of psychiatric disturbance. Archives of General Psychiatry, 33(6), 766-771.

Fairbrother, N., Janssen, P., Antony, M. M., Tucker, E., \& Young, A. H. (2016). Perinatal anxiety disorder prevalence and incidence. Journal of Affective Disorders, 200, $148-155$. 
Fairbrother, N., Young, A. H., Janssen, P., Antony, M. M., \& Tucker, E. (2015).

Depression and anxiety during the perinatal period. BioMed Central Psychiatry, $15(1), 206$.

Farr, S. L., Bitsko, R. H., Hayes, D. K., \& Dietz, P. M. (2010). Mental health and access to services among US women of reproductive age. American Journal of Obstetrics and Gynecology, 203(6), 542.e541-549. doi:

10.1016/j.ajog.2010.07.007

Farr, S. L., Hayes, D. K., Bitsko, R. H., Bansil, P., \& Dietz, P. M. (2011). Depression, diabetes, and chronic disease risk factors among US women of reproductive age. Preventing Chronic Disease, 8(6), A119.

Farr, S. L., Ko, J. Y., Burley, K., \& Gupta, S. (2016). Provider communication on perinatal depression: A population-based study. Archives of Women's Mental Health, 19(1), 35-40.

Flynn, H. A., Blow, F. C., \& Marcus, S. M. (2006). Rates and predictors of depression treatment among pregnant women in hospital-affiliated obstetrics practices. General Hospital Psychiatry, 28(4), 289-295. doi: 10.1016/j.genhosppsych.2006.04.002

Fortney, J., \& Booth, B. M. (2001). Access to substance abuse services in rural areas. Recent Developments in Alcoholism, 15, 177-197.

Gavin, A. R., Melville, J. L., Rue, T., Guo, Y., Dina, K. T., \& Katon, W. J. (2011). Racial differences in the prevalence of antenatal depression. General Hospital Psychiatry, 33(2), 87-93. 
Geier, M. L., Hills, N., Gonzales, M., Tum, K., \& Finley, P. R. (2015). Detection and treatment rates for perinatal depression in a state Medicaid population. CNS Spectrums, 20(1), 11-19. doi: 10.1017/s1092852914000510

Glasheen, C., Colpe, L., Hoffman, V., \& Warren, L. K. (2015). Prevalence of serious psychological distress and mental health treatment in a national sample of pregnant and postpartum women. Maternal and Child Health Journal, 19(1), 204216. doi: 10.1007/s10995-014-1511-2

Goodman, J. H. (2009). Women's attitudes, preferences, and perceived barriers to treatment for perinatal depression. Birth, 36(1), 60-69. doi: 10.1111/j.1523536X.2008.00296.x

Goodman, J. H., Chenausky, K. L., \& Freeman, M. P. (2014). Anxiety disorders during pregnancy: A systematic review. Journal of Clinical Psychiatry, 75(10), e11531184. doi: 10.4088/JCP.14r09035

Goodman, J. H., \& Tyer-Viola, L. (2010). Detection, treatment, and referral of perinatal depression and anxiety by obstetrical providers. Journal of Women's Health (Larchmt), 19(3), 477-490. doi: 10.1089/jwh.2008.1352

Goodman, S. H., Dimidjian, S., \& Williams, K. G. (2013). Pregnant African American women's attitudes toward perinatal depression prevention. Cultural Diversity and Ethnic Minority Psychology, 19(1), 50-57. doi: 10.1037/a0030565

Grant, B. F. (1997). Barriers to alcoholism treatment: Reasons for not seeking treatment in a general population sample. Journal of Studies on Alcohol, 58(4), 365-371.

Grigoriadis, S., VonderPorten, E. H., Mamisashvili, L., Tomlinson, G., Dennis, C. L., Koren, G., . . . Ross, L. E. (2013). The impact of maternal depression during 
pregnancy on perinatal outcomes: A systematic review and meta-analysis. Journal of Clinical Psychiatry, 74(4), e321-341. doi: 10.4088/JCP.12r07968

Guttmacher Institute. (2017). Substance use during pregnancy. Retrieved from https://www.guttmacher.org/state-policy/explore/substance-use-during-pregnancy

Haller, D. L., Miles, D. R., \& Dawson, K. S. (2003). Factors influencing treatment enrollment by pregnant substance abusers. American Journal of Drug and Alcohol Abuse, 29(1), 117-131.

Hand, D. J., Short, V. L., \& Abatemarco, D. J. (2017). Substance use, treatment, and demographic characteristics of pregnant women entering treatment for opioid use disorder differ by United States census region. Journal of Substance Abuse Treatment, 76, 58-63.

Hanley, G. E., \& Mintzes, B. (2014). Patterns of psychotropic medicine use in pregnancy in the United States from 2006 to 2011 among women with private insurance. BioMed Central Pregnancy and Childbirth, 14, 242. doi: 10.1186/1471-2393-14242

Hasin, D. S., Goodwin, R. D., Stinson, F. S., \& Grant, B. F. (2005). Epidemiology of major depressive disorder: Results from the National Epidemiologic Survey on Alcoholism and Related Conditions. Archives of General Psychiatry, 62(10), 1097-1106. doi: 10.1001/archpsyc.62.10.1097

Heil, S. H., Sigmon, S. C., Jones, H. E., \& Wagner, M. (2008). Comparison of characteristics of opioid-using pregnant women in rural and urban settings. American Journal of Drug and Alcohol Abuse, 34(4), 463-471. doi: $10.1080 / 00952990802122358$ 
Ho, D. E., Imai, K., King, G., \& Stuart, E. A. (2007). Matching as nonparametric preprocessing for reducing model dependence in parametric causal inference. Political Analysis, 15(3), 199-236.

Homish, G. G., Cornelius, J. R., Richardson, G. A., \& Day, N. L. (2004). Antenatal risk factors associated with postpartum comorbid alcohol use and depressive symptomatology. Alcoholism Clinical and Experimental Research, 28(8), 12421248.

Hudak, M. L., \& Tan, R. C. (2012). Neonatal drug withdrawal. Pediatrics, 129(2), e540560. doi: 10.1542/peds.2011-3212

Irner, T. B., Teasdale, T. W., Nielsen, T., Vedal, S., \& Olofsson, M. (2012). Substance use during pregnancy and postnatal outcomes. Journal of Addictive Diseases, 31(1), 19-28.

Jaaskelainen, M., Holmila, M., Notkola, I. L., \& Raitasalo, K. (2016). Mental disorders and harmful substance use in children of substance abusing parents: A longitudinal register-based study on a complete birth cohort born in 1991. Drug and Alcohol Review, 35(6), 728-740. doi: 10.1111/dar.12417

Jackson, A., \& Shannon, L. (2012a). Barriers to receiving substance abuse treatment among rural pregnant women in Kentucky. Maternal and Child Health Journal, 16(9), 1762-1770. doi: 10.1007/s10995-011-0923-5

Jackson, A., \& Shannon, L. (2012b). Examining barriers to and motivations for substance abuse treatment among pregnant women: Does urban-rural residence matter? Women Health, 52(6), 570-586. doi: 10.1080/03630242.2012.699508 
Jaques, S., Kingsbury, A., Henshcke, P., Chomchai, C., Clews, S., Falconer, J., . . Oei, J. (2014). Cannabis, the pregnant woman and her child: Weeding out the myths. Journal of Perinatology, 34(6), 417-424.

Jesse, D. E., Dolbier, C. L., \& Blanchard, A. (2008). Barriers to seeking help and treatment suggestions for prenatal depressive symptoms: Focus groups with rural low-income women. Issues in Mental Health Nursing, 29(1), 3-19. doi: $10.1080 / 01612840701748664$

Jordan, B. K., Karg, R. S., Batts, K. R., Epstein, J. F., \& Wiesen, C. (2008). A clinical validation of the National Survey on Drug Use and Health assessment of substance use disorders. Addictive Behaviors, 33(6), 782-798.

Kessler, R. C., Barker, P. R., Colpe, L. J., Epstein, J. F., Gfroerer, J. C., Hiripi, E., . . . Zaslavsky, A. M. (2003). Screening for serious mental illness in the general population. Archives of General Psychiatry, 60(2), 184-189.

Kessler, R. C., Berglund, P., Demler, O., Jin, R., Koretz, D., Merikangas, K. R., . . . Wang, P. S. (2003). The epidemiology of major depressive disorder: Results from the National Comorbidity Survey Replication (NCS-R). Journal of the American Medical Association, 289(23), 3095-3105. doi: 10.1001/jama.289.23.3095

Kessler, R. C., Berglund, P., Demler, O., Jin, R., Merikangas, K. R., \& Walters, E. E. (2005). Lifetime prevalence and age-of-onset distributions of DSM-IV disorders in the National Comorbidity Survey Replication. Archives of General Psychiatry, 62(6), 593-602. 
Kessler, R. C., Demler, O., Frank, R. G., Olfson, M., Pincus, H. A., Walters, E. E., . . Zaslavsky, A. M. (2005). Prevalence and treatment of mental disorders, 1990 to 2003. New England Journal of Medicine, 352(24), 2515-2523.

Kim, J. J., La Porte, L. M., Corcoran, M., Magasi, S., Batza, J., \& Silver, R. K. (2010). Barriers to mental health treatment among obstetric patients at risk for depression. American Journal of Obstetrics and Gynecology, 202(3), 312.e311-315. doi: 10.1016/j.ajog.2010.01.004

Kingston, D., Austin, M. P., Heaman, M., McDonald, S., Lasiuk, G., Sword, W., . . Biringer, A. (2015). Barriers and facilitators of mental health screening in pregnancy. Journal of Affective Disorders, 186, 350-357. doi:

10.1016/j.jad.2015.06.029

Kingston, D., Tough, S., \& Whitfield, H. (2012). Prenatal and postpartum maternal psychological distress and infant development: A systematic review. Child Psychiatry and Human Development, 43(5), 683-714. doi: 10.1007/s10578-0120291-4

Kissin, W. B., Svikis, D. S., Moylan, P., Haug, N. A., \& Stitzer, M. L. (2004). Identifying pregnant women at risk for early attrition from substance abuse treatment. Journal of Substance Abuse Treatment, 27(1), 31-38. doi: 10.1016/j.jsat.2004.03.007

Knight, D. K., Logan, S. M., \& Simpson, D. D. (2001). Predictors of program completion for women in residential substance abuse treatment. American Journal of Drug and Alcohol Abuse, 27(1), 1-18. 
Ko, J. Y., Farr, S. L., Dietz, P. M., \& Robbins, C. L. (2012). Depression and treatment among US pregnant and nonpregnant women of reproductive age, 2005-2009. Journal of Women's Health, 21(8), 830-836.

Kopelman, R. C., Moel, J., Mertens, C., Stuart, S., Arndt, S., \& O'Hara, M. W. (2008). Barriers to care for antenatal depression. Psychiatric Services, 59(4), 429-432. doi: 10.1176/ps.2008.59.4.429

Kotelchuck, M., Cheng, E. R., Belanoff, C., Cabral, H. J., Babakhanlou-Chase, H., Derrington, T. M., . . Bernstein, J. (2017). The prevalence and impact of substance use disorder and treatment on maternal obstetric experiences and birth outcomes among singleton deliveries in Massachusetts. Maternal and Child Health Journal, 21(4), 893-902.

Kuo, C., Schonbrun, Y. C., Zlotnick, C., Bates, N., Todorova, R., Kao, J. C., \& Johnson, J. (2013). A qualitative study of treatment needs among pregnant and postpartum women with substance use and depression. Substance Use and Misuse, 48(14), 1498-1508. doi: 10.3109/10826084.2013.800116

Lambert, B., \& Bauer, C. R. (2012). Developmental and behavioral consequences of prenatal cocaine exposure: A review. Journal of Perinatology, 32(11), 819-828.

Lancaster, C. A., Gold, K. J., Flynn, H. A., Yoo, H., Marcus, S. M., \& Davis, M. M. (2010). Risk factors for depressive symptoms during pregnancy: A systematic review. American Journal of Obstetrics and Gynecology, 202(1), 5-14.

Le Strat, Y., Dubertret, C., \& Le Foll, B. (2011). Prevalence and correlates of major depressive episode in pregnant and postpartum women in the United States. Journal of Affective Disorders, 135(1-3), 128-138. doi: 10.1016/j.jad.2011.07.004 
Leddy, M. A., Lawrence, H., \& Schulkin, J. (2011). Obstetrician-gynecologists and women's mental health: findings of the Collaborative Ambulatory Research Network 2005-2009. Obstetrical and Gynecological Survey, 66(5), 316-323.

Lehikoinen, A., Orden, M. R., Heinonen, S., \& Voutilainen, R. (2016). Maternal drug or alcohol abuse is associated with decreased head size from mid-pregnancy to childhood. Acta Paediatrica, 105(7), 817-822. doi: 10.1111/apa.13416

Leong, F. T., \& Kalibatseva, Z. (2011). Cross-cultural barriers to mental health services in the United States. Cerebrum, 2011, 5.

Liu, C. H., \& Tronick, E. (2012). Do patient characteristics, prenatal care setting, and method of payment matter when it comes to provider-patient conversations on perinatal mood? Maternal and Child Health Journal, 16(5), 1102-1112.

Lokuge, S., Frey, B. N., Foster, J. A., Soares, C. N., \& Steiner, M. (2011). Depression in women: Windows of vulnerability and new insights into the link between estrogen and serotonin. Journal of Clinical Psychiatry, 72(11), e1563-1569. doi: 10.4088/JCP.11 com07089

Maeda, A., Bateman, B. T., Clancy, C. R., Creanga, A. A., \& Leffert, L. R. (2014). Opioid abuse and dependence during pregnancy: Temporal trends and obstetrical outcomes. The Journal of the American Society of Anesthesiologists, 121(6), 1158-1165.

Magee, T., Lee, S. M., Giuliano, K. K., \& Munro, B. (2006). Generating new knowledge from existing data: The use of large data sets for nursing research. Nursing Research, 55(2), S50-S56. 
Marais, S., Jordaan, E., Viljoen, D., Olivier, L., de Waal, J., \& Poole, C. (2011). The effect of brief interventions on the drinking behavior of pregnant women in a high-risk rural South African community: A cluster randomized trial. Early Child Development and Care, 181(4), 463-474.

Martin, C. E., Longinaker, N., Mark, K., Chisolm, M. S., \& Terplan, M. (2015). Recent trends in treatment admissions for marijuana use during pregnancy. Journal of Addiction Medicine, 9(2), 99-104. doi: 10.1097/adm.0000000000000095

Martin, C. E., Longinaker, N., \& Terplan, M. (2015). Recent trends in treatment admissions for prescription opioid abuse during pregnancy. Journal of Substance Abuse Treatment, 48(1), 37-42. doi: 10.1016/j.jsat.2014.07.007

May, P. A., Marais, A. S., Gossage, J. P., Barnard, R., Joubert, B., Cloete, M., . . Blankenship, J. (2013). Case management reduces drinking during pregnancy among high risk women. International Journal of Alcohol and Drug Research, 2(3), 61-70. doi: 10.7895/ijadr.v2i3.79

McCabe, J. E., \& Arndt, S. (2012). Demographic and substance abuse trends among pregnant and non-pregnant women: Eleven years of treatment admission data. Maternal and Child Health Journal, 16(8), 1696-1702. doi: 10.1007/s10995-011$0872-\mathrm{z}$

Melville, J. L., Gavin, A., Guo, Y., Fan, M.-Y., \& Katon, W. J. (2010). Depressive disorders during pregnancy: Prevalence and risk factors in a large urban sample. Obstetrics and Gynecology, 116(5), 1064.

Mental Health Parity and Addiction Equity Act, Pub. L. No. 110-343, 122 Stat. 3765, H.R. 1424, 110th Cong. (2008). Retrieved from 
https://www.cms.gov/CCIIO/Programs-and-Initiatives/Other-InsuranceProtections/mhpaea_factsheet.html\#Key changes made by MHPAEA

Messer, K., Clark, K. A., \& Martin, S. L. (1996). Characteristics associated with pregnant women's utilization of substance abuse treatment services. American Journal of Drug and Alcohol Abuse, 22(3), 403-422.

Metz, T. D., \& Stickrath, E. H. (2015). Marijuana use in pregnancy and lactation: A review of the evidence. American Journal of Obstetrics and Gynecology, 213(6), 761-778.

Meunier, M. R., Bennett, I. M., \& Coco, A. S. (2013). Use of antidepressant medication in the United States during pregnancy, 2002-2010. Psychiatric Services, 64(11), $1157-1160$.

Meyer, M. C., Johnston, A. M., Crocker, A. M., \& Heil, S. H. (2015). Methadone and buprenorphine for opioid dependence during pregnancy: A retrospective cohort study. Journal of Addiction Medicine, 9(2), 81-86. doi:

10.1097/adm.0000000000000092

Ming, K., \& Rosenbaum, P. R. (2000). Substantial gains in bias reduction from matching with a variable number of controls. Biometrics, 56(1), 118-124.

Mitchell, M. M., Severtson, S. G., \& Latimer, W. W. (2008). Pregnancy and race/ethnicity as predictors of motivation for drug treatment. American Journal of Drug and Alcohol Abuse, 34(4), 397-404. doi: 10.1080/00952990802082172

Moher, D., Liberati, A., Tetzlaff, J., Altman, D. G., \& Group, P. (2009). Preferred reporting items for systematic reviews and meta-analyses: The PRISMA statement. PLoS Medicine, 6(7), e1000097. 
Mojtabai, R., \& Jorm, A. F. (2015). Trends in psychological distress, depressive episodes and mental health treatment-seeking in the United States: 2001-2012. Journal of Affective Disorders, 174, 556-561. doi: 10.1016/j.jad.2014.12.039

Mojtabai, R., Olfson, M., Sampson, N. A., Jin, R., Druss, B., Wang, P. S., . . Kessler, R. C. (2011). Barriers to mental health treatment: Results from the National Comorbidity Survey Replication. Psychological Medicine, 41(8), 1751-1761. doi: $10.1017 / \mathrm{s} 0033291710002291$

Mota, N., Cox, B. J., Enns, M. W., Calhoun, L., \& Sareen, J. (2008). The relationship between mental disorders, quality of life, and pregnancy: Findings from a nationally representative sample. Journal of Affective Disorders, 109(3), 300-304. doi: 10.1016/j.jad.2007.12.002

Mukherjee, S., Trepka, M. J., Pierre-Victor, D., Bahelah, R., \& Avent, T. (2016). Racial/ethnic disparities in antenatal depression in the United States: A systematic review. Maternal and Child Health Journal, 20(9), 1780-1797. doi: 10.1007/s10995-016-1989-х

Narkowicz, S., Plotka, J., Polkowska, Z., Biziuk, M., \& Namiesnik, J. (2013). Prenatal exposure to substance of abuse: A worldwide problem. Environment International, 54, 141-163. doi: 10.1016/j.envint.2013.01.011

Norhayati, M., Hazlina, N. N., Asrenee, A., \& Emilin, W. W. (2015). Magnitude and risk factors for postpartum symptoms: A literature review. Journal of Affective Disorders, 175, 34-52.

National Perinatal Association. (2012). Substance use among pregnant women. Retrieved from 
http://www.nationalperinatal.org/resources/Documents/Substance\%20Abuse $\% 20$ Among\%20Pregnant\%20Women\%20Position\%20Paper\%2010-1-15.pdf

National Survey on Drug Use and Health. (2016). About the survey. Retrieved from https://nsduhweb.rti.org/respweb/project_description.html

O'connor, E., Rossom, R. C., Henninger, M., Groom, H. C., \& Burda, B. U. (2016). Primary care screening for and treatment of depression in pregnant and postpartum women: Evidence report and systematic review for the US Preventive Services Task Force. Journal of the American Medical Association, 315(4), 388406.

O'Mahen, H. A., \& Flynn, H. A. (2008). Preferences and perceived barriers to treatment for depression during the perinatal period. Journal of Women's Health (Larchmt), 17(8), 1301-1309. doi: 10.1089/jwh.2007.0631

O'Mahen, H. A., Henshaw, E., Jones, J. M., \& Flynn, H. A. (2011). Stigma and depression during pregnancy: Does race matter? Journal of Nervous and Mental Disease, 199(4), 257-262. doi: 10.1097/NMD.0b013e3182125b82

Ondersma, S. J., Simpson, S. M., Brestan, E. V., \& Ward, M. (2000). Prenatal drug exposure and social policy: The search for an appropriate response. Child Maltreatment, 5(2), 93-108. doi: 10.1177/1077559500005002002

Ondersma, S. J., Winhusen, T., \& Lewis, D. F. (2010). External pressure, motivation, and treatment outcome among pregnant substance-using women. Drug and Alcohol Dependence, 107(2-3), 149-153. doi: 10.1016/j.drugalcdep.2009.10.004

Otiashvili, D., Kirtadze, I., O’Grady, K. E., Zule, W., Krupitsky, E., Wechsberg, W. M., \& Jones, H. E. (2013). Access to treatment for substance-using women in the 
Republic of Georgia: Socio-cultural and structural barriers. International Journal of Drug Policy, 24(6), 566-572.

Palladino, C. L., Fedock, G. L., Forman, J. H., Davis, M. M., Henshaw, E., \& Flynn, H. A. (2011). OB CARES - the obstetric clinics and resources study: Providers' perceptions of addressing perinatal depression —a qualitative study. General Hospital Psychiatry, 33(3), 267-278.

Pan, I.-J., \& Yi, H.-y. (2013). Prevalence of hospitalized live births affected by alcohol and drugs and parturient women diagnosed with substance abuse at liveborn delivery: United States, 1999-2008. Maternal and Child Health Journal, 17(4), 667-676.

Patient Protection and Affordable Care Act, 42 U.S.C. $§ 1800$ (2010). Retrieved from https://www.gpo.gov/fdsys/pkg/PLAW-111publ148/html/PLAW-111publ148.htm

Patrick, S. W., Davis, M. M., Lehmann, C. U., \& Cooper, W. O. (2015). Increasing incidence and geographic distribution of neonatal abstinence syndrome: United States 2009 to 2012. Journal of Perinatology, 35(8), 650-655. doi: 10.1038/jp.2015.36

Patrick, S. W., Schumacher, R. E., Benneyworth, B. D., Krans, E. E., McAllister, J. M., \& Davis, M. M. (2012). Neonatal abstinence syndrome and associated health care expenditures: United States, 2000-2009. Journal of the American Medical Association, 307(18), 1934-1940. doi: 10.1001/jama.2012.3951

Price, S. K., Corder-Mabe, J., \& Austin, K. (2012). Perinatal depression screening and intervention: Enhancing health provider involvement. Journal of Women's Health, 21(4), 447-455. 
Qiu, C., Gelaye, B., Fida, N., \& Williams, M. A. (2012). Short sleep duration, complaints of vital exhaustion and perceived stress are prevalent among pregnant women with mood and anxiety disorders. BioMed Central Pregnancy and Childbirth, 12(1), 104.

Rade, C. B., Desmarais, S. L., Van Dorn, R. A., Lutnick, A., Kral, A. H., \& Lorvick, J. (2015). Mental health correlates of drug treatment among women who use methamphetamine. American Journal on Addictions, 24(7), 646-653. doi: 10.1111/ajad.12279

Rehm, J., Üstün, T. B., Saxena, S., Nelson, C. B., Chatterji, S., Ivis, F., \& Adlaf, E. (1999). On the development and psychometric testing of the WHO screening instrument to assess disablement in the general population. International Journal of Methods in Psychiatric Research, 8(2), 110-122.

Riesenberg, L. A., \& Justice, E. M. (2014). Conducting a successful systematic review of the literature, part 2. Nursing2016, 44(6), 23-26.

Roberson, E. K., Hurwitz, E. L., Li, D., Cooney, R. V., Katz, A. R., \& Collier, A. C. (2016). Depression, anxiety, and pharmacotherapy around the time of pregnancy in Hawaii. International Journal of Behavioral Medicine, 23(4), 515-526.

Rosen, D., Tolman, R. M., \& Warner, L. A. (2004). Low-income women's use of substance abuse and mental health services. Journal of Health Care for the Poor and Underserved, 15(2), 206-219.

Rossen, L., Hutchinson, D., Wilson, J., Burns, L., C, A. O., Allsop, S., . . Mattick, R. P. (2016). Predictors of postnatal mother-infant bonding: The role of antenatal 
bonding, maternal substance use and mental health. Archives of Women's Mental Health, 19(4), 609-622. doi: 10.1007/s00737-016-0602-z

Salganicoff, A., Ranji, U., Beamesderfer, A., \& Jurani, N. (2014). Women and health care in the early years of the Affordable Care Act. Retrieved from https://kaiserfamilyfoundation.files.wordpress.com/2014/05/8590-women-andhealth-care-in-the-early-years-of-the-affordable-care-act.pdf

Shartzer, A., Garro, N., Pellegrini, C., \& Long, S. (2015). Changes in insurance coverage, access to care, and health care affordability for women of childbearing age. Retrieved from http://hrms.urban.org/briefs/Changes-in-Insurance-CoverageAccess-to-Care-and-Health-Care-Affordability-for-Women-of-ChildbearingAge.pdf

Smith, M. V., Shao, L., Howell, H., Wang, H., Poschman, K., \& Yonkers, K. A. (2009). Success of mental health referral among pregnant and postpartum women with psychiatric distress. General Hospital Psychiatry, 31(2), 155-162. doi: 10.1016/j.genhosppsych.2008.10.002

Snowden, L. R. (2001). Barriers to effective mental health services for African Americans. Mental Health Services Research, 3(4), 181-187.

Snowden, L. R. (2012). Health and mental health policies' role in better understanding and closing African American-White American disparities in treatment access and quality of care. American Psychologist, 67(7), 524-531. doi: 10.1037/a0030054

Song, D., Sands, R. G., \& Wong, Y. L. (2004). Utilization of mental health services by low-income pregnant and postpartum women on medical assistance. Women Health, 39(1), 1-24. doi: 10.1300/J013v39n01_01 
Steverson, J. W., \& Rieckmann, T. (2009). Legislating for the provision of comprehensive substance abuse treatment programs for pregnant and mothering women. Duke Journal of Gender Law and Policy, 16, 315.

Substance Abuse and Mental Health Services Administration. (2010). Reliability of Key Measures in the National Survey on Drug Use and Health (Office of Applied Studies, Methodology Series M-8, HHS Publication No. SMA 09-4425). Rockville, MD: Substance Abuse and Mental Health Services Administration. Substance Abuse and Mental Health Services Administration. (2011a). Addressing the needs of women and girls: Developing core competencies for mental health and substance abuse service professionals. Retrieved from https://store.samhsa.gov/shin/content/SMA11-4657/SMA11-4657.pdf

Substance Abuse and Mental Health Services Administration. (2011b). National Survey of Substance Abuse Treatment Services (N-SSATS): 2010. Data on Substance Abuse Treatment Facilities. Retrieved from https://wwwdasis.samhsa.gov/10nssats/NSSATS2010Web.pdf

Substance Abuse and Mental Health Services Administration. (2013). Trends in substances of abuse among pregnant women and women of childbearing age in treatment. Retrieved from http://www.samhsa.gov/data/sites/default/files/spot110trends-pregnant-women-2013.pdf

Substance Abuse and Mental Health Services Administration. (2014a). Projections of National Expenditures for Treatment of Mental and Substance Use Disorders, 2010-2020. Retrieved from http://store.samhsa.gov/shin/content/SMA144883/SMA14-4883.pdf 
Substance Abuse and Mental Health Services Administration. (2014b). Results from the 2013 National Survey on Drug Use and Health: Summary of national findings. Retrieved from http://www.samhsa.gov/data/sites/default/files/NSDUHresultsPDFWHTML2013/ Web/NSDUHresults2013.pdf

Substance Abuse and Mental Health Services Administration. (2014c). SAMHSA'S concept of trauma and guidance for a trauma-informed approach. Retrieved from http://store.samhsa.gov/shin/content/SMA14-4884/SMA14-4884.pdf

Substance Abuse and Mental Health Services Administration. (2015). National Survey of Substance Abuse Treatment Services (N-SSATS): 2014. Data on substance abuse treatment facilities. Retrieved from https://wwwdasis.samhsa.gov/dasis2/nssats/2014_nssats_rpt.pdf

Substance Abuse and Mental Health Services Administration, Center for Behavioral Health Statistics and Quality. (2017). Treatment Episode Data Set-Admissions (TEDS-A) Series. Retrieved from https://www.icpsr.umich.edu/icpsrweb/ICPSR/series/56

Terplan, M., Longinaker, N., \& Appel, L. (2015). Women-centered drug treatment services and need in the United States, 2002-2009. Journal Information, 105(11).

Terplan, M., McNamara, E. J., \& Chisolm, M. S. (2012). Pregnant and non-pregnant women with substance use disorders: The gap between treatment need and receipt. Journal of Addictive Diseases, 31(4), 342-349. doi: $10.1080 / 10550887.2012 .735566$ 
Terplan, M., Smith, E. J., Kozloski, M. J., \& Pollack, H. A. (2010). "Compassionate coercion": Factors associated with court-mandated drug and alcohol treatment in pregnancy 1994-2005. Journal of Addiction Medicine, 4(3), 147-152. doi: 10.1097/ADM.0b013e3181b562dc

Thoemmes, F. (2012). Propensity Score Matching in SPSS [Computer software]. Retrieved from https://sourceforge.net/projects/psmspss/

Thombs, B. D., Arthurs, E., Coronado-Montoya, S., Roseman, M., Delisle, V. C., Leavens, A., .. . Ciofani, L. (2014). Depression screening and patient outcomes in pregnancy or postpartum: A systematic review. Journal of Psychosomatic Research, 76(6), 433-446.

Toh, S., Li, Q., Cheetham, T. C., Cooper, W. O., Davis, R. L., Dublin, S., . . Andrade, S. E. (2013). Prevalence and trends in the use of antipsychotic medications during pregnancy in the U.S., 2001-2007: A population-based study of 585,615 deliveries. Archives of Women's Mental Health, 16(2), 149-157. doi: $10.1007 / \mathrm{s} 00737-013-0330-6$

Tolia, V. N., Patrick, S. W., Bennett, M. M., Murthy, K., Sousa, J., Smith, P. B., . . Spitzer, A. R. (2015). Increasing incidence of the neonatal abstinence syndrome in US neonatal ICUs. New England Journal of Medicine, 372(22), 2118-2126.

Tuchman, E. (2010). Women and addiction: The importance of gender issues in substance abuse research. Journal of Addictive Diseases, 29(2), 127-138.

Unites States Department of Health and Human Services. (2003). Rural mental health in the WICHE West: Meeting workforce demands through regional partnership. Retrieved from http://ruralhealth.hrsa.gov/pub/WicheMH.asp\#Ib. 
United States Department of Health and Human Services. (2009). Actions steps for improving women's mental health. Retrieved from https://store.samhsa.gov/shin/content/OWH09-PROFESSIONAL/OWH09PROFESSIONAL.pdf

United States Department of Health and Human Services, Substance Abuse and Mental Health Services Administration, Office of Applied Studies. (2013). 2012 National Survey on Drug Use and Health: Public use file codebook. Rockville, MD:

Substance Abuse and Mental Health Services Administration.

United States Department of Health and Human Services, Substance Abuse and Mental Health Services Administration, Office of Applied Studies. (2014a). 2008 National Survey on Drug Use and Health: Public use file codebook. Rockville, MD: Substance Abuse and Mental Health Services Administration.

United States Department of Health and Human Services, Substance Abuse and Mental Health Services Administration, Office of Applied Studies. (2014b). 2009 National Survey on Drug Use and Health: Public use file codebook. Rockville, MD: Substance Abuse and Mental Health Services Administration.

United States Department of Health and Human Services, Substance Abuse and Mental Health Services Administration, Office of Applied Studies. (2014c). 2010 National Survey on Drug Use and Health: Public use file codebook. Rockville, MD: Substance Abuse and Mental Health Services Administration.

United States Department of Health and Human Services, Substance Abuse and Mental Health Services Administration, Office of Applied Studies. (2014d). 2011 
National Survey on Drug Use and Health: Public use file codebook. Rockville, MD: Substance Abuse and Mental Health Services Administration.

United States Department of Health and Human Services, Substance Abuse and Mental

Health Services Administration, Office of Applied Studies. (2014e). 2013

National Survey on Drug Use and Health: Public use file codebook. Rockville,

MD: Substance Abuse and Mental Health Services Administration.

United States Department of Health and Human Services, Substance Abuse and Mental

Health Services Administration, Office of Applied Studies. (2015). 2014 National

Survey on Drug Use and Health: Public use file codebook. Rockville, MD:

Substance Abuse and Mental Health Services Administration.

United States Department of Justice, National Drug Intelligence center. (2011). National

drug threat assessment. Retrieved from

https://www.justice.gov/archive/ndic/pubs44/44849/44849p.pdf

van der Zee-van den Berg, A. I., Boere-Boonekamp, M. M., IJzerman, M.J., Haasnoot-

Smallegange, R. M., \& Reijneveld, S. A. (2017). Screening for postpartum

depression in well-baby care settings: A systematic review. Maternal and Child

Health Journal, 21(1), 9-20. doi: 10.1007/s10995-016-2088-8

Vesga-Lopez, O., Blanco, C., Keyes, K., Olfson, M., Grant, B. F., \& Hasin, D. S. (2008).

Psychiatric disorders in pregnant and postpartum women in the United States.

Archives of General Psychiatry, 65(7), 805-815. doi: 10.1001/archpsyc.65.7.805

Vittinghoff, E., Glidden, D., Shiboski, S., \& McCulloch, C. (2012). Regression methods

in biostatistics: Linear, logistic, survival, and repeated measures models (2nd

ed.). New York: Springer. 
Walton-Moss, B., \& McCaul, M. E. (2006). Factors associated with lifetime history of drug treatment among substance dependent women. Addictive Behaviors, 31(2), 246-253. doi: 10.1016/j.addbeh.2005.05.006

Weinreb, L., Byatt, N., Moore Simas, T. A., Tenner, K., \& Savageau, J. A. (2014). What happens to mental health treatment during pregnancy? Women's experience with prescribing providers. Psychiatric Quarterly, 85(3), 349-355. doi: $10.1007 / \mathrm{s} 11126-014-9293-7$

Wendell, A. D. (2013). Overview and epidemiology of substance abuse in pregnancy. Clinical Obstetrics and Gynecology, 56(1), 91-96. doi: 10.1097/GRF.0b013e31827feeb9

World Health Organization. (2014). Guidelines for the identification and management of substance use and substance use disorders in pregnancy. Retrieved from http://apps.who.int/iris/bitstream/10665/107130/1/9789241548731_eng.pdf

Witt, W. P., DeLeire, T., Hagen, E. W., Wichmann, M. A., Wisk, L. E., Spear, H. A., . . Hampton, J. (2010). The prevalence and determinants of antepartum mental health problems among women in the USA: A nationally representative population-based study. Archives of Women's Mental Health, 13(5), 425-437.

Wu, J., \& Davis-Ajami, M. L. (2014). Antidepressant treatment persistence in lowincome, insured pregnant women. Journal of Managed Care Pharmacy, 20(6), 631-637.

Yamamoto, A., McCormick, M. C., \& Burris, H. H. (2015). Disparities in antidepressant use in pregnancy. Journal of Perinatology, 35(4), 246-251. 
Yonkers, K. A., Wisner, K. L., Stewart, D. E., Oberlander, T. F., Dell, D. L., Stotland, N., . . Lockwood, C. (2009). The management of depression during pregnancy: A report from the American Psychiatric Association and the American College of Obstetricians and Gynecologists. General Hospital Psychiatry, 31(5), 403-413. 


\section{CURRICULUM VITAE}

Taghreed N. Salameh, MSN, RN, PhD Candidate

\section{GENERAL INFORMATION}

OFFICE: Research Office/School of PHONE: (502) 852-5129

Nursing

555 South Floyd Street

University of Louisville

Louisville, KY 40202

FAX: $\quad$ (502) 852-0704

E-mail: $\quad$ tnsala02@louisville.edu

tagsalameh192@gmail.com

Jordan RN License \#8040

******************************************************************************

\section{EDUCATION}

Date

Degree or Course

1999-2003

BS in Nursing

2004-2006 MSN/Maternal-newborn

Nursing

\section{Institution}

The Hashemite University, Jordan

Jordan University of Science and Technology, Jordan

\section{PROFESSIONAL EXPERIENCE}

Date

2003-2004

$1 / 6 /-$

$10 / 3 / 2004$
Title

Staff Nurse/CCU

Clinical Instructor

ACADEMIC APPOINTMENTS

Date Title

2006-2008
Teaching \& Research Assistant

\section{Institution}

Islamic Hospital, Jordan

The Hashemite University, Jordan

\section{Institution}

Maternal, Child and Family Department, Hashemite University, Jordan 
2008-2011 Full-time Lecturer

2011-2014 Full-time Lecturer
Maternal, Child and Family Department, Hashemite University, Jordan

Nursing Department, Taif University, Saudi Arabia

\section{HONORS AND AWARDS}

2003 Academic Excellence Honor Award by Princess Mona Al-Hussein, Jordan

2004-2006 Full scholarship to Jordan University of Science and Technology/ MSN Degree

2006 Academic Excellence Honor Award by Jordan University of Science and Technology, Jordan

2015 Invitation for lifetime membership into Tau Sigma National Honor Society

2015 Graduate Student Poster Award for Research!Louisville. Salameh, T., \& Smith, S. (2015, October). Maternal-Preterm infant attachment in the NICU: A concept clarification. Poster presentation, Research!Louisville, Louisville, KY, USA

2016 Top Ten Students Poster Award for 2016 Southern Nursing Research Society $\left(2^{\text {nd }}\right.$ place $)$.

Salameh, T., Oweis, A., \& Amarneh, B. (2016, February). Predictors of postpartum depression in Jordanian mothers. Poster presentation, Southern Nursing Research Society, Williamsburg, Virginia, USA

2016 Invitation for a lifetime membership into Golden Key International Honor Society

\section{RESEARCH AND CREATIVE PRODUCTIVITY}

\section{Funded Research Projects}

1. Integration of Family Centered Care in NICU in Jordan (Co-investigator with Mohammad Metleq, PI), Hashemite University, 2011-2013

2. Jordanian Parents Lived Experience of NICU: Phenomenological Study (Coinvestigator with Jamila Abudhail, PI), Hashemite University, 2011-2013

3. Impact of Psychosocial Status and Disease Knowledge on Deferoxamine Adherence among Thalassemia Major Adolescents (Co-investigator with Manal Kloub, PI), Hashemite University, 2010-2012

4. Impact of Educational Program on Protein Balance among Hemodialysis Patients (Co-investigator with Mageda Mansour, PI), Taif University, 2013-2014 


\section{Peer-reviewed Publications}

Al-Kloub, M.I., Salameh, T.N., \& Froelicher, E.S. (2014). Nursing students' evaluation of problem based learning and the impact of culture on the learning process and outcomes: A pilot project. Nurse Education in Practice, 14(2), 142-147.

Al-Kloub, M.I., Salameh, T.N., \& Froelicher, E.S. (2014). Impact of psychosocial status and disease knowledge on Deferoxamine adherence among Thalassemia major adolescents. International Journal of Nursing Practice, 20(3), 265-274.

Mansour, M., Yousef, H., Salameh, T., \& Yaseen, R. (2014). Impact of education program on protein balance among hemodialysis patients. World Journal of Medical Sciences, 11(1), 69-77.

Al-Motlaq, M., Abuidhail, J., Salameh, T., \& Awwad, W. (2016). Development and validation of an instrument to assess the implementation of family-centered care in traditional open bay Neonatal Intensive Care Units. Early Child Development and Care, [Published Online]. doi.http://dx.doi.org/10.1080/03004430.2016.1154050

Abuidhail, J., Al-Motlaq, M., Mrayan, L., \& Salameh, T. (2017). The lived experience of Jordanian parents in a neonatal intensive care unit: A phenomenological study. The Journal of Nursing Research, 25(2), 156-162.

\section{Presentations}

Salameh, T., \& Smith, S. (2015, October). Maternal-Preterm infant attachment in the NICU: A concept clarification. Poster presentation, Research!Louisville, Louisville, KY, USA

Salameh, T., Oweis, A., \& Amarneh, B. (2016, February). Predictors of postpartum depression in Jordanian mothers. Poster presentation, Southern Nursing Research Society, Williamsburg, Virginia, USA

Salameh, T., Hall, L., \& Crawford, T. (2017, February 24). Determinants of parenting stress in Jordanian mothers. Southern Nursing Research Society. Dallas, TX. (Presenter)

\section{TEACHING AND ADVISING}

\section{Courses Taught at Taif University}

- Pediatric Nursing (Theory \& Clinical)

- Maternity Nursing (Clinical)

- Community Nursing (Clinical)

- Nursing Administration (Clinical)

Courses Taught at the Hashemite University

- Nursing Ethics 
- Pediatric Nursing (Theory \& Clinical)

- Maternity Nursing (Theory \& Clinical)

- Fundamental of Nursing (Clinical)

- Health Assessment (Clinical)

\section{UNIVERSITY SERVICE}

\section{Hashemite University}

2006-2011 Academic Advising Committee

2009-2011 Simulation Lab Committee

\section{Taif University}

2011-2014 Academic Advising Committee

2011-2014 Simulation Lab Committee

2011-2013 File Subject Committee

2013-2014 Head Deputy of Quality Unit

\section{PROFESSIONAL ACTIVITY AND PUBLIC SERVICE}

\section{Memberships}

Jordanian Nurses and Midwives Council

Southern Nursing Research Society

Sigma Theta Tau International Honor Society

Tau Sigma National Honor Society

Golden Key International Honor Society

\section{Conferences /Workshops/Training Courses}

Training course of SPSS for teaching staff, 2012, Taif University (Coordinator)

Innovation in Teaching Health Sciences: From Words to Action, 2012, Purdue University $\&$ Taif University

Adobe Photoshop, 2012, Training and Continuous Education/Taif University

Symposium on International Nurses' Day/Closing the Gap from Evidence to Action, 2012 (Speaker: Role of National Nurses' Association)

Nursing Process Application: From Theory to Practice, 2013, Taif University, (Speaker $\&$ Facilitator)

Nursing Management Workshop, 2014, Taif University (Facilitator) 


\section{Public Service}

2002 Volunteer at Islamic Hospital/ Critical Care Unit and Medical Surgical Floor from April 1 to Aug

2007 Volunteer at Maternal and Child Health Center-Zarqa-UNRWA (Education for staff)

2011 International Diabetes Day Education and Prevention (Education at Secondary School in Taif)

2012 First Aid Training Course--Taif (Trainer)

2013 The Current Paradigm of Diabetes Prevention and Education: A Vital Investment (Facilitator)

2013 Volunteer at Maternal and Child Health Center-Taif (Education for staff)

2014 First Aid Training Course--Taif (Trainer)

2014 A promise is a promise: Stop violence against women--Taif (Facilitator) 